MARIA CLÁUdIA GATTO CARDIA

\title{
Efeitos da caminhada em imersão em mulheres quinquagenárias saudáveis
}

Tese apresentada à Faculdade de Medicina da Universidade de São Paulo para a obtenção do título de Doutora em Ciências

Programa de Ciências da Reabilitação Orientadora: Profa. Dra. Fátima Aparecida Caromano

\section{São Paulo}




\section{Dados Internacionais de Catalogação na Publicação (CIP)}

Preparada pela Biblioteca da

Faculdade de Medicina da Universidade de São Paulo

Creprodução autorizada pelo autor

Cardia, Maria Claudia Gatto

Efeitos da caminhada em imersão em mulheres

quinquagenárias saudáveis / Maria Claudia Gatto

Cardia. -- São Paulo, 2018.

Tese (doutorado)--Faculdade de Medicina da

Universidade de São Paulo.

Programa de Ciências da Reabilitação.

orientadora: Fátima Aparecida Caromano.

Descritores: 1.Hidroterapia 2.Assistência integral à saúde 3.Força muscular 4.Amplitude de movimento articular 5.Equilibrio postural

6. Envelhecimento

USP/FM/DBD-255/18

Responsável: Kátia Maria Bruno Ferreira - CRB-8/6008 
TODOS SOMOS UNO

La fuerza que nos conduce es la misma que enciende el sol que anima los mares y hace florecer los cerezos.

La fuerza que nos mueve es la misma que agita las semillas con su mensaje inmemorial de vida. La danza genera el destino bajo las mismas leyes que vinculan la flor a la brisa.

Bajo el girasol de armonía todos somos uno.

Rolando Toro Araneda 


\section{Dedicatória}

Aos meus pais Ricardo Augusto Cardia (In Memorian) e Edinaide Gatto Cardia, que me deram a vida, amor, carinho e proteção; me ensinaram o valor do estudo, do conhecimento e do trabalho. E sobretudo me apoiaram nos meus sonhos, ainda que renunciando à minha presença nos momentos de grandes alegrias ou sofrimento. 


\section{Agradecimentos}

À minha orientadora Professora Fátima Aparecida Caromano, por sua generosidade; pela grandeza de conhecimento com simplicidade de ser. Por me aceitar e me conduzir com atenção e eficiência, e principalmente com a calma e a leveza necessárias nos momentos mais difíceis.

Ás mulheres, "quinquagenárias" como eu, participantes deste estudo, pois sem elas nada seria possível.

À coordenação do Programa de Doutorado em Ciências da Reabilitação da Universidade de São Paulo pela iniciativa deste Doutorado Inter Institucional (DINTER) com a Universidade Federal da Paraíba.

Aos professores, secretárias e técnicos do DINTER (núcleo do FOFITO da Faculdade de Ciências Médicas da Universidade de São Paulo - FCMUSP), pelo desafio virtual e pela paciência com as dificuldades relacionadas à distância física.

Ao nosso coordenador local (núcleo da UFPB) Professor Heleodório da Silva Santos e aos amigos de turma: Juerila, Mallison, Carina, Lígia, Socorro, Moema, Cristina, Flávia, Cláudia, Bárbara e Marília, Professores dos Departamentos de Fisioterapia e de Terapia Ocupacional.

Ao Departamento de Fisioterapia da UFPB e em especial à professora Simone dos Santos Maciel por mais esta oportunidade. 
Às Professoras Dra Maria Helena Morgani de Almeida, Dra Renata Escorcio e Dra Fabíola Carvalho Lopes dos Santos pelas valiosas contribuições no exame de qualificação.

À Professora Juliana Pedreschi Rodrigues e à toda turma da EACH pela convivência agradável e pelas oportunidades de divulgação de trabalhos na USP.

À rede de amigos e principalmente de amigas que me apoiaram e me sustentaram emocionalmente com compreensão, palavras e afetos. Entre tantos, deixo meu especial agradecimento para:

- Neide Lucena, pela amizade, por tantas benesses e maravilhosas oportunidades, e por sempre acreditar em mim.

- Márcia, Vânia, Eliane, Cida, Robson e Dudu pelo conforto entre cafés e desabafos na Clínica Infantil.

- Roseli, Maria Eulina, Andréa, Débora, Betânia, Leonardo, Carminha e Carlinhos, Miriam, Marcos e Lulú, Marluce, Rossana e Miranda, amigos de todos os tempos e para todas as horas.

- Vitória, Inger, Lú, Vilani, Nadilza, Genilda, Rosa e Ana Adelaide pela preocupação com esta tese em nossos alegres e desestressantes encontros.

- Os amigos da Biodanza (Sinfrônio Lima e Escola de Formação de Facilitadores e grupo da UFPB), Virgivane Feitosa, Justina Ferreira, Gustavo Kniest e Helizene Moura por, além da amizade, também cuidarem do meu corpo e da minha saúde. 
- Junio, pela atenção e ajuda tecnológica na reta final e aos meus queridos alunos da UFPB, em especial à toda turma da Escola de Posturas.

À Família Martins e Martins Pereira pelos incentivos e principalmente pelo acolhimento e carinho com que me recebem.

À minha mãe e toda família, simplesmente por existirem em minha vida $\mathrm{e}$ em especial ao núcleo paulistano da minha linda e amorosa irmã (Regina, Glauco e Vicente) e de Santo André - toda família da querida tia Irma Gatto Rosa, nossa "borboleta mor".

À Clélia Maria M. Pereira, pela compreensão e tolerância; pelos mimos e cuidados nas horas mais difíceis; por suportar minhas ausências e meus rompantes de mau humor e especialmente por compartilhar seu amor, vida, sonhos e esperanças.

E a Deus, por me despertar todos os dias, me permitir caminhar, ouvir, ver, sentir, rir, chorar, compreender e discernir; por me ensinar que, quanto mais estudo, aprendo que nada sei, e que, quanto mais apreendo, entendo que menos preciso para ser feliz. 


\section{Normalização adotada}

Esta tese está de acordo com as normas em vigor no momento desta publicação:

Referências: adaptado de International Committee of Medical Journals Editors (Vancouver).

Universidade de São Paulo. Faculdade de Medicina. Divisão de Biblioteca e Documentação. Guia de apresentação de dissertações, teses e monografias. Elaborado por Anneliese Carneiro da Cunha, Maria Julia de A. L. Freddi, Maria F. Crestana, Marinalva de Souza Aragão, Suely Campos Cardoso, Valéria Vilhena. 3a ed. São Paulo: Divisão de Biblioteca e Documentação; 2011.

Abreviaturas dos títulos dos periódicos de acordo com a List of Journals Indexed in Index Medicus. 


\section{SUMÁRIO}

Lista de abreviaturas, símbolos e siglas

Lista de figuras

Lista de tabelas

Resumo

Summary/Abstract

1 INTRODUÇÃO.

1.1 A mulher quinquagenária e os desafios da assistência integral à saúde da mulher

1.2 Os declínios funcionais do sistema musculoesquelético e do controle postural.

1.3 Hidroterapia como recurso facilitador na promoção de saúde física.

1.4 Movimento em imersão

1.5 A caminhada na água como recurso terapêutico.

2. OBJETIVOS

2.1 Objetivo primário.

2.2 Objetivos secundários.

3. MÉTODO

3.1 Desenho e aspectos éticos da pesquisa

3.2 Participantes, critérios de inclusão e exclusão

3.3 Procedimentos.

3.4 Instrumentos e procedimentos de avaliação

3.4.1 Estado de saúde, mobilidade e humor

3.4.2 Força muscular isométrica.

3.4.3 Flexibilidade corporal

3.4.4 Equilíbrio estático.

3.4.5 Equilíbrio dinâmico.

Análise dos dados. 


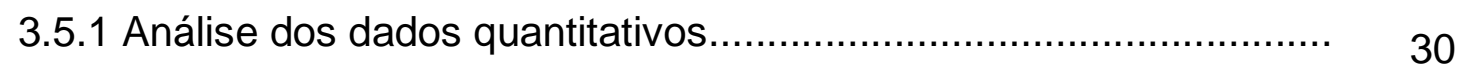

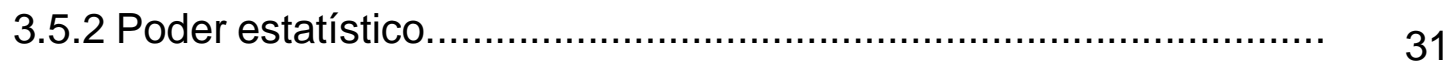

3.5.3 Análise qualitativa................................................................ 31

4. RESULTADOS.............................................................................. 33

4.1 Aderência, características antropométricas e psicossociais.

4.2 Estado de saúde, Mobilidade e humor........................................ 37

4.2.1 Análise quantitativa dos dados obtidos com a escala numérica.

4.2.2 Análise qualitativa do relato aberto das participantes no final do programa.

4.3 Força de contração isométrica................................................ 42

4.4 Flexibilidade corporal.............................................................. 44

4.5 Equilíbrio estático e dinâmico...................................................... 46

5. DISCUSSÃO.

5.1 Aderência ao estudo e percepção subjetiva sobre o estado de saúde, mobilidade e humor.

5.2 Força dos flexores e extensores do quadril, dos flexores plantares e dorsiflexores.

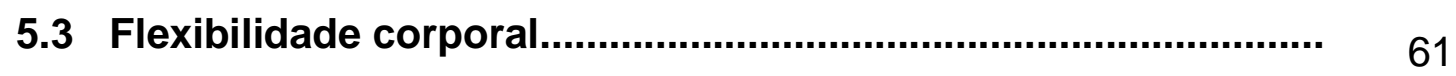

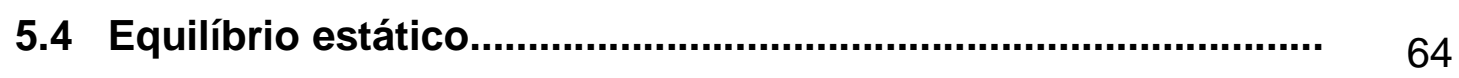

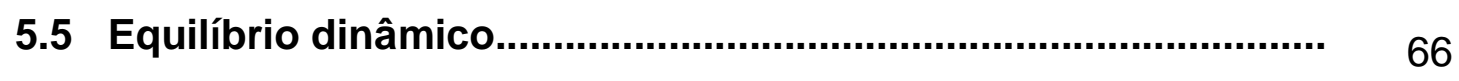

5.6 Limitações da pesquisa......................................................... 69

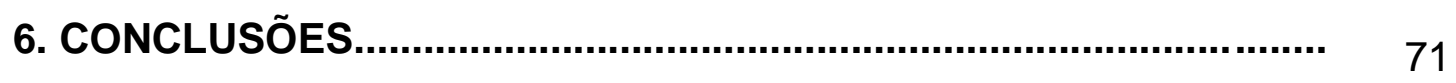

6.1 Considerações finais................................................................. 72

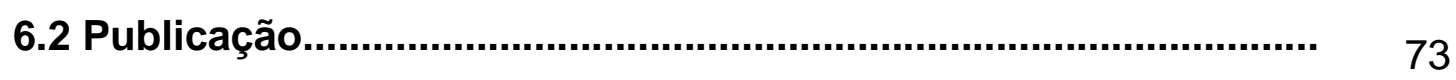

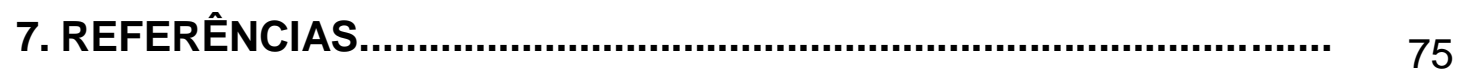

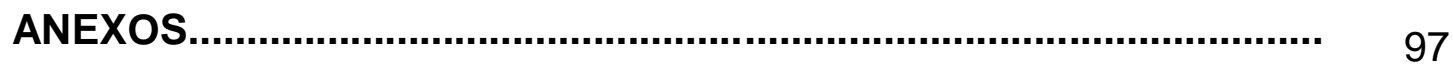




\section{LISTA DE ABREVIATURAS, SÍMBOLOS E SIGLAS}

\section{ABREVIATURAS}

et al. e outros

n número

t0 tempo zero de avaliação, anterior à intervenção

t1 tempo 1 de avaliação, após 3 meses de intervenção

t2 tempo 2 de avaliação, após 6 meses de intervenção

t3 tempo 3 de avaliação, após 9 meses de intervenção

t4 tempo 4 de avaliação, após 12 meses de intervenção

\section{SímBOLOS}

$\Delta \%$

Variação percentual

Rho

Correlação de Spearman

\section{SIGLAS}

ACS

American College of Sports

$\mathrm{AHA}$

American Heart Association

CSTF

Canadian Standardized Test of Fitness

IMC

Índice de Massa Corporal

OMS

Organização Mundial de Saúde

TAU-OA

Teste de Apoio Unipodal com olhos abertos

TAU-OF

Teste de Apoio Unipodal com olhos fechados

TSA

Teste Sentar e Alcançar

VA

Variação absoluta

VP

Variação Percentual

WCPT

World Confederation for Physical Therapy

WHO

World Health Organization 


\section{LISTAS DE FIGURAS}

\section{QUADROS}

Quadro 1 - Estudos que utilizaram a caminhada na água como

recurso de intervenção e variáveis avaliadas

Quadro 2 - Detalhamento do programa de caminhada em imersão

(etapa 1)

Continuação do quadro 2 (etapas 2 e 3)

Continuação do quadro 2 (etapa 4)

\section{FLUXOGRAMA}

Fluxograma 1- Distribuição da amostra.

\section{GRÁFICOS}

Gráfico 1 - Gráfico de distribuição das participantes, nos 5 tempos de avaliação do programa segundo o IMC categorizado pela OMS/WHO.... Gráfico 2 - a) Distribuição da taxa VA e b) Distribuição da taxa $\Delta \%$ do início e final do programa (t0-t4) das variáveis subjetivas do estado de saúde, mobilidade e estado de humor

Gráfico 3 - a) Evolução do equilíbrio estático e b) Evolução do equilíbrio dinâmico.

Gráfico 4 - a) Diagrama de caixa da variação absoluta e b) Diagrama de caixa da variação percentual das variáveis de equilíbrio estático e dinâmico.

Gráfico 5 - Evolução das médias e variação percentual dos testes TAUOA; TAU-OF e TUG

\section{FIGURAS}

Figura 1 - Dinamômetro portátil.

Figura 2 - Banco de Wells Instant Flex.

Figura 3 - Teste de Apoio Unipodal (TAU).

Figura 4 - Teste Timed Up and Go (TUG). 


\section{LISTA DE TABELAS}

Tabela 1 - Comparação das variáveis peso e IMC entre as etapas do programa.

Tabela 2 - Dados descritivos da percepção subjetiva do estado de saúde, mobilidade e humor.

Tabela 3 - Comparação de variáveis de saúde, mobilidade e humor entre etapas do programa.

Tabela 4 - Análise qualitativa dos comentários realizados no final do programa.

Tabela 5 - Variáveis descritivas de força dos músculos do quadril e do tornozelo

Tabela 6 - Comparação das variáveis de força dos extensores e flexores do quadril e do tornozelo entre as etapas do programa..

Tabela 7 - Descritivos da variável Flexibilidade corporal e classificação da média

Tabela 8 - Porcentagem por nível de flexibilidade medida pelo teste sentar e alcançar - Classificações CSTF (1986) e de Ribeiro (2010) para mulheres entre 50 e 59 anos.

Tabela 9 - Comparação das variáveis categorizadas de flexibilidade entre as etapas do programa de acordo com as classificações CSTF (1986) e de Ribeiro (2010)

Tabela 10 - Comparação das variáveis de flexibilidade entre as etapas do programa.

Tabela 11 - Variáveis descritivas do equilíbrio estático e dinâmico

Tabela 12 - Comparação das variáveis de equilíbrio entre as etapas do programa. 


\section{RESUMO}

Cardia MCG. Efeitos da caminhada em imersão em mulheres quinquagenárias saudáveis [tese]. São Paulo: Faculdade de Medicina, Universidade de São Paulo; 2018.

INTRODUÇÃO: Estudos com mulheres na faixa dos 50 anos justificam-se porque nesta etapa da vida os declínios fisiológicos são bastante evidentes e relacionados ao climatério e período pós-menopausa. Apesar de viverem mais do que os homens, adoecem mais frequentemente e registram índices mais baixos de saúde percebida do que eles. Melhoras funcionais foram evidenciadas com exercícios na água, todavia são raros os estudos que utilizam a caminhada em imersão como método exclusivo ou principal recurso de intervenção para promoção de saúde. OBJETIVO: Avaliar os efeitos de um programa de 12 meses de caminhada em imersão em mulheres quinquagenárias saudáveis. MÉTODOS: Participaram 59 mulheres em grupos de 10 a 12 participantes que configuraram um único grupo caracterizando-se como um estudo quaseexperimental. A intervenção foi realizada 2 vezes por semana em sessões de 30 minutos, por um ano, em piscina aquecida em aproximadamente $31^{\circ}$. $O$ programa foi dividido em 4 etapas de 3 meses cada, com evolução crescente na dificuldade dos exercícios. Foram realizadas 5 avaliações: inicial (t0), após 3 meses (t1), 6 meses (t2), 9 meses (t3) e no final do programa - 12 meses (t4). Para a avaliação subjetiva sobre o estado de saúde, mobilidade e humor, foi utilizada uma escala mista de zero a dez. Um breve relato sobre os principais efeitos do programa, com base em questão aberta, também foi analisado. Para a avaliação da força isométrica dos músculos flexores e extensores do quadril e do tornozelo utilizou-se um dinamômetro portátil e para a avaliação da flexibilidade foi utilizado o teste de sentar e alcançar. Para avaliação do equilíbrio foram utilizados os testes de apoio unipodal com olhos abertos (TAU-OA) e fechados (TAU-OF) e o teste "timed up and go" (TUG). RESULTADOS: Os resultados observados entre a avaliação inicial e final (t0-t4) do programa mostraram que houve melhora de $16,13 \%$ na percepção de saúde $(p<0,001)$, de $22,15 \%$ na mobilidade $(p<0,001)$ e de $9,69 \%$ no humor $(p=0,003)$. Na análise de conteúdo, $49,4 \%$ das falas relacionaram-se com a melhora da saúde; $22,9 \%$ com a autoestima e satisfação e $19,3 \%$ foram relacionadas à capacidade física. A força dos extensores do quadril melhorou 27,67\% ( $p<0,001)$, dos flexores do quadril $48,81 \% \quad(p<0,001)$, dos flexores plantares $32,59 \%(p<0,001)$ e dos dorsiflexores $40,75 \%(p<0,001)$. A melhora observada na flexibilidade foi de $54,55 \%$ ( $p<0,001)$. O equilíbrio estático avaliado pelo TAU-OA melhorou $35,51 \%$ e pelo TAU-OF $261,96 \%$ ambos com $p<0,001$. Houve melhora de $31,78 \%$ no equilíbrio dinâmico $(p<0,001)$; O equilíbrio, tanto estático como dinâmico e a 
flexibilidade tiveram melhora em todas as etapas. CONCLUSÃO: O estudo mostrou que esta forma de atividade, realizada em grupos com programa de longa duração, porém de fácil replicação, em 4 etapas progressivas melhorou o estado de saúde, a mobilidade e o estado de humor; a força dos músculos do quadril e do tornozelo, a flexibilidade, bem como o equilíbrio estático e dinâmico das mulheres participantes. Com isto ressaltamos a relevância de políticas públicas que favoreçam e incentivem a prática dos exercícios físicos prazerosos visando um envelhecimento natural e com autonomia funcional.

Descritores: hidroterapia; assistência integral à saúde; força muscular; amplitude de movimento articular; equilíbrio postural; envelhecimento. 


\begin{abstract}
Cardia MCG. Effects of immersion walk in healthy 50 year-old women [thesis] São Paulo: "Faculdade de Medicina, Universidade de São Paulo"; 2018
\end{abstract}

INTRODUCTION: Studies with 50 year-old women are justified because in this stage of life physiological declines are quite evident and related to climacteric and postmenopausal period. Although women live longer than men they fall sick more often and register lower perceived health indices than men do. Functional improvements were observed with immersion exercises, however, studies that use immersion walk as the only method or main intervention resource to promote health are rare. OBJECTIVE: To evaluate the effects of a 12-month immersion walk program in healthy 50 year-old women. METHOD: 59 women participated in groups of 10 to 12 participants which constituted a unique group thus characterized as a quasi-experimental study. The intervention was conducted twice a week, in 30 minute-sessions, for a year, in a pool heated at approximately $31^{\circ} \mathrm{C}$. The program was divided into 4 phases of 3 months each, with increasing evolution in exercise difficulty. 5 evaluations were carried out: initially (t0), after 3 months (t1), 6 months (t2), 9 months (t3) and at the end of the program, 12 months (t4). For the subjective assessment of the health status, mobility and mood, a mixed scale from zero to ten was used. A brief report of the main effects of the program, based on an open question, was also analysed. To evaluate the isometric strength of the flexion and extension muscles of the hip and ankle, a portable dynamometer was used and to evaluate flexibility the sit and reach test was used. To evaluate balance the one-legged stance-open eyes (OLS-OE), the one-legged stance-closed eyes (OLS-CE), and the timed up and go (TUG) tests were used. RESULTS: The results observed between the initial and final evaluation of the program (t0-t4) showed $16.13 \%$ improvement in the perception of health $(p<0,001), 22.15 \%$ in mobility $(p<0,001)$ and $9.69 \%$ in $\operatorname{mood}(p=0,003)$. In the content analysis, $49.4 \%$ of speeches were related to health improvement; $22.9 \%$ to self-esteem and satisfaction and $19.3 \%$ were related to physical capacity. The strength of hip extensors improved $27.67 \%$ ( $p<0,001)$, hip flexors $48.81 \%(p<0,001)$, plantar flexors $32.59 \%(p<0,001)$, and dorsiflexors $40.75 \%$ $(\mathrm{p}<0,001)$. Improvement observed in flexibility was $54.55 \%(\mathrm{p}<0,001)$. Static balance assessed by OLS-OE improved $35.51 \%$ and by OLS-CE $261.96 \%$, both with $(p<0,001)$. There was a $31.78 \%$ improvement in dynamic balance $(p<0,001)$. Both static and dynamic balance as well as flexibility improved in all phases. CONCLUSION: The study showed that this form of activity, developed in groups with a long-term program, but easily replicated, in 4 progressive stages has improved health status, mobility and mood; hip and ankle muscle strength; 
flexibility, as well as static and dynamic balance of participating women. Thus, we emphasize the relevance of public policies that favour and encourage the practice of pleasurable physical exercises, aiming at a natural aging process with functional autonomy.

Descriptors: hydrotherapy; comprehensive health care; muscle strength; range of motion, articular; postural balance; aging. 
1. INTRODUÇÃO 


\subsection{A mulher quinquagenária e os desafios da assistência integral à saúde da mulher}

As mulheres representam $51,03 \%$ da população brasileira e a expectativa média de vida ao nascer é de 75,8 anos, sendo 72,2 anos para os homens e 79,4 anos para as mulheres (dados de 2016) ${ }^{1}$. Apesar de viverem mais do que os homens, adoecem mais frequentemente e registram índices mais baixos de saúde percebida do que os homens, e são as principais usuárias do Sistema Único de Saúde (SUS) $)^{2-4}$.

As políticas voltadas à saúde da mulher no país estavam limitadas ao processo gravídico e puerperal, mas a partir de 1984, inicia-se o Programa de Assistência Integral à Saúde da Mulher (PAISM), com critérios para identificar e cuidar das prioridades desta população 5 .

A senescência é compreendida como o processo de envelhecimento natural, de diminuição progressiva da reserva funcional dos indivíduos. A Organização Mundial da Saúde (OMS) considera o limite de idade entre o indivíduo adulto e o idoso aos 65 anos em nações desenvolvidas e aos 60 anos nos países emergentes ${ }^{6,7}$. Todavia, as mulheres percebem o processo de envelhecimento durante o período do climatério e mais fortemente pósmenopausa, sendo que, na população brasileira, a menopausa ocorre em média aos $51,2 \operatorname{anos}^{8-13}$.

A idade como referência cronológica define ciclos e trajetórias de vida; idades ou segmentos geracionais definidos como "infância", "juventude", "meia 
idade" ou "terceira idade" expressam um modo de ser e de estar no mundo ${ }^{14}$. Se num passado recente ter 50 anos significava o início da velhice, hoje com o avanço da expectativa de vida temos outra relação com a senescência, que se caracteriza pelo processo de envelhecimento saudável ${ }^{7,8}$.

Contudo, esse prolongamento da vida trouxe um distanciamento entre a juventude e a velhice demarcado como a "meia idade". Com este aumento da longevidade, a faixa compreendida entre meia idade e velhice já não tem uma posição geracional precisa, possibilitando o surgimento de novos segmentos de "jovens-idosos", "idosos-jovens" e inclusive de "pessoas centenárias"14,15.

Para a mulher quinquagenária (entre 50 e 59 anos), diferentes questões podem ser refletidas desde o ponto de vista biológico (sexo) ou social (gênero), dentre as quais destacamos o declínio do ciclo vital em que cessa a sua capacidade procriativa, o papel de cuidadora e de pivô inter geracional familiar, e o conflito midiático da ditadura da beleza e da jovialidade ${ }^{15,16}$. Outras questões relacionadas ao processo saúde-doença, tais como o estilo e condições de vida e do trabalho, também podem influenciar negativamente a senescência, sendo o sedentarismo um dos principais fatores para o declínio da capacidade funcional ${ }^{9}$.

A presença de grande número de mulheres em idade avançada é, em muitas sociedades, um fenômeno demográfico recente e a preparação para o envelhecimento saudável deve ser mais do que uma busca pessoal, e sim, um desafio para gestores de políticas públicas, quer seja pela simples justificativa populacional, econômica ou pelo débito histórico de desigualdade de poder entre 
homens e mulheres que impacta fortemente as condições de saúde da mulher ${ }^{2,16}$.

Os custos da assistência à saúde em função do envelhecimento populacional são maiores do que das outras faixas etárias populacionais devido à incapacidade e ao processo degenerativo; desta forma, mulheres ativas e saudáveis consomem consideravelmente menos recursos ${ }^{17}$. Grande parte das mulheres quinquagenárias contemporâneas tem se preocupado com seu estado de saúde buscando recursos para o autocuidado, inclusive de atividades físicas que lhes proporcionem bem estar ${ }^{18}$.

No entanto, nem sempre é possível prescrever programas individualizados, quer seja pelo baixo número de profissionais inseridos na rede pública ou em razão do custo elevado. Programas em grupo devem ser estimulados, assim como atividades preventivas complementares à fisioterapia reabilitadora convencional. E, apesar da dificuldade de aderência à atividade física regular, observa-se uma estreita relação entre prática de exercícios e a melhora em indicadores de saúde ${ }^{19}$.

A mudança de comportamento individual é fundamental para facilitar a prática de atividade física adaptada ao estilo de vida ${ }^{20}$, mas este processo envolve uma multiplicidade de variáveis complexas, incluindo fatores sociais, ambientais e familiares ${ }^{21}$. A questão da motivação e da aderência ao exercício é multidimensional $^{18,22}$.

Programas simples, atrativos, de baixo custo, com indicadores de evolução pré-definidos, dirigidos por profissionais especializados podem apresentar boa aderência e promover melhoras funcionais e neste sentido, os 
exercícios físicos na água surgem como uma excelente opção para trabalhos preventivos realizados em grupo.

\subsection{Os declínios funcionais do sistema musculoesquelético e do controle postural}

A faixa etária entre 40 a 65 anos é o período em que os principais sistemas biológicos começam a apresentar declínios funcionais relevantes. Esses declínios variam de 10 a 30\% em relações aos valores máximos do encontrado na pessoa adulta mais jovem ${ }^{23}$. No entanto, a perda de força muscular se inicia a partir de 25 a 30 anos de idade e ocorre devido a vários fatores. Está intimamente associada à redução da massa muscular e à capacidade dos músculos de gerarem força ou uma combinação destes mecanismos ${ }^{24}$.

Sarcopenia é o termo que caracteriza a diminuição da massa muscular associada à idade, no entanto, o tamanho de um músculo não é equivalente à qualidade muscular, bem como não é o ponto determinante da função muscular. A perda de força muscular é mais evidente que a perda de massa em participantes sedentários, e por sua vez, os ganhos de força muscular superam os ganhos de massa em participantes submetidos a treino de resistência ${ }^{25,26}$.

A diminuição significativa da atividade física é um fator contributivo importante para a sarcopenia relacionada ao envelhecimento. O número de fibras no adulto é $20 \%$ maior do que nos idosos e depois dos 30 anos ocorre uma redução na secção transversa do músculo, com maior conteúdo gorduroso 
intramuscular e de colágeno. No entanto, sua reversibilidade está relacionada ao desempenho musculoesquelético decorrente de atividade física adequada ${ }^{27}$.

Com o envelhecimento, as alterações na massa muscular, massa de gordura e massa óssea estão estreitamente relacionadas, sendo afetadas pela prática de atividade física ${ }^{25}$. A menopausa também interfere na composição de massa gorda e massa magra na mulher ${ }^{28}$, e a diminuição da massa magra total está mais relacionada à menopausa, enquanto que a mudança da distribuição da gordura corporal e da adiposidade geral estão mais relacionadas à idade ${ }^{29}$.

Outro aspecto relacionado ao desempenho do sistema musculoesquelético na senescência é a diminuição da amplitude de movimento, geralmente multiarticular, percebida como uma diminuição global da flexibilidade corpora $^{30}$. Flexibilidade é a capacidade de execução voluntária de um movimento de amplitude angular máxima, por uma articulação ou conjunto de articulações, dentro dos limites morfológicos, que atinge o seu pico máximo na infância, piorando com o passar dos anos quando não estimulado ${ }^{30-32}$.

A flexibilidade é considerada como um dos componentes da aptidão e desempenho físico, sendo relevante para execução de movimentos simples ou complexos, desempenho desportivo, manutenção da saúde e preservação da qualidade de vida durante $\mathrm{o}$ processo de envelhecimento saudável ${ }^{33}$. $\mathrm{O}$ American College of Sports Medicine (ACS) e a American Heart Association $(A H A)$ recomendam a execução de atividades que mantenham ou aumentem a flexibilidade especialmente para a população com mais idade ${ }^{21,34}$.

Com a perda de força muscular, diminuição da amplitude de movimentos articulares e outras perdas decorrentes do processo de envelhecimento, também 
ocorrem as consequentes falhas nos sistemas de equilíbrio, que aumentam o risco de quedas e diminuem ainda mais a independência funcional ${ }^{35,36}$.

O controle postural é desempenhado por dois sistemas de equilíbrio, o de orientação postural, mais estático e relacionado ao mecanismo de ajuste e manutenção dos segmentos corporais e o de equilíbrio postural, mais dinâmico e relacionado às ações motoras exigida pelas tarefas do cotidiano ${ }^{37}$. Para manter o controle postural, os seres humanos utilizam continuamente informações sensoriais, provenientes dos sistemas visuais, vestibulares, auditivos e somatossensoriais que auxiliam o sistema nervoso central na realização de ajustes posturais ${ }^{38}$.

O equilíbrio ou estabilidade postural é a capacidade de manter o centro de massa dentro dos limites da base de apoio, denominados limites da estabilidade. Estes limites não são fixos e modificam-se de acordo com a tarefa a ser executada, a biomecânica individual e a demanda ambiental ${ }^{39}$. Está relacionado ao controle da relação entre forças externas que agem sobre o corpo e internas que são produzidas pelo corpo. Desta forma, o equilíbrio corporal é alcançado quando todas as forças estão controladas permitindo que o corpo se mantenha em equilíbrio estático numa determinada posição ou em equilíbrio dinâmico movendo-se de uma maneira controlada ${ }^{40}$. 


\subsection{Hidroterapia como recurso facilitador na promoção de saúde física}

Existe uma diversidade de nomenclatura e tipos de recursos terapêuticos relacionados à água ${ }^{41,42}$. Hidroterapia, terapia de SPA (salute per acqua), balneoterapia, hidroginástica, terapia aquática, duchas de Kneipp, hidromassagem, fisioterapia aquática, imersão em águas termais, renascimento em água, banhos de contraste e talassoterapia, são alguns dos termos mais comuns relacionados às terapias em imersão na água ${ }^{43,44}$.

A água, como meio para relaxamento e cura, não é privilégio do homem moderno. A prática dos exercícios físicos em meio aquático acontece há muitos séculos ${ }^{45}$. Imprescindível para nossa sobrevivência, a água também é uma fonte de prazer, podendo ser um meio de lazer, recreação, atividade física e reabilitação. Exercícios em imersão provocam sensações de alegria, felicidade e bem estar que devem ser considerados como benefício desta atividade ${ }^{46}$. Somos gerados em meio líquido e, por essa razão, espera-se que nossa relação com a água seja natural ${ }^{47}$

Exercícios na água proporcionam efeitos fisiológicos benéficos que envolvem respostas cardíacas, respiratórias, renais e musculoesqueléticas ${ }^{43,48}$, e podem atuar na redução da dor, melhora de estados de humor, qualidade de vida, percepção da imagem corporal e controle postural ${ }^{43,46,49}$. Embora estas condições subjetivas sejam consideradas como importantes ganhos desta 
atividade na saúde geral, poucos autores avaliaram as percepções de mulheres sobre os efeitos benéficos de uma intervenção com terapia aquática ${ }^{50,51}$.

Com o surgimento da epidemiologia, a saúde começou a ser expressa por números (batimentos cardíacos, frequência respiratória, temperatura corporal) e, em seu aspecto social, passou a ter também seus indicadores ${ }^{52}$. No entanto, definir objetivamente a saúde produz um distanciamento do corpo subjetivo, o que destaca a importância da narrativa na primeira pessoa, aquela que sente a dor e sofrimento ou felicidade e prazer valorizando os indicadores subjetivos do estado de saúde $52-54$.

Neste sentido, entende-se que "estado de saúde" seja uma condição subjetiva influenciada por fatores culturais, socioeconômicos e biológicos que reflete a conjuntura de uma época e de um lugar ${ }^{55}$. A Organização Mundial de Saúde (OMS) define saúde não apenas como a ausência de doença, mas como a situação de completo estado de bem-estar físico, mental e social; mas existe uma contraposição ao caráter utópico, irreal e inalcançável da perfeição deste "completo estado" indicando que "a saúde é um estado de razoável harmonia entre o sujeito e a sua própria realidade" 56 .

Desta forma, acreditamos que o relato das pacientes em relação à evolução de sinais e sintomas decorrentes da intervenção seja uma fonte de informação relevante, desde que explorada de forma sistemática para que as categorias de resposta possam ser usadas como feedback mensuráveis. 


\subsection{Movimento em imersão}

O termo hidroterapia, registrado como uma prática em fisioterapia, se desenvolveu a partir de teorias científicas da hidrodinâmica, das propriedades físicas da água e da fisiologia da imersão humana, visando restaurar o movimento humano ${ }^{57}$.

Alguns programas de exercícios em imersão são apontados com o objetivo de organizar sequências em função dos objetivos terapêuticos, e estabelecer duração, frequência, e variáveis pertinentes para avaliação em situação de análise evolutiva ou comparados a programas realizados no solo ${ }^{58}$. Entretanto, os programas de hidroterapia estabelecem parâmetros muitas vezes difíceis de serem seguidos, como a profundidade da piscina, velocidade, sentido do movimento ${ }^{59}$, comando e estímulo, frequência e intensidade dos exercícios ${ }^{60}$.

Estudos têm demonstrado os benefícios dos exercícios em imersão para mulheres no período pós-menopausa: na melhora da densidade mineral óssea do trocânter femoral ${ }^{10,11}$, na melhora na saúde cardiovascular e na capacidade física $^{12}$. E o Grupo de Fisioterapia Aquática da Associação Australiana de Fisioterapia (Australian Physiotherapy Association / National Aquatic Physiotherapy Group) apontou evidência para apoiar a fisioterapia aquática na gestão de diversas condições incluindo a pós-menopausa ${ }^{43}$.

Outros estudo com senescentes saudáveis ${ }^{60}$ indicam que estes programas podem trazer benefícios para prevenir, manter, retardar, melhorar ou tratar as disfunções físicas características do envelhecimento e diversos autores 
afirmam que a terapia aquática diminui o risco de quedas ${ }^{45,46,61-64}$, mas ainda não está claro qualquer influência sobre o medo de cair ${ }^{57}$.

Exercícios em imersão permitem a participação de movimentos de membros superiores e inferiores em sua amplitude de movimento total, com o mínimo de sobrecarga articular, favorecendo a mobilidade e flexibilidade corporal. Existe forte evidência de que o exercício realizado em água seja eficaz para melhorar a força em idosos saudáveis e evidência moderada para melhorar a flexibilidade ${ }^{46}$.

Estes exercícios podem ser organizados de tal forma a utilizar o princípio físico que permite gerar resistência multidimensional constante, favorecendo o ganho de força ${ }^{45,58,65-67}$. Caminhar na água com imersão até a altura da cicatriz umbilical aumenta a atividade dos músculos eretores da coluna e ativa o reto femoral para níveis próximos ou superiores ao caminhar no solo ${ }^{68}$.

Neste sentido alguns estudos têm demonstrado os benefícios da terapia aquática na melhora da força e/ou flexibilidade em pessoas saudáveis $24,58,69-71$, com fibromialgia ${ }^{72,73}$, com lombalgia ${ }^{74,75}$, osteoartrite de quadril e/ou joelho ${ }^{76}$ ou espondilite anquilosante ${ }^{77}$.

A World Confederation for Physical Therapy - WCPT ${ }^{57}$ sustenta que o ambiente aquático é um meio de exercício seguro contra quedas ou lesão, podendo ser altamente desafiador para atividades que demandam muito equilíbrio, incluindo a prática de postura em um único membro em imersão em diferentes níveis. Movimentos mais amplos dos membros e do tronco com maior deslocamento do centro de gravidade podem ser terapeuticamente úteis no treinamento do equilíbrio ${ }^{57}$. 
Os exercícios aquáticos permitem criar diversas situações de instabilidade com utilização dos efeitos da turbulência, fornecendo grande quantidade de informações sensoriais, promovendo melhora nas reações de equilíbrio corporal e agilidade $^{78}$. O equilíbrio é específico para cada ambiente e tarefa, mas programas aquáticos têm mostrado mudanças positivas em medidas obtidas no solo 57 .

Ganho significativo de equilíbrio sugere que exercícios em meio aquático são uma alternativa viável para as mulheres mais velhas, especialmente as que têm dificuldade na realização de exercício no solo ${ }^{36}$. Outros estudos investigaram efeitos do exercício aquático na capacidade de equilíbrio e manutenção da postura em pessoas adultas com doenças associadas ${ }^{79,80}$. Contudo, não encontramos estudos que apontem melhora do equilíbrio em mulheres saudáveis na meia idade.

\subsection{A caminhada na água como recurso terapêutico}

Estudos específicos que utilizam a caminhada em imersão como método exclusivo ou principal recurso de intervenção para promoção de saúde são ainda mais escassos (Quadro 1).

Arrieiro ${ }^{81}$ avaliou os efeitos de um programa de treinamento aeróbico de caminhada em imersão e no solo, no desempenho físico-funcional e na qualidade de vida em idosas com osteoartrose em joelhos. O programa teve a duração de 12 semanas com carga controlada e progressiva. Antes e após o 
período de treinamento, as voluntárias foram submetidas a avaliações do desempenho funcional por meio do teste de caminhada de seis minutos (TC6), do teste de escada (TE); análise do consumo máximo de oxigênio $\left(\mathrm{VO}_{2}\right.$ máx) e do limiar anaeróbio (LA), obtidos por meio de teste progressivo até a fadiga em esteira ergométrica.

O autor também coletou o autorrelato de dor, função física e rigidez articular, por meio da aplicação do Western Ontario and McMaster Universities Osteoarthritis Index (WOMAC) e da qualidade de vida, por meio do questionário Medical Outcomes Study 36-Item Short Form Health Survey (SF-36). A comparação entre grupos demonstrou que não houve diferença significativa em nenhuma das variáveis antes e após o programa de treino. No entanto, a análise intragrupo evidenciou melhora significativa no autorrelato de dor e função física, no desempenho do TC6 e TE, no $\mathrm{VO}_{2}$ máx e $\mathrm{VO}_{2}$ máx correspondente ao LA e em todos os domínios, excetuando aspectos sociais, do questionário SF-36, para ambos os grupos, após o comparação antes-após intervenção. $\mathrm{O}$ autor concluiu que a realização de um programa de caminhada com carga progressiva e controlada melhora o desempenho físico e funcional, bem como a qualidade de vida, independente do meio (água ou solo) para idosas com osteoartrose de joelhos.

O estudo de Candeloro e Caromano ${ }^{58}$ avaliou o efeito de um programa de hidroterapia na flexibilidade e na força muscular de mulheres idosas sedentárias. Foram realizados testes de força muscular por meio de miometria em músculos dos membros superiores, inferiores e tronco, e realizada avaliação fotográfica da flexibilidade, utilizando os testes de envergadura e flexão anterior do tronco, 
antes e depois do programa. O protocolo constou de 28 sessões de uma hora, durante 14 semanas consecutivas. Os exercícios físicos foram organizados em sete níveis de dificuldade visando ganho de flexibilidade e força muscular.

As autoras encontraram diminuição estatisticamente significativa na medida referente à flexão anterior de tronco e aumento na medida do teste de envergadura. Nos músculos abdominais, glúteos e iliopsoas não ocorreu alteração estatisticamente significativa de força, e nos músculos quadríceps femoral, isquiotibiais, bíceps braquial, peitoral maior e médio e deltóide médio, foi encontrado aumento estatisticamente significativo. Concluíram que o programa de hidroterapia proposto foi eficiente para melhorar a flexibilidade e, parcialmente, a força muscular das mulheres jovens idosas que participaram do estudo.

Kaneda et al. ${ }^{35}$ compararam os efeitos de 2 tipos de programas de exercícios em imersão na capacidade de equilíbrio de 30 idosos saudáveis que foram aleatoriamente alocados em 2 grupos experimentais: um com exercícios de corrida em águas profundas (DWRE, n=15) e outro com exercícios em águas rasas (NWE, $n=15)$. Os participantes realizaram as sessões 2 vezes por semana durante 12 semanas. $O$ teste de equilíbrio estático postural foi realizado em uma plataforma estabilométrica com os pés descalços, com os olhos abertos, durante 30 segundos. Em ambos os grupos, os tempos de reação simples diminuíram significativamente. Os resultados deste estudo sugerem que um programa de exercícios em águas profundas é melhor do que em águas rasas para melhorar a capacidade de equilíbrio dinâmico em idosos. 
Quadro 1 - Estudos que utilizaram a caminhada na água como recurso de intervenção e variáveis avaliadas

\begin{tabular}{|c|c|c|c|c|c|c|c|}
\hline Estudo & Amostra & $\begin{array}{l}\text { Tempo total de } \\
\text { intervenção }\end{array}$ & $\begin{array}{l}\text { Duração da } \\
\text { sessão }\end{array}$ & $\begin{array}{l}\text { Avaliação subjetiva } \\
\text { de Saúde e } \\
\text { aspectos } \\
\text { psicossocial }\end{array}$ & \begin{tabular}{|l|} 
Avaliação do \\
Equilibrio Estático e \\
Dinâmico
\end{tabular} & $\begin{array}{l}\text { Avaliação de } \\
\text { Flexibilidade }\end{array}$ & $\begin{array}{l}\text { Avaliação de } \\
\text { Força }\end{array}$ \\
\hline ARRIEIRO (2011) & $\begin{array}{l}\mathrm{N}=16 \text { mulheres idosas } \\
\text { com OA do joelho } \\
\text { Caminhada no solo }(\mathrm{N}=8) \\
\mathrm{Na} \text { água }(\mathrm{N}=8)\end{array}$ & $\begin{array}{l}12 \text { semanas } \\
\text { (24 sessões) }\end{array}$ & $30-55 \mathrm{~min}$ & $\begin{array}{l}\text { Auto-relato de dor, } \\
\text { função física e } \\
\text { rigidez (WOMAC) } \\
\text { e Qualidade de } \\
\text { vida (SF-36). }\end{array}$ & Não & Não & Não \\
\hline $\begin{array}{l}\text { CANDELORO e } \\
\text { CAROMANO } \\
\text { (2007) }\end{array}$ & $\begin{array}{l}\mathrm{N}=31 \text { idosas, saudáveis e } \\
\text { sedentárias } \\
\text { Grupo experimental = } 16 \\
\text { Grupo controle }=15\end{array}$ & $\begin{array}{l}14 \text { semanas } \\
\text { (28 sessões) }\end{array}$ & $60 \mathrm{~min}$ & Não & Não & $\begin{array}{l}\text { Fotografia } \\
\text { testes de } \\
\text { envergadura e } \\
\text { flexão anterior do } \\
\text { tronco - TSA }\end{array}$ & $\begin{array}{l}\text { Miometria } \\
\text { músculos do } \\
\text { MMSS, MMII € } \\
\text { tronco }\end{array}$ \\
\hline $\begin{array}{l}\text { KANEDA et al. } \\
(2008)\end{array}$ & $\begin{array}{l}\mathrm{N}=30 \text { pessoas ambos os } \\
\text { sexos } \\
\text { Águas profundas }=15 \\
\text { Água normal }=15 .\end{array}$ & $\begin{array}{l}12 \text { semanas } \\
\text { (24 sessões) }\end{array}$ & $80 \mathrm{~min}$ & Não & $\begin{array}{l}\text { Plataforma } \\
\text { estabilométrica }\end{array}$ & Não & Não \\
\hline $\begin{array}{l}\text { KATSURA et al. } \\
(2010)\end{array}$ & $\begin{array}{l}\mathrm{N}=20 \text { idosos saudáveis } \\
\text { Com equipamento }=12 \\
\text { Sem o equipamento }=8\end{array}$ & $\begin{array}{l}8 \text { semanas } \\
(24 \text { sessões - } \\
3 x / \text { sem) }\end{array}$ & $90 \mathrm{~min}$ & $\begin{array}{l}\text { POMS - profile of } \\
\text { mood states }\end{array}$ & TUG & TSA & $\begin{array}{l}\text { Miometria - } \\
\text { músculos do } \\
\text { tornozelo }\end{array}$ \\
\hline
\end{tabular}

Fonte: Da autora, 2018 
O estudo de Katsura et al. ${ }^{67}$ avaliou a eficácia do treinamento de exercícios aquáticos utilizando um novo equipamento de resistência atado aos tornozelos. Uma amostra com 20 idosos saudáveis com média de 69,1 $( \pm 4,5)$ anos foi aleatoriamente designada em dois grupos, um utilizando o novo equipamento e o outro sem o equipamento. $\mathrm{O}$ treinamento consistiu basicamente em caminhar na água. Todos os sujeitos foram submetidos a medições antropométricas, testes de desempenho físico (flexibilidade, força dos músculos do tornozelo e equilíbrio dinâmico) e também responderam ao questionário POMS (Profile Of Mood States) sobre estados de humor. Foram observadas melhoras significativas em ambos os grupos.

Face ao limitado número de estudos direcionados para análise da caminhada na água com mulheres de meia idade, saudáveis e sedentárias, e frente aos benefícios dos exercícios no meio aquático apontados na literatura para outras populações, compreendemos ser relevante o desenvolvimento de estudos que possam ser utilizados como biomarcadores na redução de danos e na manutenção da saúde de mulheres quinquagenárias.

Desta forma objetivou-se avaliar os efeitos de um programa anual de caminhada em imersão sobre o estado de saúde, mobilidade, humor, força, flexibilidade, equilíbrio estático e dinâmico, de mulheres quinquagenárias saudáveis. 
2. OBJETIVOS 


\subsection{OBJETIVO PRIMÁRIO}

Avaliar os efeitos de um programa anual de caminhada em imersão em mulheres quinquagenárias saudáveis.

\subsection{OBJETIVOS SECUNDÁRIOS:}

- Avaliar a percepção subjetiva no estado de saúde, humor e mobilidade.

- Conhecer a aderência ao programa proposto e a visão das participantes em relação aos efeitos percebidos.

- Analisar o efeito da intervenção na força muscular.

- Analisar o efeito da intervenção na flexibilidade corporal.

- Analisar o efeito da intervenção no equilíbrio estático e dinâmico. 
3. MÉTODO 


\subsection{Delineamento e aspectos éticos da pesquisa}

Trata-se de um estudo quase-experimental, de caráter quantitativo, longitudinal e descritivo sobre o desenvolvimento e avaliação do programa de caminhada em imersão em quatro etapas.

O projeto de pesquisa foi aprovado pelo Comitê de Ética em Pesquisa da Faculdade de Medicina da Universidade de São Paulo (Anexo A).

\subsection{Participantes, critérios de inclusão e exclusão}

Para fins de inclusão no estudo foram admitidas mulheres entre 50 e 59 anos, saudáveis e sedentárias.

Para o atestado de saúde, as participantes apresentaram parecer médico afirmando que estavam em condições clínicas para frequentar programa de exercícios físicos de baixa a moderada intensidade, em imersão em água aquecida, constatando não serem portadoras de doenças cardiopulmonares, musculoesqueléticas, neurológicas ou dermatológicas que limitassem a prática de hidroterapia. As participantes também afirmaram não fazer uso de medicamentos, e declararam não ter praticado qualquer atividade física específica ou caminhadas regulares (mínimo 30 minutos, pelo menos duas vezes por semana) há cinco anos, caracterizando o estado de sedentarismo. Foram critérios de exclusão a falta ao treinamento sem reposição na mesma semana, intercorrências clínicas ou sociais que impedissem a continuidade no programa e a falta de interesse nas atividades físicas durante as aulas. Concluíram o programa 59 mulheres. 


\subsection{Procedimentos}

Foram organizados grupos de 10 a 12 participantes. A piscina com dimensão de 12 por 8 metros e profundidade de 1,3 metros permitiu a imersão até o nível das axilas e a temperatura se manteve em uma média de $31^{\circ} \mathrm{C} \pm 1^{\circ} \mathrm{C}$. $\mathrm{A}$ intervenção foi realizada 2 vezes por semana, por 30 minutos.

O programa de doze meses foi dividido em 4 etapas, de 3 meses cada, e a avaliação funcional ocorreu em 5 tempos, a saber, antes do treinamento ou inicial (t0), após 3 meses de treinamento (t1), após 6 meses de treinamento (t2), após 9 meses de treinamento (t3) e após 12 meses de treinamento ou final (t4).

O quadro 2 especifica todas as atividades desenvolvidas nas 4 etapas do programa de caminhada em imersão.

Quadro 2 - Detalhamento do programa de caminhada em imersão

\begin{tabular}{|c|c|c|}
\hline Etapa/Mês & Atividades em imersão & $\begin{array}{l}\text { Duração } \\
\text { (minutos) }\end{array}$ \\
\hline & Avaliação inicial - to & \\
\hline \multirow{4}{*}{$\begin{array}{l}\text { Etapa } 1 \text { - } \\
\text { Mês } 1\end{array}$} & Caminhar ao redor da piscina (CARP) com tranquilidade & 10 \\
\hline & CARP com tranquilidade - invertendo direção a cada 2 minutos & 10 \\
\hline & Caminhar rápido & 8 \\
\hline & Flutuar relaxando & 2 \\
\hline \multirow{6}{*}{$\begin{array}{l}\text { Etapa } 1 \text { - } \\
\text { Mês } 2\end{array}$} & Caminhar ao redor da piscina (CARP) com tranquilidade & 5 \\
\hline & CARP com tranquilidade - andando para trás & 5 \\
\hline & CARP com tranquilidade - invertendo direção a cada 2 minutos & 5 \\
\hline & CARP com movimentos laterais, para direita e depois para esquerda (2,5 minutos cada) & 5 \\
\hline & Caminhar rápido & 8 \\
\hline & Flutuar relaxando & 2 \\
\hline \multirow{8}{*}{$\begin{array}{l}\text { Etapa } 1 \text { - } \\
\text { Mês } 3\end{array}$} & Caminhar ao redor da piscina (CARP) com tranquilidade & 3 \\
\hline & CARP com tranquilidade - andando para trás & 3 \\
\hline & CARP com tranquilidade - invertendo direção a cada 3 minutos & 6 \\
\hline & $\begin{array}{l}\text { CARP com tranquilidade - com movimentos laterais, para direita e depois para esquerda } \\
\text { ( } 3 \text { minutos cada) }\end{array}$ & 6 \\
\hline & Caminhar rápido & 5 \\
\hline & Caminhar saltando para frente & 5 \\
\hline & Flutuar relaxando & 2 \\
\hline & Avaliação t1 após o término da etapa 1 & \\
\hline
\end{tabular}


Continuação da página 21 / Quadro 2 - Detalhamento do programa de caminhada em imersão

\begin{tabular}{|c|c|c|}
\hline \multirow{7}{*}{$\begin{array}{l}\text { Etapa } 2- \\
\text { Mês } 4\end{array}$} & Caminhar ao redor da piscina (CARP) com tranquilidade & 3 \\
\hline & CARP com tranquilidade - andando para trás & 3 \\
\hline & $\begin{array}{l}\text { CARP com tranquilidade - com os braços apoiados no participante que vai à frente, } \\
\text { saltando com } 1 \text { perna (direita e depois esquerda - } 3 \text { minutos cada) Fisioterapeuta vai à } \\
\text { frente do grupo. }\end{array}$ & 6 \\
\hline & CARP com movimentos laterais, para direita e depois para esquerda (3 minutos cada) & 6 \\
\hline & Caminhar rápido & 5 \\
\hline & Caminhar saltando para frente & 5 \\
\hline & Flutuar relaxando & 2 \\
\hline \multirow{7}{*}{$\begin{array}{l}\text { Etapa } 2- \\
\text { Mês } 5\end{array}$} & Caminhar ao redor da piscina (CARP) com tranquilidade & 2 \\
\hline & CARP com tranquilidade, andando para trás & 2 \\
\hline & $\begin{array}{l}\text { CARP com tranquilidade - com os braços apoiados no participante que vai à frente, } \\
\text { saltando com } 1 \text { perna (alternando - } 3 \text { minutos cada perna) }\end{array}$ & 4 \\
\hline & CARP com movimentos laterais, para direita e depois para esquerda (3 minutos cada) & 6 \\
\hline & Caminhar rápido & 1 \\
\hline & Caminhar saltando para frente & 5 \\
\hline & Flutuar relaxando & 2 \\
\hline \multirow{8}{*}{$\begin{array}{l}\text { Etapa } 2- \\
\text { Mês } 6\end{array}$} & Caminhar ao redor da piscina (CARP) com tranquilidade & 2 \\
\hline & CARP com tranquilidade, andando para trás & 2 \\
\hline & $\begin{array}{l}\text { CARP com tranquilidade - com os braços apoiados no participante que vai à frente, } \\
\text { saltando com } 1 \text { perna ( } 3 \text { minutos cada) }\end{array}$ & 4 \\
\hline & $\begin{array}{l}\text { CARP com movimentos laterais, para direita e depois para esquerda ( } 3 \text { minutos cada } \\
\text { perna) }\end{array}$ & 6 \\
\hline & Caminhar rápido & 10 \\
\hline & Caminhar saltando para frente & 5 \\
\hline & Flutuar relaxando & 2 \\
\hline & Avaliação t2 após o término da etapa 2 & \\
\hline \multirow{7}{*}{$\begin{array}{l}\text { Etapa } 3- \\
\text { Mês } 7\end{array}$} & Caminhar ao redor da piscina com passos normais & 2 \\
\hline & Caminhar ao redor da piscina com passos normais, andando para trás & 2 \\
\hline & $\begin{array}{l}\text { Caminhar ao redor da piscina com passos normais com os braços apoiados no } \\
\text { participante que vai à frente, saltando com } 1 \text { perna (alternando }-3 \text { minutos cada perna) }\end{array}$ & 4 \\
\hline & $\begin{array}{l}\text { Caminhar ao redor da piscina com movimentos laterais, para direita e depois para } \\
\text { esquerda ( } 3 \text { minutos cada), com passos normais }\end{array}$ & 6 \\
\hline & Caminhar rápido & 10 \\
\hline & Caminhar saltando para frente, passos normais & 5 \\
\hline & Flutuar relaxando & 2 \\
\hline \multirow{7}{*}{$\begin{array}{l}\text { Etapa } 3- \\
\text { Mês } 8\end{array}$} & Caminhar ao redor da piscina com passos normais & 2 \\
\hline & Caminhar ao redor da piscina com passos normais, andando para trás & 2 \\
\hline & $\begin{array}{l}\text { Caminhar ao redor da piscina com passos normais com os braços apoiados no } \\
\text { participante que vai à frente, saltando com } 1 \text { perna (direita e depois esquerda - } 2 \text { minutos } \\
\text { cada) }\end{array}$ & 4 \\
\hline & Caminhar rápido & 10 \\
\hline & Caminhar saltando para frente com rápido & 5 \\
\hline & Caminhar rápido dando chutes na água com rápido & 5 \\
\hline & Flutuar relaxando & 2 \\
\hline \multirow{7}{*}{$\begin{array}{l}\text { Etapa } 3- \\
\text { Mês } 9\end{array}$} & Caminhar ao redor da piscina com passos normais & 2 \\
\hline & Caminhar ao redor da piscina rápido, andando para trás & 2 \\
\hline & Caminhar rápido & 10 \\
\hline & Caminhar saltando para frente com passos normais & 5 \\
\hline & Caminhar rápido dando chutes na água rápido & 5 \\
\hline & $\begin{array}{l}\text { Caminhar rápido com resistor (prancha de isopor de } 20 \text { × } 20 \mathrm{~cm} \text { usada em paralelo ao } \\
\text { corpo, segura pelas mãos), rápido }\end{array}$ & 4 \\
\hline & Flutuar relaxando & 2 \\
\hline
\end{tabular}


Continuação da página 22 / Quadro 2 - Detalhamento do programa de caminhada em imersão

\begin{tabular}{|l|l|c|}
\hline \multirow{4}{*}{ Etapa 4 - 10} & Caminhar ao redor da piscina muito rápido & 2 \\
\cline { 2 - 3 } & Caminhar rápido & 5 \\
\cline { 2 - 3 } & Caminhar saltando para frente com resistor frontal, rápido & 10 \\
\cline { 2 - 3 } & Caminhar rápido dando chutes na água, rápido & 5 \\
\cline { 2 - 3 } & $\begin{array}{l}\text { Caminhar rápido com resistor (prancha de isopor de 20 x 20 cm usada em paralelo ao } \\
\text { corpo, segura pelas mãos), passos normais }\end{array}$ & 6 \\
\cline { 2 - 3 } & Flutuar relaxando & 2 \\
\hline \multirow{5}{*}{ Etapa 4 - } & Caminhar ao redor da piscina muito rápido & 5 \\
\cline { 2 - 3 } & Caminhar rápido com resistor frontal rápido & 10 \\
\cline { 2 - 3 } & Caminhar saltando para frente com resistor frontal rápido & 1 \\
\cline { 2 - 3 } & Caminhar ao redor da piscina com rápido & 2 \\
\cline { 2 - 3 } & Caminhar rápido com resistor frontal rápido & 2 \\
\cline { 2 - 3 } & Flutuar relaxando & 6 \\
\hline \multirow{5}{*}{ Etapa 4 - } & Caminhar ao redor da piscina muito rápido & 10 \\
\cline { 2 - 3 } & Caminhar rápido com resistor frontal muito rápido & 10 \\
\cline { 2 - 3 } & Caminhar saltando para frente com resistor frontal muito rápido & 2 \\
\cline { 2 - 3 } & Caminhar rápido com resistor frontal muito rápido & 2 \\
\cline { 2 - 3 } & Flutuar relaxando & 2 \\
\hline
\end{tabular}

Fonte: Própria da pesquisa. Protocolo desenvolvido pela Profa. Dra. Fátima A. Caromano - Laboratório de Fisioterapia e Comportamento da FMUSP, 2015.

As atividades propostas caracterizaram-se por ser de leve intensidade a partir da análise de dados gerados pelo acompanhamento da frequência cardíaca (FC).

A realização de exercício físico impõe sobrecarga para o sistema cardiovascular, fato que pode ser observado imediatamente e de forma simples, por meio da medida da (FC). Para compreensão do efeito do exercício no sistema cardiovascular são necessárias algumas medidas usadas isoladamente ou de forma comparativa, ou seja, minimamente durante o repouso antes e após o exercício. Considerando que a imersão na água provoca alterações cardiocirculatórias decorrentes da pressão hidrostática da água sobre o sistema de retorno venoso, deve considerar-se também a medida da FC após a imersão, antes do exercício ${ }^{58}$.

No presente estudo, foi medida a FC em quatro momentos diferentes das sessões, a saber, FC de repouso no solo (A), FC de repouso em imersão (B), (ambas em bipedestação), FC após os exercícios e FC de repouso (C), em imersão, 3 minutos 
após o final dos exercícios (D), nos momentos t0 (quinta sessão - após 4 sessões de adaptação ao meio aquático), a cada 3 meses (t1, t2 e t3) e no final do treinamento (t4).

A frequência cardíaca máxima (FCmáx) é um biomarcador para o planejamento do treinamento e seu controle. Segundo a fórmula da OMS (Organização Mundial de Saúde) - Karvonen ${ }^{82}$, a FCmáx é igual a 220 menos a idade em anos. Considerando que a idade das mulheres deste estudo variou entre 50 e 55 anos, e considerando a fórmula da OMS - Karvonen, a FCmáx prevista para a população estudada poderia variar de 165 a 170 bpm, enquanto que a FC sub-máxíma (75\% da FCmáx) esperada, que é o mínimo a ser atingido em exercício de condicionamento cardiovascular, seria de 132 a $128 \mathrm{bpm}$.

Desta forma, como esperado, a frequência cardíaca não apresentou variações significativas durante as sessões. Da $5^{\text {a }}$ para a $32^{a}$, no momento A, ocorreu aumento de $3,4 \%(p=0,530)$; no momento $B$, queda de $8,8 \%(p=0,339)$; no momento $C$, queda de $2,0 \%(p=0,603)$; e no momento $D$, aumento de $0,5 \%(p=0,220)$.

A média da FC de repouso do grupo sofreu aumento mínimo da sessão de base para a última sessão, de $80,3 \pm 13,35 \mathrm{bpm}$, para $81,3 \pm 11,33 \mathrm{bpm}$, não sendo estatisticamente significante, e indicando ausência de condicionamento cardiovascular. No entanto, se considerarmos que as atividades físicas sofreram um acréscimo de dificuldade durante o tempo, a não variação da FC cardíaca pode ser considerada um indicador de uma leve adaptação do sistema à prática de atividade física. 


\subsection{Instrumentos e procedimentos de avaliação}

\subsubsection{Estado de saúde, mobilidade e humor}

Para a avaliação subjetiva do estado de saúde, mobilidade e humor foi utilizada uma escala numérica com 10 centímetros e marcas a cada 1 centímetro, na qual o zero indicava a pior situação possível e o 10 a melhor situação possível para cada variável. $\mathrm{Na}$ análise dos resultados foram considerados os seguintes critérios: avaliação subjetiva precária entre as notas 0 e 3,9; ruim entre 4 e 5,9; regular entre 6 e 7,9; boa entre 8 e 8,9, muito boa entre 9 e 9,9 e excelente com a nota 10 .

Após a última sessão, as mulheres foram incentivadas a deixarem um relato escrito sobre os efeitos que acreditavam estar relacionados com a prática de exercícios que realizaram.

\subsubsection{Força muscular isométrica}

Para mensurar a força muscular, foi utilizado um dinamômetro portátil da marca Lafayette, que pode medir forças de 0.0 a $100 \mathrm{~kg} / \mathrm{F}$ (Figura 1). No presente estudo foi investigada a força isométrica. Foram estudados os grupos musculares dos flexores e extensores do quadril e do tornozelo; os testes musculares foram realizados de acordo com o descrito por Kendall ${ }^{82}$, e a resistência manual foi substituída pelo dinamômetro que mediu o pico de força isométrica do músculo ou grupo muscular contra resistência oferecida pelo examinador, devidamente treinado ${ }^{58,84}$. Essa técnica é recomendável por ser um teste rápido, diminuir a repetição do teste manual e fornecer dados numéricos para o estudo da evolução ${ }^{85}$. 
O protocolo utilizado, denominado make test, avaliou a força que a participante exerce contra o aparelho ${ }^{86}$. Para cada coleta foram realizadas três mensurações para cada grupo muscular, coletadas de forma padrão no membro inferior direito e esquerdo; para fins de estudo, foi considerado o melhor resultado das três medidas $^{86,87}$.

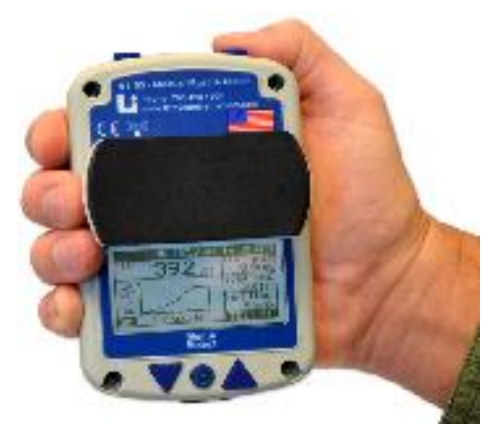

Figura 1 - Dinamômetro portátil

Lafayette Instruments, Model 01165

Fonte: Lafayette Manual Muscle Testing System

http://lafayetteevaluation.com/products/manual-muscle-testing-system

\subsubsection{Flexibilidade corporal}

O teste de sentar e alcançar (TSA) ou "Sit and Reach test" foi proposto por Wells e Dillon no ano de 1952, e foi inicialmente utilizado para avaliar a flexibilidade da coluna lombar e dos músculos isquiotibiais ${ }^{88}$, entretanto, por envolver todo o corpo e diversas articulações pode ser adotado como um teste de avaliação geral da flexibilidade corporal.

O TSA é um teste de fácil aplicação, tem baixo custo operacional e é recomendado e utilizado pelas principais baterias de testes como a Canadian Standardized Test of Fitness (1986), Eurofit (1988) e YMCA Physical Test Battery, Celafiscs ${ }^{31,32,89}$ e os resultados permitem avaliações baseadas em tabelas normativas de acordo com o gênero e a idade ${ }^{32,82}$. 
O participante realiza o teste sentado no chão, com os joelhos estendidos e as plantas dos pés apoiadas na parede anterior do instrumento de medida (banco de Wells) e flexiona o tronco com os membros superiores também estendidos registrando-se o maior valor alcançado ao final do movimento ${ }^{74,90}$. Foi utilizado um banco de Wells Instant Flex da marca Sanny (Figura 2).

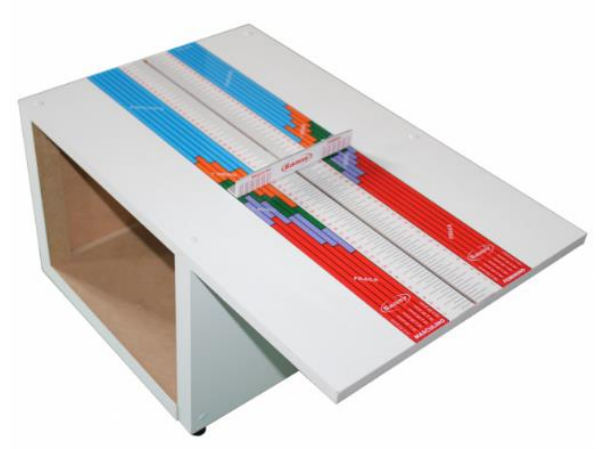

Figura 2 - Banco de Wells Instant Flex Sanny Fonte: https://www.sanny.com.br/banco-de-wells-sanny.html

\subsubsection{Equilíbrio estático}

Para a avaliação do equilíbrio estático foram utilizados os testes de apoio unipodal com olhos abertos (TAU-OA) e fechados (TAU-OF).

O TAU foi utilizado com o objetivo de avaliar o tempo de execução (em segundos) em que as participantes se mantiveram em apoio unipodal ${ }^{91}$ (Figura 3). Foi realizado três vezes, para cada membro inferior, sendo considerado para análise o maior valor encontrado no teste de cada membro inferior somado e dividido por 2. A 
medida de tempo foi coletada utilizando-se cronômetro digital e comandos verbais bem específicos.

Foi realizada a seguinte sequência de testes, com intervalo de 3 minutos de repouso entre cada teste: TAU-OA - Em pé, apoio bipodal, sobre superfície rígida, com os olhos abertos; TAU-OF - Em pé, apoio bipodal, sobre superfície rígida, com os olhos fechados. TAU - Quanto maior o tempo de realização do teste melhores são as condições de equilíbrio estático ${ }^{91}$.
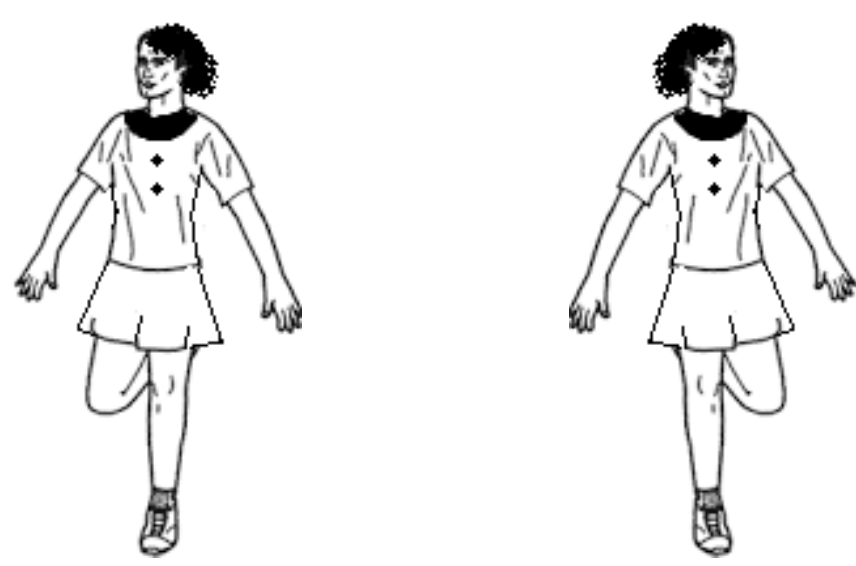

Figura 3 - Teste de Apoio Unipodal (TAU)

Fonte: Própria, 2018

\subsubsection{Equilíbrio dinâmico}

Para a avaliação do equilíbrio dinâmico foi utilizado o teste "timed up and go" (TUG).

O TUG avalia o equilíbrio em mobilidade, mensurando em segundos o tempo gasto para levantar-se de uma cadeira padrão, sem ajuda dos braços, andar uma distância de 3 metros, dar a volta e retornar ${ }^{92}$. No início do teste, a voluntária foi posicionada com as costas apoiadas no encosto da cadeira e ao final, deveria encostar novamente. $O$ trajeto foi demarcado no chão e a participante foi orientada 
para iniciar no comando "vá". O tempo foi cronometrado a partir da voz de comando até o momento em que a voluntária apoiou novamente suas costas no encosto da cadeira. $O$ teste foi realizado uma vez para familiarização e na sequência, para coleta de dados (Figura 4).

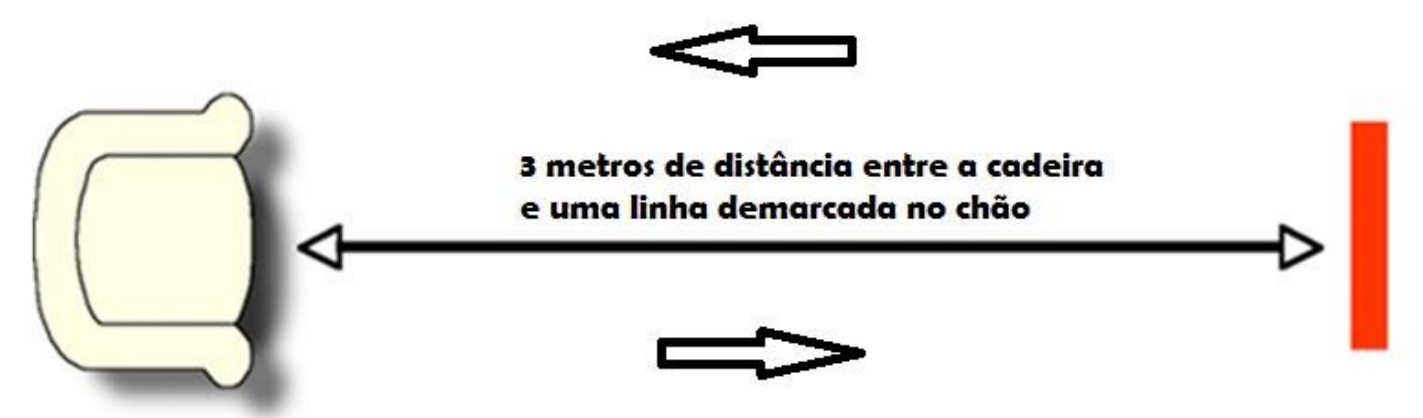

Figura 4 - Teste Timed up and go (TUG)

Fonte: Própria, 2018.

Este teste é uma medida útil e prática de mobilidade física; é rápido e fácil de executar sem equipamento especial ou treinamento. É confiável entre os avaliadores e ao longo do tempo. Tem validade de conteúdo, na medida em que avalia uma série bem reconhecida de manobras utilizadas na vida diária, e validade concorrente, na medida em que se correlaciona bem com medidas mais amplas de equilíbrio, velocidade de marcha e habilidades funcionais ${ }^{92}$.Este teste é de fácil entendimento, realizado em pouco tempo e amplamente utilizado na literatura ${ }^{91,93}$, e desde 2011, é indicado pelas Sociedades Americana e Britânica de Geriatria como teste para avaliação de indicador de quedas em idosos ${ }^{94}$.

Quanto à execução do teste TUG, quanto menor o tempo de realização, melhor é a condição de equilíbrio dinâmico como a realização de atividades cotidianas de levantar e sentar, caminhar, entre outras ${ }^{19,91,95}$. Indivíduos adultos independentes e sem alterações no equilíbrio realizam o teste em 10s ou menos; os dependentes em 
transferências básicas realizam em 20s ou menos e os que necessitam mais de 20s são dependentes em muitas atividades da vida diária e na mobilidade. Na ausência de valor de referência para a faixa etária do estudo foram considerados os valores de referência de 8,1s para a faixa etária de 60 a 69 anos; de 9,2s (70 a 79 anos) e 11,3s (80 a 99 anos), determinados por Bohannon ${ }^{84}$ para a execução do TUG mediante um estudo de meta-análise.

\subsection{Análise dos dados}

\subsubsection{Análise dos dados quantitativos}

Foi utilizado o programa estatístico IBM SPSS - v.22 (Statistical Package for the Social Sciences). Os dados foram analisados inicialmente por estatística descritiva (média, desvio padrão da média mediana-P50, valores mínimo e máximo).

Devido às características de um estudo quase-experimental com apenas um grupo, a análise de medidas repetidas foi realizada pelo teste não paramétrico de Friedman. Em seguida passou-se a observar cada tempo de avaliação par a par através do teste de Wilcoxon. Foram analisadas todas as possibilidades de pareamento, entretanto para uma maior clareza e compreensão das etapas de tratamento foram detalhados nos resultados apenas os tempos de avaliação: t0-t1; t1t2; t2-t3; t3-t4 e t0-t4. As demais possibilidades estão apresentadas no Anexo B.

O teste de Sinais também foi detalhado para possibilitar a análise de distribuição de melhora, piora ou estagnação das participantes em cada etapa do programa. Ainda foram utilizados o teste de correlação de Spearman e a análise de 
variação de grandezas ao longo do tempo observadas pelos índices e taxas de variação:

- Variação absoluta (VA) que é a diferença entre os valores da maior grandeza menos os da menor grandeza. $V A=t 4-t 0$. Nossa base de comparação foi o instante de tempo 0 (avaliação inicial ou de base) e avaliações realizadas ao final de cada fase (t1, t2, t3 e t4).

— Variação relativa que é uma forma de quantificar a importância da diferença entre variáveis diferentes observando o quanto a variação absoluta representa no valor da grandeza no período base. É chamada taxa de variação quando apresentada em forma percentual (TVP), sendo igual a (t4 - t0) / t0 x 100. O símbolo da medida de variação percentual é $\Delta \%$.

\subsubsection{Poder Estatístico}

O poder estatístico foi calculado utilizando o software $G^{*}$ Power 3.1.9.2 com o teste post-hoc para duas amostras dependentes (pareadas) com o cálculo amostral de 58 sujeitos, considerando um nível de significância de $5 \%$ e tamanho do efeito de 0,5. Desta forma, o tamanho da amostra será suficiente para fornecer $95,0 \%$ de poder estatístico para as variáveis de classificação de Wilcoxon (Anexo C).

\subsubsection{Análise Qualitativa}

A análise de narrativa neste protocolo cumpre o importante papel de fornecer elementos subjetivos que não seriam possíveis de serem identificados por meio de 
instrumentos estruturados ou semi-estruturados. São relatos cujos referenciais são as experiências das pessoas e não dos narradores ${ }^{96-98}$.

Os relatos foram inicialmente organizados em 5 categorias com base na frequência dos temas nas respostas, a saber, mobilidade e capacidade física, satisfação, aspectos sociais, estado de Saúde e prática alimentar.

A análise de conteúdo ${ }^{99}$ dos relatos neste protocolo cumpre o importante papel de fornecer elementos subjetivos que não poderiam ser identificados por meio de instrumentos estruturados ou semi-estruturados.

Os relatos foram organizados em torno do tema norteador "possíveis benefícios do programa de imersão" e todas as respostas foram identificadas e categorizadas com base na ocorrência e frequência. 
4. RESULTADOS 


\subsection{Aderência, características antropométricas e psicossociais}

O estudo teve a aderência inicial de 136 mulheres jovens idosas saudáveis e terminou com 59, apresentando uma aderência ao programa de 43\% (Fluxograma 1). As intercorrências familiares agruparam mudança de bairro, mudança de cidade, mudança na estrutura familiar, morte em família, nascimento de neto e desemprego em família. As intercorrências clínicas deveram-se a gripes, pneumonia, fratura, dermatite, anemia e dengue.

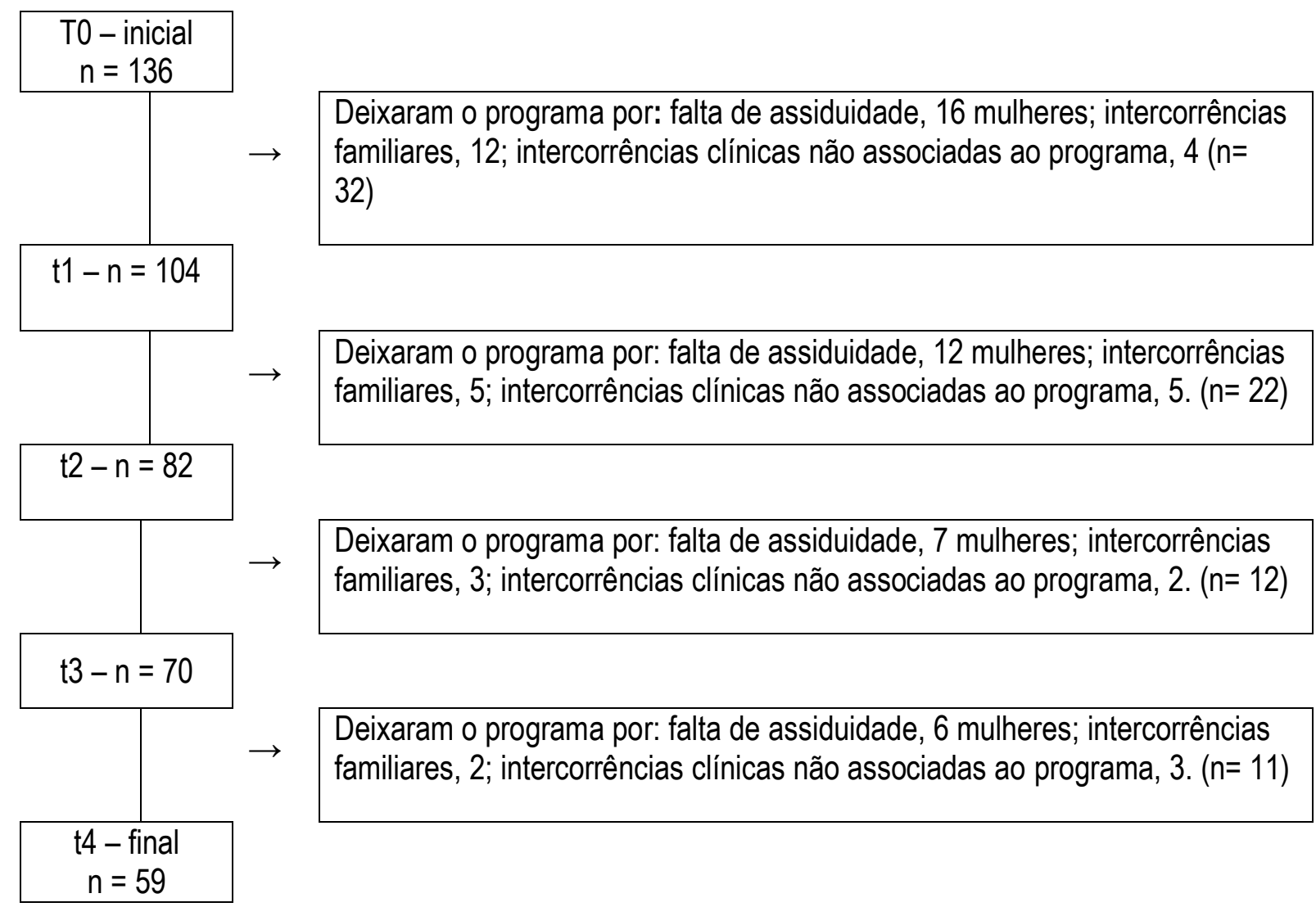

Fluxograma 1- Distribuição da amostra

As mulheres deste estudo tinham idade média de $52,9( \pm 1,2)$ anos no início do estudo; 78\% eram profissionalmente ativas, com uma média de escolaridade de 10,9 
$( \pm 2,8)$ anos de estudo e $49,2 \%$ eram casadas. Nenhuma realizava atividade física regularmente.

Apresentaram média de altura de $162,6( \pm 3,2)$, peso médio de $75,7( \pm 8,9)$. Somente 15,3\% apresentavam índice de massa corpórea (IMC) na faixa de normalidade, estando $52,5 \%$ com sobrepeso e $32,2 \%$ delas com obesidade, segundo categorização do IMC pela Organização Mundial de Saúde (OMS/WHO) e validado pela ABESO - Associação Brasileira para o estudo da Obesidade e Síndrome Metabólica $^{100}$ (Tabela 1).

Tabela 1 - Evolução das variáveis peso e IMC entre as etapas do programa

\begin{tabular}{|c|c|c|c|c|c|c|}
\hline \multirow{2}{*}{ Variáveis } & \multirow{2}{*}{ P (Sig) } & \multicolumn{2}{|c|}{ Taxa de variação } & \multicolumn{3}{|c|}{ Distribuição $¥$} \\
\hline & & VA & $\operatorname{VP}(\Delta \%)$ & Igual & $\uparrow(+)$ & $\downarrow(-)$ \\
\hline Peso_t0 / Peso_t1 & $0,167^{*}$ & 0,11 & $0,13 \%$ & 1 & 36 & 22 \\
\hline Peso_t1 / Peso_t2 & $0,824^{*}$ & $-0,10$ & $-0,08 \%$ & 2 & 29 & 28 \\
\hline Peso_t2 / Peso_t3 & $0,455^{\star}$ & $-0,13$ & $-0,15 \%$ & 1 & 27 & 31 \\
\hline Peso_t3 / Peso_t4 & $<0,001^{*}$ & $-0,53$ & $-0,71 \%$ & 1 & 12 & 46 \\
\hline Peso_t0 / Peso_t4 & $0,049^{* *}$ & $-0,66$ & $-0,81 \%$ & 1 & 26 & 32 \\
\hline IMC_to / IMC_t1 & $0,167^{*}$ & 0,04 & $0,13 \%$ & $1(51)^{\star}$ & $36(5)^{\star}$ & $22(3)^{\star}$ \\
\hline IMC_t1 / IMC_t2 & $0,775^{\star}$ & $-0,03$ & $-0,08 \%$ & $2(52)^{\bullet}$ & $29(2) \bullet$ & $28(5)^{\bullet}$ \\
\hline IMC_t2 / IMC_t3 & $0,400^{*}$ & $-0,04$ & $-0,15 \%$ & $1(56) \bullet$ & $27(0)$ • & $31(3)$ \\
\hline IMC_t3 / IMC_t4 & $<0,001^{*}$ & $-0,20$ & $-0,71 \%$ & $1(54)^{\bullet}$ & $12(1)^{\bullet}$ & $46(4)^{\bullet}$ \\
\hline IMC_t0 / IMC_t4 & $0,046^{* *}$ & $-0,24$ & $-0,81 \%$ & $1(46)$ • & $26(3)$ • & $32(10)$ • \\
\hline
\end{tabular}

\footnotetext{
*Teste não paramétrico de Classificações de Wilcoxon; Teste de medidas repetidas de Friedman $¥$ Distribuição das participantes do estudo pelo Teste de Sinal

- Valores absolutos do IMC e (valores categorizados pela OMS apud ABESO, 2016)

Em negrito: avaliação inicial e final com a evolução do programa

Fonte: Dados da pesquisa, 2018.
}

VA - Variação absoluta em Quilograma para a variável peso e pontos para o IMC; VP $(\Delta \%)$ - Variação percentual

A média de peso do grupo variou muito pouco entre cada etapa do programa e o conjunto das medidas repetidas demonstrou diferença significativa $(p=0,001)$ revelada pelo teste de Friedman. Na comparação par a par pelo teste de Wilcoxon 
verificaram-se diferenças significativas no peso e no IMC entre a medida inicial (t0) e as medidas (t3) com $p<0,001$ e ( $t 4$ ) com $p=0,032$ (tabela 1) sugerindo que esse tipo de programa necessita de pelo menos 9 meses para alcançar alguma mudança no peso e no índice de massa corporal das participantes.

Uma análise descritiva de distribuição de peso mostrou que na etapa (t3), $77,9 \%$ das mulheres diminuíram de peso e com isto o valor bruto do IMC; todavia o IMC quando categorizado, segundo a classificação da OMS/WHO referendada pela $\mathrm{ABESO}^{100}$, mostrou que apenas $6,7 \%$ mudaram de classe. No final do programa (t4) $77,9 \%$ das participantes permaneceram na mesma classe do IMC, 5,1\% aumentaram e 16,9\% diminuiram o IMC (Tabela 1).

A análise do IMC categorizado demonstrou um ligeiro aumento na classificação de IMC normal e diminuição da obesidade tipo I e tipo II (Gráfico 1).

Gráfico 1 - Gráfico de distribuição das participantes, nos 5 tempos de avaliação do programa segundo o IMC categorizado pela OMS/WHO*

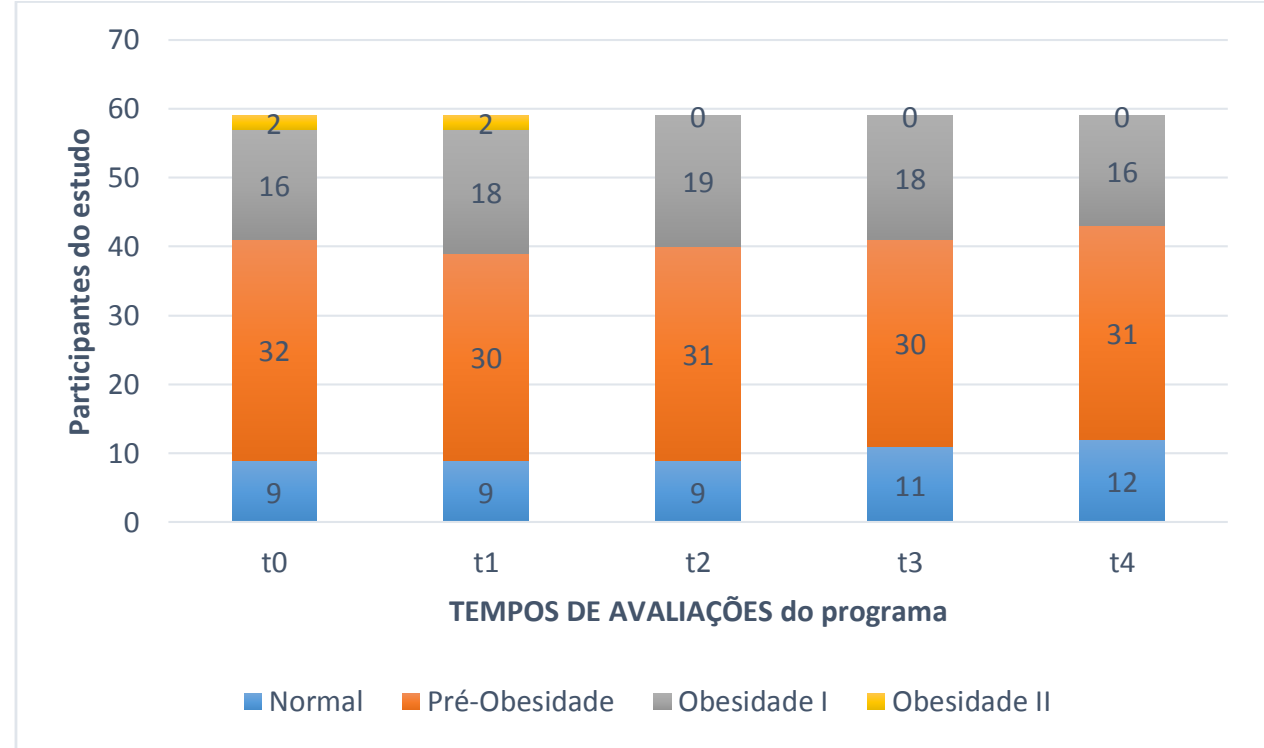

* Organização Mundial de Saúde/World Health Organization apud ABESO, 2016, p.16

Fonte: Dados da pesquisa, 2018. 
A variável IMC não apresentou correlação com as varáveis flexibilidade, TAUOA e TUG e apresentou correlação muito fraca inversa com as variáveis força (Rho= $-0,330, p=0,011)$ e TAU-OF (Rho $=-0,249 ; p=0,057)$.

O estudo de revisão sobre o estado nutricional da população brasileira de Nascimento et al ${ }^{101}$ encontrou uma prevalência, em relação ao gênero, mais alta de sobrepeso e obesidade entre as mulheres. Os autores alegam o fato de as mesmas apresentarem mais acúmulo de gordura visceral e maior expectativa de vida, e também atentaram para a mudança hormonal decorrente da menopausa. Entretanto, os autores salientam que o sobrepeso e a obesidade diminuem, entre homens e mulheres, com o avanço da idade.

\subsection{Estado de saúde, Mobilidade e Humor}

\subsubsection{Análise quantitativa dos dados obtidos com a escala numérica}

$\mathrm{Na}$ avaliação subjetiva, realizada com a escala numérica de 0 a 10 (de pior situação possível à melhor situação possível), encontramos aumento progressivo nas médias das variáveis de percepção do estado de saúde, da mobilidade e do humor (Tabela 2).

A percepção inicial do estado de saúde teve uma média regular de 6,95 $( \pm 1,4)$, mas foi considerada alta por $25,4 \%$ das participantes, com 8 pontos atribuídos por $8,5 \%$ das mulheres; com 9 pontos por $10,2 \%$ e com 10 pontos (nota máxima) por $6,8 \%$ delas. 
O teste de Friedman apontou diferença significativa com $p<0,001$ no conjunto dos 5 tempos de avaliações e o teste de Wilcoxon não mostrou diferença significativa apenas entre os tempos t0-t1 $(p=0,058)$ e t2-t3 $(p=0,340)$ (Tabela 3$)$.

Tabela 2 - Dados descritivos da percepção subjetiva do estado de saúde, mobilidade e humor

\begin{tabular}{l|c|c|c}
\hline \multicolumn{1}{c|}{ Variáveis } & Mediana & Média (DP) & Mínimo - Máximo \\
\hline Saúde t0 & 7,0 & $6,95(1,4)$ & $5-10$ \\
Saúde t1 & 7,0 & $7,17(1,3)$ & $5-10$ \\
Saúde t2 & 7,0 & $7,46(1,1)$ & $6-10$ \\
Saúde t3 & 7,0 & $7,54(1,2)$ & $5-10$ \\
Saúde t4 & 8,0 & $7,88(1,1)$ & $6-10$ \\
\hline Mobilidade t0 & 6,0 & $6,56(0,9)$ & $5-9$ \\
Mobilidade t1 & 7,0 & $7,17(0,8)$ & $6-9$ \\
Mobilidade t2 & 7,0 & $7,42(1,0)$ & $6-10$ \\
Mobilidade t3 & 8,0 & $7,69(1,0)$ & $6-10$ \\
Mobilidade t4 & 8,0 & $7,92(1,0)$ & $6-10$ \\
\hline Humor t0 & 7,0 & $6,95(1,3)$ & $4-9$ \\
Humor t1 & 7,0 & $7,15(1,0)$ & $5-9$ \\
Humor t2 & 7,0 & $7,32(1,1)$ & $5-10$ \\
Humor t3 & 7,0 & $7,39(1,1)$ & $6-10$ \\
Humor t4 & 7,0 & $7,46(1,1)$ & $6-10$ \\
\hline
\end{tabular}

*DP - Desvio Padrão da média

Fonte: Dados da pesquisa, 2018.

A mobilidade também teve uma média regular de $6,56( \pm 0,9)$ na avaliação inicial, sendo considerada alta por $18,6 \%$ das participantes, com 8 pontos atribuídos por $15,3 \%$ das mulheres e com 9 pontos por $3,4 \%$, todavia nenhuma das participantes atribuiu a nota máxima. 
A mobilidade foi considerada melhor desde a etapa inicial (t1) quando 52,6\% das participantes já atribuíram maior valor que na avaliação inicial e, na etapa final (t4), quando $86,4 \%$ das mulheres consideraram ter melhor mobilidade; $10,2 \%$ relataram ter a mesma mobilidade que no início do programa e apenas 3,4\% tiveram a percepção de piora na mobilidade. Houve diferença significativa em todos os momentos do programa (Tabelas 2 e 3) corroborada pelo teste de Friedman $(p<0,001)$

Tabela 3 - Evolução de variáveis de saúde, mobilidade e humor entre etapas do programa

\begin{tabular}{|c|c|c|c|c|c|c|}
\hline \multirow{2}{*}{ Variáveis } & \multirow[b]{2}{*}{$P($ Sig) } & \multicolumn{2}{|c|}{ Variação } & \multicolumn{3}{|c|}{ Distribuição ¥ } \\
\hline & & VA & $\operatorname{VP}(\Delta \%)$ & Igual & $\uparrow(+)$ & $\downarrow(-)$ \\
\hline Saúde to / t1 & $0,058^{*}$ & 0,22 & 4,25 & 24 & 23 & 12 \\
\hline Saúde t1 / t2 & $0,007^{*}$ & 0,29 & 5,35 & 37 & 18 & 4 \\
\hline Saúde t2 / t3 & $0,340^{*}$ & 0,08 & 1,27 & 38 & 13 & 8 \\
\hline Saúde $\mathrm{t} 3$ / t4 & $<0,001^{*}$ & 0,34 & 5,29 & 38 & 19 & 2 \\
\hline Saúde to / t4 & $<0,001^{* *}$ & 0,93 & 16,13 & 19 & 37 & 3 \\
\hline Mobilidade t0 / t1 & $<0,001^{*}$ & 0,61 & 10,21 & 27 & 31 & 1 \\
\hline Mobilidade t1 / t2 & $0,004^{*}$ & 0,25 & 3,76 & 38 & 17 & 4 \\
\hline Mobilidade t2 / t3 & $<0,001^{*}$ & 0,27 & 3,98 & 42 & 16 & 1 \\
\hline Mobilidade $\mathrm{t} 3$ / t4 & $0,002^{*}$ & 0,22 & 3,13 & 42 & 15 & 2 \\
\hline Mobilidade to / t4 & $<0,001^{* *}$ & 1,36 & 22,15 & 6 & 51 & 2 \\
\hline Humor t0 / t1 & $0,051^{*}$ & 0,20 & 4,51 & 11 & 23 & 25 \\
\hline Humor t1 / t2 & $0,012^{*}$ & 0,17 & 2,09 & 43 & 13 & 3 \\
\hline Humor t2 / t3 & $0,317^{*}$ & 0,07 & 1,27 & 43 & 10 & 6 \\
\hline Humor t3 / t4 & $0,206^{*}$ & 0,07 & 1,02 & 49 & 7 & 3 \\
\hline Humor to / t4 & $0,002^{* *}$ & 0,51 & 9,69 & 20 & 28 & 11 \\
\hline
\end{tabular}

${ }^{*}$ Teste não paramétrico de Classificações de Wilcoxon; **Teste de medidas de Friedman VA (s) - Variação absoluta em segundos; VP $(\Delta \%)$ - Variação percentual;

Distribuição das participantes do estudo pelo Teste de Sinal;

Em negrito: avaliação inicial e final com a evolução do programa

Fonte: Dados da pesquisa, 2018. 
A percepção inicial do estado de humor teve igualmente uma média regular de $6,95( \pm 1,2)$, sendo considerada alta por $40,7 \%$ das participantes, com 8 pontos atribuídos por $33,9 \%$ das mulheres, e com 9 pontos por 6,8\%, mas nenhuma participante atribuiu a nota máxima. (Tabelas 2 e 3).

Apesar do alto número de participantes ter atribuído escores acima de 8 pontos na avaliação inicial, conseguimos observar os efeitos positivos do programa na percepção da saúde com melhora de 16,13\%; da mobilidade com melhora de 22,15\% e do estado de humor com melhora de 9,69\% por meio da análise de variação percentual (t0-t4) (Gráfico 2). O teste de medidas repetidas de Friedman também revelou diferença significativa $(p<0,001)$.

Gráfico 2 - a) Distribuição da taxa VA e b) Distribuição da taxa $\Delta \%$ do início e final do programa (tot4) das variáveis subjetivas do estado de saúde, mobilidade e estado de humor.

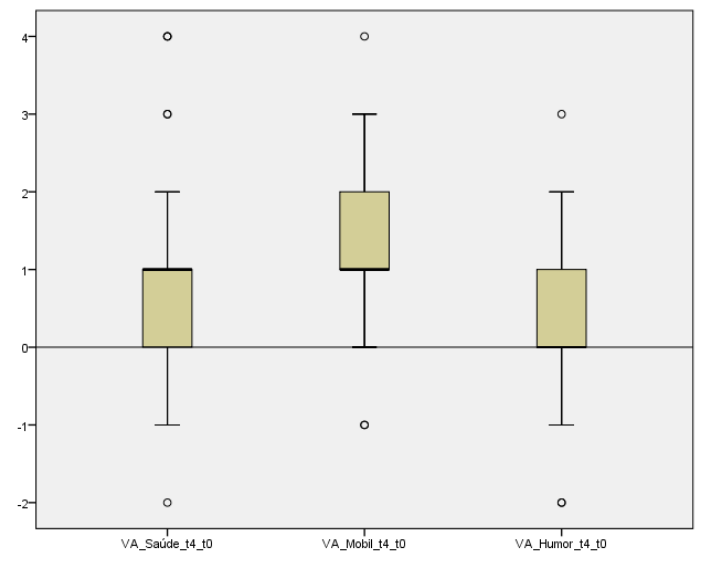

Taxa de Variação Absoluta (VA)

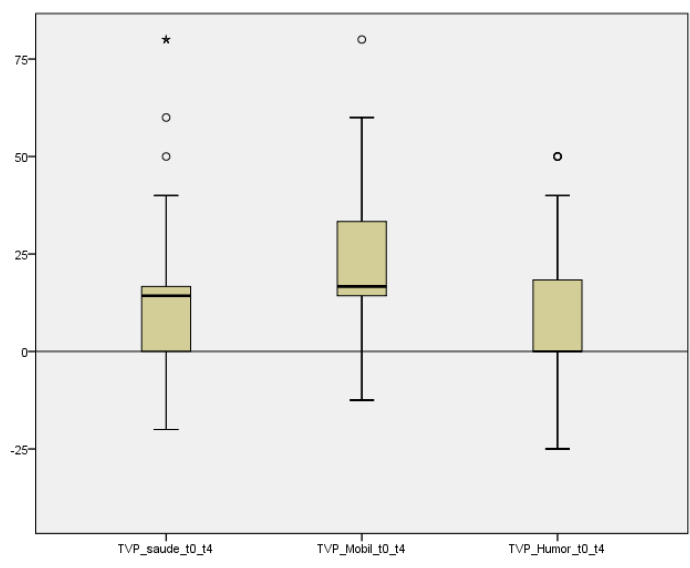

Taxa de Variação Percentual $(\Delta \%)$

Fonte: Dados da pesquisa, 2018.

\subsubsection{Análise qualitativa do relato aberto das participantes no final do programa}

O relato das participantes sobre o programa, realizado após a última sessão, foi composto por 83 comentários feitos por $94,9 \%$ das mulheres. Uma análise 
qualitativa foi realizada, selecionando os temas presentes nas falas, e 5 domínios e 23 categorias foram estabelecidas (Tabela 4).

Tabela 4 - Análise qualitativa dos comentários realizados no final do programa

\begin{tabular}{|c|c|c|c|}
\hline Domínios & Categorias & $\mathrm{N}$ & Freq \% \\
\hline $\begin{array}{l}\text { Mobilidade e } \\
\text { Capacidade Física }\end{array}$ & $\begin{array}{l}\text { andar melhor, com mais confiança ou maior resistência - } 6 \\
\text { subir escadas (melhor, sem medo ou mais confiante) - } 3 \\
\text { me equilibro melhor - } 1 \\
\text { mais forte }-5 \\
\text { mais ágil }-1\end{array}$ & 16 & $19,3 \%$ \\
\hline $\begin{array}{l}\text { Autoestima e } \\
\text { Satisfação } \\
\text { (sentir-se melhor, } \\
\text { mais confiante e } \\
\text { mais feliz) }\end{array}$ & $\begin{array}{l}\text { mais sexy - } 2 \\
\text { se sente melhor com o corpo ou } \\
\text { gosta mais do corpo agora - } 5 \\
\text { se sente mais feliz - } 4 \\
\text { mais confiante, mais confiante no corpo e mais animada com a } \\
\text { vida, durmo e acordo mais animada - } 5 \\
\text { adorei ter começado este programa - } 1 \\
\text { mais coragem para enfrentar novos desafios - } 1 \\
\text { mais solta - } 1\end{array}$ & 19 & $22,9 \%$ \\
\hline Aspectos Sociais & $\begin{array}{l}\text { tenho feito mais amigos - } 1 \\
\text { estou mais sociável - } 1 \\
\text { percebo que as pessoas veem que estou mudando - } 1\end{array}$ & 3 & $3,6 \%$ \\
\hline Estado de Saúde & $\begin{array}{l}\text { corpo menos dolorido - } 8 \\
\text { menos inchaço - } 6 \\
\text { intestino funciona melhor - } 5 \\
\text { qualidade do sono - } 10 \\
\text { maior disposição - } 11 \\
\text { mais tranquila - } 1\end{array}$ & 41 & $49,4 \%$ \\
\hline Alimentação & $\begin{array}{l}\text { sentia muita fome }-2 \\
\text { estimulada para controlar alimentação }-2\end{array}$ & 4 & $4,8 \%$ \\
\hline & Total & 83 & $100 \%$ \\
\hline
\end{tabular}

Fonte: Dados da pesquisa, 2018.

$\mathrm{Na}$ análise qualitativa, $49,4 \%$ das falas foram relacionadas com a melhora da saúde (diminuição da dor, do inchaço, melhor funcionamento do intestino, melhora na qualidade do sono, mais disposição e tranquilidade); 22,9\% relacionadas à autoestima e satisfação (sentir-se mais sexy, melhor com o corpo, mais feliz, mais confiante e contente com o programa); 19,3\% relacionadas à capacidade física (andar e subir 
escadas melhor e com mais confiança, melhor equilíbrio, mais força e agilidade); 4,5\% relacionadas à alimentação (sentir fome e estímulo para controlar a alimentação) e 3,6\% relacionadas aos aspectos sociais (mais amigos e mais sociável).

\subsection{Força de contração isométrica}

Os dados descritivos da força de contração isométrica podem ser observados na Tabela 5.

Tabela 5 - Variáveis descritivas de força dos músculos do quadril e do tornozelo

\begin{tabular}{l|c|c|c}
\hline \multicolumn{1}{c|}{ Variáveis } & Mediana & Média $(\mathrm{DP})^{*}$ & Mínimo - Máximo \\
\hline ExtQ t0 & 15 & $14,64(1,98)$ & $10-17$ \\
ExtQ t1 & 15 & $14,86(1,43)$ & $12-18$ \\
ExtQ t2 & 16 & $15,76(1,41)$ & $12-18$ \\
ExtQ t3 & 17 & $16,71(1,37)$ & $14-19$ \\
ExtQ t0 & 18 & $18,44(1,60)$ & $14-22$ \\
\hline FlexQ t0 & 14 & $13,97(2,19)$ & $9-20$ \\
FlexQ t1 & 14 & $14,17(2,33)$ & $10-20$ \\
FlexQ t2 & 16 & $16,34(1,91)$ & $13-21$ \\
FlexQ t3 & 19 & $19,00(1,94)$ & $15-24$ \\
FlexQ t0 & 20 & $\mathbf{2 0 , 3 7 ( 1 , 5 0 )}$ & $17-24$ \\
\hline FPlan t0 & 12 & $11,36(1,20)$ & $10-14$ \\
FPlan t1 & 11 & $11,19(1,47)$ & $9-14$ \\
FPlan t2 & 13 & $12,85(1,38)$ & $10-16$ \\
FPlan t3 & 13 & $13,58(1,63)$ & $11-17$ \\
FPlan t0 & 15 & $15,00(1,59)$ & $12-18$ \\
\hline FDors t0 & 12 & $11,41(1,17)$ & $9-14$ \\
FDors t1 & 12 & $11,37(1,27)$ & $9-14$ \\
FDors t2 & 13 & $13,22(1,17)$ & $11-16$ \\
FDors t3 & 15 & $15,93(1,59)$ & $13-19$ \\
FDors t0 & 16 & $1,40)$ & \\
\hline ExQ = Ex & & \\
\hline
\end{tabular}

ExtQ = Extensores do Quadril; FlexQ= Flexores do Quadril;

FPlan = Flexores plantares do Tornozelo; FDors = Dorsiflexores do Tornozelo.

Em negrito: avaliação inicial e final com a evolução do programa. *DP - Desvio Padrão da média.

Fonte: Dados da pesquisa, 2018. 
A melhora na força foi verificada a partir da avaliação t1-t2 indicando que o programa de caminhada em imersão necessitou de seis meses de intervenção para atingir este objetivo.

O conjunto de medidas repetidas observado pelo teste de Friedman apontou diferença significativa com $p<0,001$ nas quatro variáveis de força (Tabela 6).

Tabela 6 - Evolução das variáveis de força dos extensores e flexores do quadril e do tornozelo entre as etapas do programa

\begin{tabular}{|c|c|c|c|c|c|c|}
\hline \multirow{2}{*}{ Variáveis } & \multirow{2}{*}{$P($ Sig) } & \multicolumn{2}{|c|}{ Variação } & \multicolumn{3}{|c|}{ Distribuição ¥ } \\
\hline & & VA & $\operatorname{VP}(\Delta \%)$ & Igual & $\uparrow(+)$ & $\downarrow(-)$ \\
\hline ExtQ t0-t1 & $0,103^{*}$ & 0,22 & 2,40 & 40 & 11 & 8 \\
\hline ExtQ t1-t2 & $<0,001^{*}$ & 0,89 & 6,26 & 13 & 44 & 2 \\
\hline ExtQ t2-t3 & $<0,001^{*}$ & 0,94 & 6,22 & 17 & 42 & 0 \\
\hline ExtQ t3-t4 & $<0,001^{*}$ & 1,72 & 10,43 & 5 & 54 & 0 \\
\hline ExtQ t0-t4 & $<0,001^{* *}$ & 3,79 & 27,67 & 0 & 59 & 0 \\
\hline FlexQ t0-t1 & $0,048^{*}$ & 0,20 & 1,50 & 34 & 17 & 8 \\
\hline FlexQ t1-t2 & $<0,001^{*}$ & 2,16 & 16,86 & 8 & 51 & 0 \\
\hline FlexQ t2-t3 & $<0,001^{*}$ & 2,66 & 16,90 & 3 & 56 & 0 \\
\hline FlexQ t3-t4 & $<0,001^{*}$ & 1,37 & 7,76 & 8 & 46 & 5 \\
\hline FlexQ to-t4 & $<0,001^{* *}$ & 6,40 & 48,81 & 0 & 59 & 0 \\
\hline FPlan t0-t1 & $0,077^{*}$ & $-0,16$ & $-1,60$ & 30 & 9 & 20 \\
\hline FPlan t1-t2 & $<0,001^{*}$ & 1,66 & 15,48 & 2 & 57 & 0 \\
\hline FPlan t2-t3 & $<0,001^{*}$ & 0,72 & 5,76 & 18 & 37 & 4 \\
\hline FPlan t3-t4 & $<0,001^{*}$ & 1,42 & 10,83 & 7 & 52 & 0 \\
\hline FPlan t0-t4 & $<0,001^{* *}$ & 3,64 & 32,59 & 0 & 59 & 0 \\
\hline FDors t0-t1 & $0,683^{*}$ & $-0,03$ & $-0,22$ & 30 & 9 & 20 \\
\hline FDors t1-t2 & $<0,001^{*}$ & 1,84 & 16,86 & 2 & 57 & 0 \\
\hline FDors t2-t3 & $<0,001^{*}$ & 1,40 & 10,72 & 18 & 37 & 4 \\
\hline FDorst3-t4 & $<0,001^{*}$ & 1,33 & 9,64 & 7 & 52 & 0 \\
\hline FDors t0-t4 & $<0,001^{* *}$ & 4,55 & 40,75 & 0 & 59 & 0 \\
\hline
\end{tabular}

ExtQ $=$ Extensores do Quadril; FlexQ $=$ Flexores do Quadril

FPlan $=$ Flexores plantares do Tornozelo; FDors $=$ Dorsiflexores do Tornozelo

${ }^{*}$ Teste não paramétricos de Classificações de Wilcoxon; **Teste de medidas repetidas de Friedman

VA (s) - Variação absoluta em Kg/força; VP $(\Delta \%)$ - Variação percentual;

$¥$ Distribuição das participantes do estudo pelo Teste de Sinal

Em negrito: avaliação inicial e final com a evolução do programa; Fonte: Dados da pesquisa, 2018. 


\subsection{Flexibilidade}

Os dados descritivos mostraram uma melhora progressiva na média da flexibilidade (em centímetros) avaliada pelo teste sentar e alcançar com o banco de Wells. Os dados descritivos, bem como a classificação do valor médio em cada tempo de avaliação, podem ser visualizados na Tabela 7 .

Tabela 7 - Descritivos da variável Flexibilidade corporal e classificação da média

\begin{tabular}{l|c|c|c|c|c}
\hline Variáveis & Mediana & Média (DP) & Mínimo - Máximo & CSTF $^{*}$ & Ribeiro** $^{\star *}$ \\
\hline Flexib t0 & 22,8 & $\mathbf{2 2 , 7 1 ( 1 0 , 8 )}$ & $7,0-41,5$ & Ruim / Fraco & Abaixo da média \\
Flexib t1 & 26,0 & $\mathbf{2 4 , 4 2 ( 1 0 , 7 )}$ & $8,5-43,0$ & Abaixo da média & Na Média \\
Flexib t2 & 27,5 & $\mathbf{2 6 , 0 4}(\mathbf{1 0 , 6 )}$ & $9,8-44,4$ & Abaixo da média & Na Média \\
Flexib t3 & 27,6 & $\mathbf{2 8 , 2 8}(\mathbf{1 0 , 4 )}$ & $12,3-45,7$ & Abaixo da média & Na Média \\
Flexib t4 & 30,5 & $\mathbf{3 1 , 4 3 ( 1 0 , 3 )}$ & $14,9-49,0$ & Na Média & Acima da média \\
\hline
\end{tabular}

Flexib - Flexibilidade medida (centímetros) com o banco de Wells.

*Classificação de acordo com Canadian Standardized Test of Fitness - CSTF (1986)

${ }^{* *}$ Classificação de acordo com Ribeiro (2010)

Fonte: Dados da pesquisa, 2018.

A frequência por nível de flexibilidade, calculada em porcentagem, pode ser observada na Tabela 8, segundo critérios de classificação do Canadian Standardized Test of Fitness (1986) e com critérios estabelecidos para a população da Grande São Paulo por Ribeiro (2010); Ribeiro et al. (2010).

$\mathrm{Na}$ Tabela 9 é possível observar a diferença significativa entre as variáveis categorizadas na avaliação inicial e final, nos 4 momentos parciais de avaliação do programa e a distribuição de melhora, piora ou estagnação das participantes em cada etapa. 
Tabela 8 - Porcentagem por nível de flexibilidade medida pelo teste sentar e alcançar - Classificações CSTF (1986) e de Ribeiro (2010) para mulheres entre 50 e 59 anos.

\begin{tabular}{l|cc|cc|cc|cc|cc}
\hline & \multicolumn{2}{|c|}{$\begin{array}{c}\text { Fraca / Ruim } \\
(\%)\end{array}$} & \multicolumn{2}{c|}{$\begin{array}{c}\text { Abaixo da média } \\
(\%)\end{array}$} & \multicolumn{2}{c|}{$\begin{array}{c}\text { Na média } \\
(\%)\end{array}$} & \multicolumn{2}{c|}{$\begin{array}{c}\text { Acima da média } \\
(\%)\end{array}$} & \multicolumn{2}{c}{$\begin{array}{c}\text { Excelente } \\
(\%)\end{array}$} \\
\hline & CSTF & Ribeiro & CSTF & Ribeiro & CSTF & Ribeiro & CSTF & Ribeiro & CSTF & Ribeiro \\
\hline Flex t0 & 57,6 & 45,8 & 8,5 & 10,2 & 11,9 & 6,8 & 13,6 & 22,0 & 8,5 & 15,3 \\
\hline Flex t1 & 49,2 & 37,3 & 11,9 & 10,2 & 15,3 & 11,9 & 13,6 & 23,7 & 10,2 & 16,9 \\
\hline Flex t2 & 47,5 & 32,2 & 10,2 & 13,6 & 11,9 & 10,2 & 16,9 & 20,3 & 13,6 & 23,7 \\
\hline Flex t3 & 42,4 & 27,1 & 10,2 & 11,9 & 5,1 & 11,9 & 25,4 & 16,9 & 16,9 & 32,2 \\
\hline Flex t4 & 32,2 & 18,6 & 13,6 & 11,9 & 8,5 & 11,9 & 18,6 & 13,6 & 27,1 & 44,1 \\
\hline
\end{tabular}

Flex - Flexibilidade medida pelo teste sentar e alcançar com o banco de Wells

Referências para classificação da flexibilidade de acordo com a CSTF = Fraca $(\leq 24 \mathrm{~cm})$; Abaixo da média $(25-29 \mathrm{~cm})$; Na média $(30-32 \mathrm{~cm})$; Acima da média $(33-38 \mathrm{~cm})$; Excelente $(\geq 39 \mathrm{~cm})$.

Referências para classificação segundo Ribeiro $(2010)=$ Fraca $(\leq 18 \mathrm{~cm})$; Abaixo da média $(19-23 \mathrm{~cm})$; Na média $(24-$ $28 \mathrm{~cm})$; Acima da média $(29-34 \mathrm{~cm})$; Excelente $(\geq 35 \mathrm{~cm})$.

Fonte: Dados da pesquisa, 2018.

\section{O conjunto de medidas repetidas observado pelo teste de Friedman apontou}

melhora na flexibilidade $(p<0,001)$. Os valores médios da variável flexibilidade, os índices de variação dos ganhos nesta variável e a distribuição das participantes entre cada etapa de avaliação do programa estão descritos na Tabela 10.

Tabela 9 - Comparação das variáveis categorizadas de flexibilidade entre as etapas do programa de acordo com as classificações CSTF (1986) e de Ribeiro (2010)

\begin{tabular}{l|c|c|c|c|c|c|c|c}
\hline \multirow{2}{*}{ Variáveis } & CSTF & \multicolumn{3}{|c|}{ Distribuição $¥$} & \multicolumn{3}{c|}{ Ribeiro } & \multicolumn{3}{c}{ Distribuição $¥$} \\
& $\mathrm{P}(\mathrm{Sig})^{*}$ & Igual & $\uparrow(+)$ & $\downarrow(-)$ & $\mathrm{P}(\text { Sig })^{*}$ & lgual & $\uparrow(+)$ & $\downarrow(-)$ \\
\hline Flex t0-t1 & 0,002 & 49 & 10 & 0 & $<0,001$ & 46 & 13 & 0 \\
Flex t1-t2 & 0,003 & 50 & 9 & 0 & 0,003 & 50 & 9 & 0 \\
Flex t2-t3 & 0,001 & 41 & 16 & 2 & $<0,001$ & 25 & 33 & 1 \\
Flex t3-t4 & $<0,001$ & 39 & 19 & 1 & $<0,001$ & 33 & 24 & 2 \\
Flex t0-t4 & $<\mathbf{0 , 0 0 1}$ & $\mathbf{2 7}$ & $\mathbf{3 2}$ & $\mathbf{0}$ & $<0,001$ & $\mathbf{1 9}$ & $\mathbf{3 8}$ & $\mathbf{2}$ \\
\hline
\end{tabular}

Flex - Flexibilidade medida pelo teste sentar e alcançar com o banco de Wells

*Variáveis categorizadas (Classificação CSTF e Classificação Ribeiro) - teste Wilcoxon

$¥$ Distribuição das participantes do estudo pelo Teste de sinais

Em negrito: avaliação inicial e final com a evolução do programa

Fonte: Dados da pesquisa, 2018. 
Tabela 10 - Comparação das variáveis de flexibilidade entre as etapas do programa

\begin{tabular}{l|c|c|c|c|c|c}
\hline \multirow{2}{*}{ Variáveis } & \multirow{2}{*}{$\mathrm{P}(\mathrm{Sig})$} & \multicolumn{2}{|c|}{ Variação } & \multicolumn{3}{|c}{ Distribuição $¥$} \\
\cline { 3 - 7 } & & $\mathrm{VA}$ & $\mathrm{VP}(\Delta \%)$ & Igual & $\uparrow(+)$ & $\downarrow(-)$ \\
\hline Flex t0-t1 & $<0,001^{*}$ & 1,71 & 10,32 & 0 & 59 & 0 \\
Flex t1-t2 & $<0,001^{*}$ & 1,61 & 8,81 & 1 & 58 & 0 \\
Flex t2-t3 & $<0,001^{*}$ & 2,24 & 11,78 & 0 & 58 & 1 \\
Flex t3-t4 & $<0,001^{*}$ & 3,14 & 13,17 & 0 & 58 & 1 \\
Flex t0-t4 & $<0,001^{* *}$ & $\mathbf{8 , 7 2}$ & $\mathbf{5 4 , 5 5}$ & $\mathbf{0}$ & $\mathbf{5 7}$ & $\mathbf{2}$ \\
\hline
\end{tabular}

Flex = Flexibilidade medida pelo teste sentar e alcançar com o banco de Wells

*Teste não paramétrico de Classificações de Wilcoxon; **Teste de medidas repetidas de Friedman

VA (s) - Variação absoluta (centímetros); VP $(\Delta \%)$ - Variação percentual;

$¥$ Distribuição das participantes do estudo pelo Teste de Sinal

Em negrito: avaliação inicial e final com a evolução do programa

Fonte: Dados da pesquisa, 2018.

\subsection{Equilíbrio Estático e Dinâmico}

A média de tempo dos testes de apoio unipodal, com os olhos abertos (TAUOA) e fechados (TAU-OF), aumentou progressivamente em cada etapa do programa e a média de tempo do TUG diminuiu progressivamente em cada etapa do treinamento, mostrando melhora tanto no equilíbrio estático como no dinâmico. Os dados descritivos podem ser visualizados na Tabela 11.

Em ambas as formas do teste TAU e do teste TUG, 100\% das mulheres terminaram o programa com equilíbrio melhor do que começaram, com aumento do tempo de execução da atividade teste nos testes TAU (AO e OF) e diminuição ao tempo de prova no teste TUG (t0-t4) (Gráfico 3).

Os testes de equilíbrio estático apresentaram aumento crescente na média do tempo de execução das atividades-teste nas diferentes etapas do programa. A variação de melhora no teste TAU (OF) teve um comportamento decrescente. 
Tabela 11 - Variáveis descritivas do equilíbrio estático e dinâmico

\begin{tabular}{l|c|c|c}
\hline \multicolumn{1}{c|}{ Variáveis } & Mediana & Média (DP) & Mínimo - Máximo \\
\hline TAU-OA t0 & 23,00 & $21,93(4,1)$ & $12-29$ \\
TAU-OA t1 & 23,00 & $23,24(2,9)$ & $17-30$ \\
TAU-OA t2 & 25,00 & $25,03(2,5)$ & $19-30$ \\
TAU-OA t3 & 27,00 & $26,27(2,2)$ & $21-30$ \\
TAU-OA t4 & 29,00 & $28,66(1,6)$ & $25-30$ \\
\hline TAU-OF t0 & 6,00 & $7,20(2,9)$ & $3-19$ \\
TAU-OF t1 & 11,00 & $12,19(4,1)$ & $5-20$ \\
TAU-OF t2 & 17,00 & $16,49(4,8)$ & $7-25$ \\
TAU-OF t3 & 20,00 & $19,69(5,1)$ & $8-30$ \\
TAU-OF t4 & 24,00 & $23,19(5,3)$ & $10-30$ \\
\hline TUG t0 & 12,00 & $12,15(2,2)$ & $8-19$ \\
TUG t1 & 11,00 & $11,22(1,7)$ & $8-17$ \\
TUG t2 & 10,00 & $10,02(1,4)$ & $7-15$ \\
TUG t3 & 9,00 & $9,02(1,1)$ & $7-12$ \\
TUG-t4 & 8,00 & $8,10(0,9)$ & $6-11$
\end{tabular}

TAU-OA - Teste e Apoio Unipodal com olhos abertos

TAU-OF - Teste de Apoio Unipodal com olhos fechados

TUG - "Timed Up and Go" / teste de equilibrio dinâmico

Fonte: Dados da pesquisa, 2018.

Gráfico 3 - a) Evolução do equilíbrio estático e b) Evolução do equilíbrio dinâmico


Fonte: Dados da pesquisa, 2018. 
O conjunto das medidas repetidas demonstrou diferença significativa $(p<0,001)$ revelada pelo teste de Friedman. Na comparação par a par pelo teste de Wilcoxon verificaram-se diferenças significativas $(p<0,001)$ em todas as etapas do programa (tabela 12).

Tabela 12 - Comparação dos escores das variáveis de equilibrio entre as etapas do programa

\begin{tabular}{l|c|c|c|c|c|c}
\hline \multirow{2}{*}{ Variáveis } & \multirow{2}{*}{$\mathrm{P}(\mathrm{Sig})$} & \multicolumn{2}{|c|}{ Variação } & \multicolumn{3}{c}{ Distribuição $¥$} \\
& & VA $(\mathrm{s})$ & $\mathrm{VP}(\Delta \%)$ & Igual & $\uparrow(+)$ & $\downarrow(-)$ \\
\hline TAU OA t0-t1 & $<0,001$ & 1,30 & 8,39 & 8 & 36 & 15 \\
TAU OA t1-t2 & $<0,001$ & 1,79 & 8,28 & 3 & 51 & 5 \\
TAU OA t2-t3 & $<0,001$ & 1,23 & 5,28 & 14 & 40 & 5 \\
TAU OA t3-t4 & $<0,001$ & 2,38 & 9,48 & 5 & 53 & 10 \\
TAU OA t0-t4 & $<0,001$ & $\mathbf{6 , 7 2}$ & $\mathbf{3 5 , 5 1}$ & $\mathbf{0}$ & $\mathbf{5 9}$ & $\mathbf{0}$ \\
\hline TAU-OF t0-t1 & $<0,001$ & 4,98 & 79,96 & 3 & 56 & 0 \\
TAU-OF t1-t2 & $<0,001$ & 4,30 & 39,18 & 1 & 57 & 1 \\
TAU-OF t2-t3 & $<0,001$ & 3,20 & 21,17 & 3 & 55 & 1 \\
TAU-OF t3-t4 & $<0,001$ & 3,49 & 19,41 & 3 & 56 & 0 \\
TAU-OF t0-t4 & $<0,001$ & 15,98 & $\mathbf{2 6 1 , 9 6}$ & $\mathbf{0}$ & $\mathbf{5 9}$ & $\mathbf{0}$ \\
\hline TUG t0-t1 & $<0,001$ & $-4,05$ & 6,87 & 22 & 2 & 35 \\
TUG t1-t2 & $<0,001$ & $-0,93$ & 10,42 & 8 & 1 & 50 \\
TUG t2-t3 & $<0,001$ & $-1,20$ & 9,39 & 16 & 1 & 42 \\
TUG t3-t4 & $<0,001$ & $-1,00$ & 9,78 & 19 & 0 & 40 \\
TUG t0-t4 & $<0,001$ & $\mathbf{- 0 , 9 1}$ & $\mathbf{3 1 , 7 8}$ & $\mathbf{0}$ & $\mathbf{0}$ & $\mathbf{5 9}$ \\
\hline TAU_OA - & &
\end{tabular}

TAU_OA - Teste e Apoio Unipodal com olhos abertos; TAU_OF - Teste de Apoio Unipodal com olhos fechados; TUG - Timed Up and Go / teste de equilibrio dinâmico. Em negrito: dados da avaliação inicial e final *Teste não paramétrico de Classificações de Wilcoxon; ${ }^{* *}$ Teste de medidas repetidas de Friedman VA (s) - Variação absoluta em segundos; $\operatorname{VP}(\Delta \%)$ - Variação percentual $¥$ Distribuição das participantes do estudo pelo Teste de Sinal;

Fonte: Dados da pesquisa, 2018.

No teste TAU-OA houve variação percentual entre as avaliações inicial e final de $35,51 \%$ e no TAU-OF a porcentagem de variação foi de $261,96 \%$, indicando um ganho rápido de equilíbrio, com uma grande melhora do tempo de execução de atividade-teste de equilíbrio, que passou de uma média de 7,20 s no t0 para 23,19 s no t4, apesar de encontrarmos diferenças relevantes entre as participantes (Tabela 12). 
Gráfico 4 - a) Diagrama de caixa da variação absoluta e b) Diagrama de caixa da variação percentual das variáveis de equilíbrio estático e dinâmico

VA - Variação Absoluta

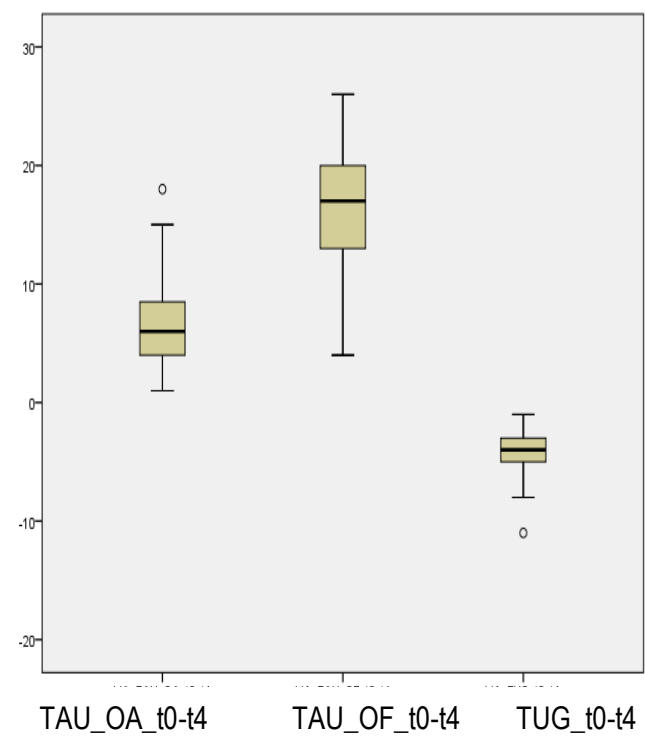

$(\Delta \%)$ - Variação Percentual

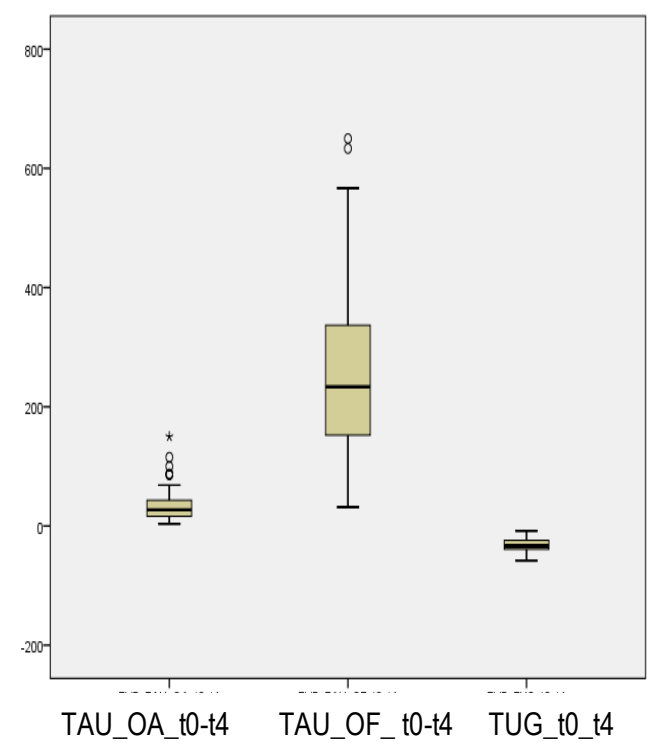

Fonte: Dados da pesquisa, 2018.

Nos dados do TUG encontramos variação entre t0-t4 de 31,78\%, indicando melhora do tempo de realização do teste, que passou de uma média de 12,15 $( \pm 2,2)$ s na avaliação inicial para $8,10(0,9)$ s na final. O diagrama de caixa do teste TUG evidencia o comportamento de evolução das participantes em relação ao equilíbrio dinâmico (Gráficos 4 e 5).

$\mathrm{Na}$ avaliação inicial (t0) a variável de equilíbrio estático com olhos fechados (TAO-OF) demonstrou correlação com a variável de equilíbrio dinâmico (TUG) com Rho $=0,344 ; p=0,008$. Entretanto, na avaliação final (t4), as variáveis de equilíbrio estático (TAU-OA e TAU-OF) apresentaram uma correlação positiva entre si (Rho= 0,313; $p=0,016)$ e não apresentaram correlação com a variável de equilíbrio dinâmico (TUG). 
Gráfico 5 - Evolução das médias e variação percentual dos testes TAU-OA; TAU-OF e TUG

Média
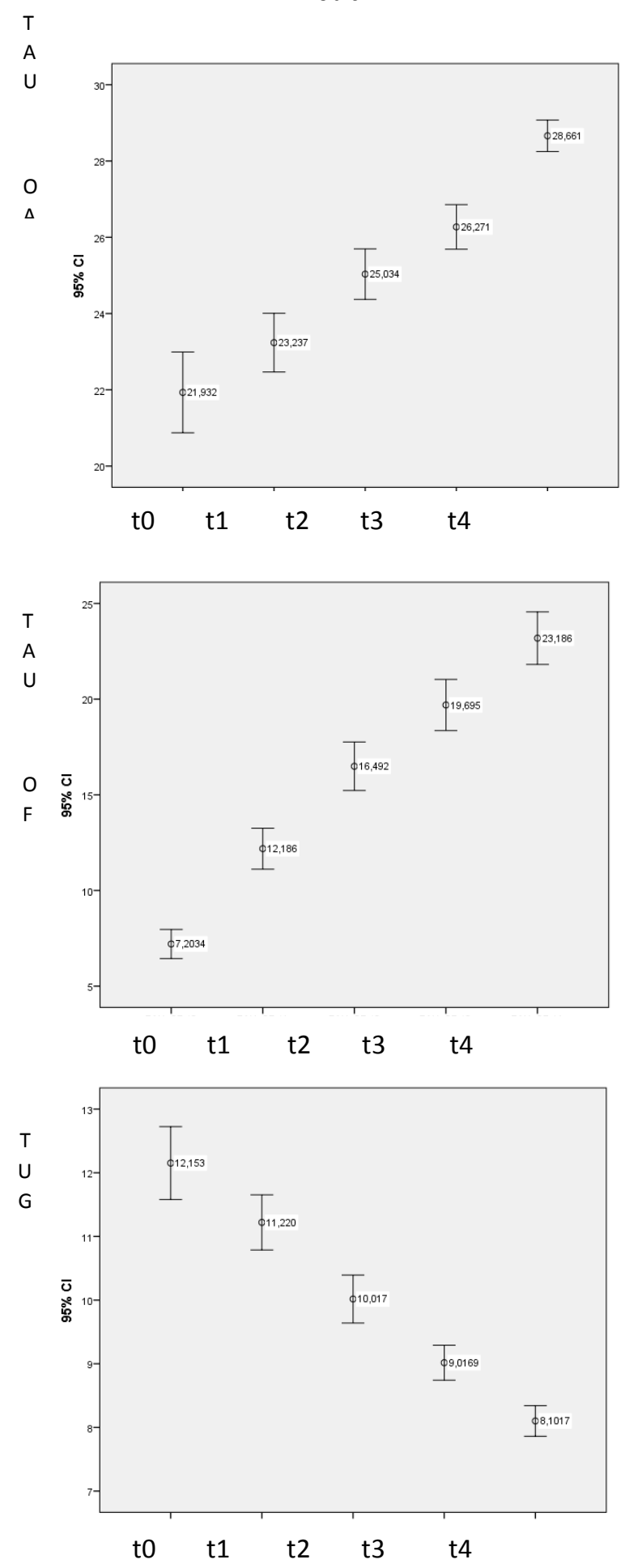

Variação Percentual $(\Delta \%)$
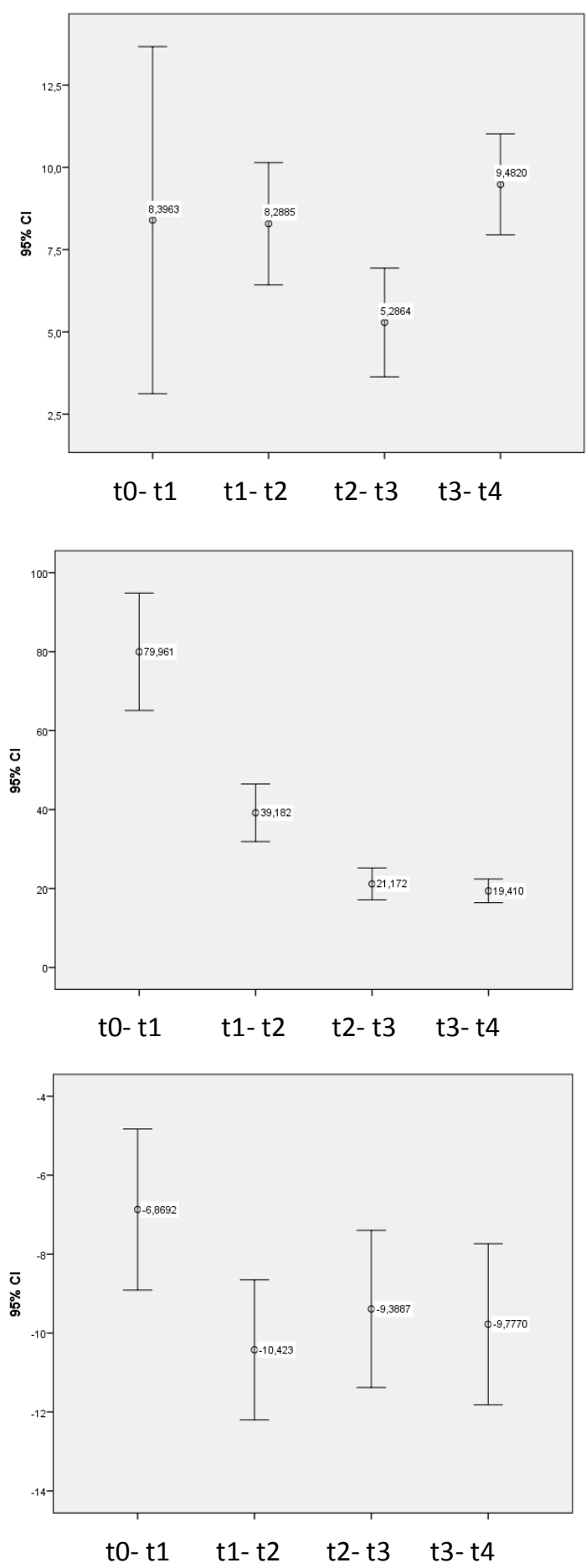

Barra de erros com IC 95\%.

Fonte: Dados da pesquisa, 2018. 
5. DISCUSSÃO 


\subsection{Aderência ao estudo e Percepção subjetiva sobre o Estado de Saúde, Mobilidade e Humor}

Das 136 mulheres que iniciaram o programa de caminhada em imersão, 59 o finalizaram um ano após seu início, apresentando $43 \%$ de adesão ou aderência. Considerando que adesão possa significar concordância ativa, consciente e realmente voluntária, admite-se que as 59 assíduas participantes tenham extraído relevante proveito do programa, o que se expressa na melhora dos estados de saúde, humor e mobilidade e nos relatos positivos associados, na melhora da força isométrica de músculos do quadril e tornozelo, da flexibilidade corporal e do equilíbrio estático e dinâmico.

Por outro lado, a não-adesão é bastante comum em programas de atividade física, e foi observada neste estudo. Para aumentar a adesão, Belza et al. ${ }^{102}$ reforçaram a necessidade de aprimoramento dos métodos com maior atenção ao papel de fatores intrínsecos, como auto-eficácia e sistemas de crença.

Acreditamos que, neste estudo, a prática em grupo, com objetivos de melhora de desempenho em exercícios físicos com níveis crescentes de dificuldade previamente programados, supervisão constante e especializada, associados ao conforto da prática de exercícios em imersão na água termoneutra influenciaram positivamente a aderência por parte das participantes, especialmente quando consideramos o longo período do estudo, de um ano.

Este estudo mostrou que, por meio de informações objetivas, foi possível descrever um quadro de percepções subjetivas referentes aos prováveis benefícios de programa anual de caminhada em imersão, na modalidade grupal. Foram 
conhecidas percepções dos participantes sobre a saúde, a mobilidade e o estado de humor em mulheres quinquagenárias saudáveis, a partir de indicações qualitativas quantificáveis por meio de uma escala numérica, na qual o zero indicava a pior situação possível e o 10 a melhor situação possível. Percepções adicionais foram expressas por meio de relatos escritos. Considera-se que, em conjunto, a análise dessas informações revelou a percepção subjetiva destas mulheres sobre os efeitos do programa.

São poucos os estudos que utilizaram caminhada em imersão como recurso terapêutico e dentre eles apenas dois estudos ${ }^{67,81}$ observaram os efeitos da caminhada na água nos aspectos psicossociais, que não podem ser comparados ao presente estudo. $O$ estudo de Katsura et al. ${ }^{67}$ avaliou os efeitos de um treinamento de exercícios aquáticos utilizando um novo equipamento de resistência à água no desempenho do exercício e na promoção dos estados de humor (Profile Of Mood States - POMS) de 20 idosos saudáveis $(69,1( \pm 4,5)$ anos). Os autores concluíram que o treinamento melhorou a capacidade de caminhada, bem como a pontuação de tensão e ansiedade do POMS.

Arrieiro ${ }^{81}$ utilizou o autorrelato de dor, função física e rigidez articular pela aplicação do Western Ontario and Mc Master Universities Osteoarthritis Index (WOMAC) e analisou a qualidade de vida, por meio do questionário Medical Outcomes Study 36-Item Short Form Health Survey (SF-36) tendo observado uma relação direta entre a melhora dos aspectos emocionais dos indivíduos com OA de joelho e a melhora do quadro clínico.

Estudos de Sabioni, Galante e Pelá ${ }^{0}$ e de Santana et al. ${ }^{51}$, realizados com mulheres entre 31 e 80 anos utilizando como intervenção a terapia aquática, analisaram o conteúdo das falas dos participantes a respeito da intervenção, todavia 
a terapia aquática não foi especificamente a caminhada. Embora com métodos de pesquisa diferentes do utilizado neste estudo, conteúdos semelhantes foram revelados.

Nossos resultados demonstraram um incremento positivo e significativo no estado de saúde entre as medidas t1-t2 ( $p=0,007)$, t3-t4 $(p<0,001)$ e t0-t4 $(p<0,001)$, com variação percentual do ganho entre a medida inicial e final de 16,13\% $(p<0,001)$. A maior parte dos relatos $(49,4 \%)$ foi relacionada com a melhora geral referida da saúde, como nos exemplos: "diminuição da dor, do inchaço, melhor funcionamento do intestino, melhora na qualidade do sono, mais disposição e tranquilidade".

Sabioni, Galante e Pelá50 relataram que a hidroterapia foi apresentada como algo importante na vida das mulheres estudadas, por proporcionar bem-estar, melhora na qualidade de vida e alívio da dor. Estes autores registraram $24,5 \%$ das falas relacionadas à sensação de bem-estar.

O estudo de Gomes e Zazá103 com 20 mulheres idosas $(69,7 \pm 7,1$ anos) demonstrou que, entre os motivos mais importantes para praticarem atividade física, estavam melhorar ou manter o estado de saúde, prevenir doenças e aprender novas atividades.

Estado de saúde é uma condição subjetiva influenciada por fatores culturais, socioeconômicos e biológicos e reflete a conjuntura de uma época e lugar ${ }^{52}$. Assim, embora a epidemiologia expresse a saúde por meio de números, admitem-se indicadores subjetivos do estado de saúde. Desta forma, buscou-se avaliar o estado de saúde, a mobilidade e o humor com medidas quantitativas da percepção subjetiva, bem como pelos relatos das mulheres que vivenciaram o estudo. 
A mobilidade é um constructo importante para a percepção do estado de saúde e pode ser influenciada diretamente pela atividade física; nessa perspectiva, a Sociedade Brasileira de Medicina do Esporte (SBME) identificou relação inversa entre o exercício praticado regularmente e as principais causas de morte na mulher pósmenopausa $^{104}$

Nossos resultados demonstraram que o programa de caminhada em imersão melhorou significativamente a mobilidade das mulheres participantes em todos os momentos de avaliação: t0-t1 $(p<0,001) ;$ t1-t2 $(p=0,004) ; t 2-t 3 \quad(p<0,001)$ e t3-t4 $(p=0,002)$ apresentando uma variação percentual do ganho entre a medida inicial (t0) e final ( $t 4)$ de $22,15 \%(p<0,001)$ na mobilidade percebida pelas participantes. Quanto às narrativas relacionadas à mobilidade e capacidade física, 19,3\% das mulheres expressaram sentir-se "mais ágeis, com maior confiança para andar e subir escadas".

Estes dados corroboram os estudos de Sabioni, Galante e Pelá ${ }^{50}$ que registraram falas relacionadas à mobilidade e à capacidade física; e de Santana et al. ${ }^{51}$, com relato específico de melhora de movimentos e sensação de relaxamento muscular. É comum a estes estudos e ao nosso o reconhecimento do efeito do programa de intervenção nos aspectos físicos de origem musculoesquelética.

Sobre os estados de humor, o estudo de validação do instrumento de avaliação do perfil de estados de humor - POMS (Profile of Mood States) apontou uma associação positiva entre prática de atividades físicas e desportivas e os estados emocionais e a saúde mental ${ }^{105}$. Entretanto, o benefício do exercício nos estados de humor parece depender da boa interação entre usuário e o responsável pela intervenção, características do exercício e do ambiente. Estudos ressaltam que os exercícios podem ser de diferentes tipos e intensidade, desde que estejam adequados ao praticante e sejam executados em ambiente agradável e de forma prazerosa ${ }^{106}$. 
Nossos resultados apontaram uma análise de variação percentual (t0-t4) do efeito da caminhada em imersão no estado de humor com melhora de 9,69\% $(p=0,002)$. A melhora foi estatisticamente significativa nas avaliações entre o t1-t2 $(p=0,012)$ e t0-t4 $(p=0,002)$, contudo deve-se considerar que a avaliação inicial das participantes já apresentava um alto escore. Apesar do "efeito teto", ou seja, dos índices iniciais relacionados ao estado de humor das participantes neste estudo já serem bons, houve uma variação percentual de melhora, ainda que mais baixa, quando comparada às variáveis estado de saúde e mobilidade ${ }^{106}$.

Sabioni, Galante e Pelá50 não apontaram nenhuma fala específica com a palavra humor, todavia o estado de humor pode ser percebido em diversas falas do referido estudo, em que também se evidencia o prazer em realizar atividades em imersão. E o estudo de Vieira, Rocha e Porcu ${ }^{107}$, realizado com mulheres com idade média de 43,33 $( \pm 3,56)$ anos e diagnóstico de depressão moderada, mostrou que um programa de hidroginástica de 12 semanas diminuiu a depressão e melhorou o humor das participantes do grupo experimental e não alterou o do grupo controle.

Da mesma forma, o estudo de Agra et al. ${ }^{8}$, com mulheres com idade variando entre 55 e 75 anos, submetidas a um programa de 12 meses de exercícios aquáticos, alongamentos e fortalecimento muscular, também apontou melhoras significativas na depressão, imagem corporal, autoestima e no estado de humor.

Queiroz Júnior et al. ${ }^{18}$ ressaltaram que benefícios psicossociais, como o alívio da depressão, o aumento da autoconfiança e a melhora da autoestima, podem ser percebidos pelas pessoas que praticam regularmente exercícios físicos. Belza et al. ${ }^{102}$, em um estudo com intervenção com exercícios aquáticos em adultos com osteoartrite, encontraram que a qualidade do bem-estar e o humor deprimido melhoraram para os aderentes, mas não para os não aderentes. 
No estudo de Gomes e Zazá103, o estado de humor não foi considerado especificamente, porém "aumentar o contato social" (85\%), e melhora da "autoestima" $(82,5 \%)$ foram destacados como aspectos relevantes da intervenção pelos participantes.

\subsection{Força dos flexores e extensores do quadril, dos flexores plantares e dorsiflexores}

Quanto à força de contração isométrica, observou-se a melhora significativa dos músculos flexores do quadril em todas as fases da intervenção $(p<0,001)$ com $48,81 \%$ de ganho de força. A força dos músculos extensores do quadril com $27,67 \%$ de ganho, os flexores plantares com $32,59 \%$ e dorsiflexores com $40,75 \%$ de incremento na força, e melhoram $(p<0,001)$ nas fases $\mathrm{t} 1$-t2; $\mathrm{t} 2-\mathrm{t} 3$ e $\mathrm{t} 3-\mathrm{t} 4$, bem como entre a avaliação inicial e final (t0-t4). Todas as mulheres melhoraram a força entre a avaliação inicial e final (t0-t4).

Wang, Olson e Protas ${ }^{108}$, em um estudo de teste-reteste para confiabilidade da força medida por dinamômetro de mão, compararam a força entre homens e mulheres e encontraram uma média, para as mulheres, de $6,9( \pm 2,7) \mathrm{kg}$ dos músculos responsáveis pela extensão do quadril; de $7,9( \pm 2,0)$ dos flexores do quadril e de 6,8 $( \pm 1,6)$ dos dorsiflexores do tornozelo. As mulheres deste estudo tinham uma média de idade de $75,8( \pm 8,6)$ anos, mais alta que do nosso estudo o que justifica os valores mais baixos que os nossos, além disto, o citado estudo não teve intervenção, o que impossibilita comparação entre os dados. 
Da mesma forma, Bohannon ${ }^{109}$ avaliou a confiabilidade da dinamometria manual para avaliar a força muscular em 10 ações musculares entre elas a dorsiflexão do tornozelo, extensão do joelho e flexão do quadril, mas tão pouco houve intervenção.

Apesar de a dinamometria manual apresentar algumas limitações, envolvendo a força e a técnica do avaliador, especialmente em grupos musculares de membros inferiores maiores ${ }^{110}$, a confiabilidade dos testes musculares do dinamômetro portátil tem sido bem estabelecida nas extremidades inferiores ${ }^{108,109,111}$.

O único estudo encontrado na literatura que verificou o efeito de uma terapia aquática na força muscular de membros inferiores utilizando um dinamômetro similar foi o estudo de Candeloro e Caromano ${ }^{58}$. Neste estudo as autoras apresentaram os dados de força muscular dos membros inferiores esquerdo (MIE) e direito (MID) separadamente. Relataram melhora significativa na força dos músculos quadríceps, isquiotibiais, bíceps braquial, peitoral maior e deltóide médio, entretanto não encontraram melhora estatisticamente significativa para os músculos glúteos, iliopsoas e reto do abdome, em um programa de hidroterapia de 32 sessões, aplicado durante 16 semanas consecutivas, em 16 mulheres saudáveis com idade entre 65 e 70 anos.

Com relação aos músculos extensores e flexores do quadril, nossos resultados demonstraram no final do (t1) equivalente a 24 sessões, que não houve melhora significativa na força dos extensores do quadril mas houve uma melhora significativa $(p=0,048)$ para os flexores do quadril. Com este tempo de intervenção os ganhos percentuais de força foram pequenos para ambos os grupos musculares: de 2,40\% para os músculos extensores e 1,50\% para os flexores. Contudo, com 24 sessões a mais a cada trimestre, observaram-se incrementos significativos $(p<0,001)$ na força 
dos extensores de $6,26 \%$ ao final do (t2); de 6,22\% (t3) e de 10,43\% a mais no final do (t4), totalizando um ganho percentual de $27,64 \%$.

Igualmente significativos $(p<0,001)$ foram os ganhos de força dos flexores do quadril com $16,86 \%$ (t2); $16,90 \%$ no (t3) e 7,76\% (t4) totalizando um ganho percentual de $48,81 \%$. Nossos dados indicam que, com 48 sessões, consegue-se fortalecer a musculatura do quadril de mulheres jovens idosas; não sabemos todavia por quanto tempo mais obteríamos incremento de força realizando a caminhada em imersão, no entanto estes dados reforçam a importância de um programa anual para melhorar de maneira mais efetiva a força da musculatura do quadril.

Nossos resultados também corroboram o estudo de Bento et al. ${ }^{66}$, que avaliou os mesmos músculos em 24 idosos com média de 65,6 \pm 4,2 anos, porém utilizou-se uma célula de carga para avaliar os torques de força. Os autores verificaram uma grande mudança no pico de torque do grupo com exercícios na água apresentando um incremento de $40 \%$ nos extensores do quadril e de $18 \%$ nos flexores do quadril. Também houve diferença significativa $(p<0,05)$ entre grupos para os músculos flexores plantares com um ganho registrado de $42 \%$ e de $12 \%$ para os flexores do joelho, mas não foi verificada diferença entre grupos na melhoria de força dos músculos extensores do joelho e dorsiflexores do tornozelo.

Segundo os autores, a influência do programa de treinamento com exercícios e caminhada em imersão sobre a capacidade de gerar torque rapidamente pode ser explicada pelo fato de que andar e exercitar-se na água requerem torques maiores para impulsionar o corpo para a frente. Em nosso protocolo as participantes andaram para trás e para os lados em várias etapas do programa. 
Outros estudos demonstraram os benefícios da terapia aquática na melhora da força em mulheres saudáveis ${ }^{24,67-70}$, com fibromialgia ${ }^{72,73}$ e com lombalgia ${ }^{74,75}$. Contudo, não utilizaram o mesmo tipo de dinamômetro portátil para avaliação de força muscular, não sendo possível comparar os resultados. Existe uma variedade de instrumentos e métodos para aferição da força muscular, o que dificulta as comparações de resultados.

O estudo de Katsura et al. ${ }^{67}$, que utilizou a caminhada em imersão como recurso terapêutico, analisou o ganho de força dos músculos flexores plantares e dorsiflexores após 24 semanas de intervenção, todavia, seus resultados também não podem ser diretamente comparados aos nossos. Os autores verificaram ganhos significativos apenas para os flexores plantares, entretanto, as forças musculares do tríceps sural e do tibial anterior foram medidas usando um acessório de força de tração acoplado a uma célula de força.

No presente estudo, com outro tipo de dinamômetro, também observou-se ganhos de força dos músculos flexores plantares e dorsiflexores. Após a intervenção com caminhada em imersão na avaliação do final do (t2) equivalente às 24 semanas utilizadas no estudo de Katsura et al. ${ }^{67}$ foi verificado um ganho de $15,48 \%$ de força nos flexores plantares e de $16,86 \%$ nos dorsiflexores, todavia, por ser um programa anual, obtivam-se ganhos incrementais até o final da $48^{\mathrm{a}}$ semana (t4).

Ao final do (t3) observou-se um incremento de força de $5,76 \%$ e no (t4) de $10,83 \%$ a mais de ganho de força nos flexores plantares, totalizando um incremento de força de $32,59 \%$ no final do programa. Para os dorsiflexores o ganho percentual foi de $10,72 \%$ no (t3) e $9,64 \%$ no (t4), totalizando um incremento de força de $40,75 \%$ para este grupo muscular no final do programa. Estes dados reforçam a importância de um 
programa anual com caminhada em imersão para um ganho de força maior em mulheres quinquagenárias saudáveis e sedentárias.

Rizzi et al. ${ }^{24}$ analisaram o ganho de força em 3 grupos musculares dos membros inferiores: isquiotibiais, quadríceps e gastrocnêmio, em um estudo com 24 sessões de hidrocinesioterapia com mulheres com idade média de 68,13 $\pm 5,04$ anos e verificaram melhora significativa dos isquiotibiais e do quadríceps, por meio do teste de força manual.

Os resultados do estudo de Pöyhönen et al. ${ }^{69}$ mostraram que, em mulheres saudáveis, 10 semanas de treinamento aquático resultaram em melhorias significativas nos torques estáticos e dinâmicos (dinamômetro isocinético) dos músculos extensores e flexores do joelho em conjunto com aumentos na atividade muscular e ganhos nas áreas de corte transversal do tecido magro do quadríceps e dos músculos isquiotibiais.

Tsourlou et al. ${ }^{70}$ verificaram melhoras significativas no pico de torque (dinamômetro isocinético) em 10,5\% na extensão do joelho e em 13,4\% na flexão do joelho. Também observaram melhora significativa na força de preensão manual (dinamômetro hidráulico) em 13\% no grupo que recebeu treinamento com exercícios na água e o grupo controle não obteve ganhos significativos.

\subsection{Flexibilidade corporal}

Neste estudo, a flexibilidade foi observada comparada com as informações de duas tabelas de classificação dos resultados. O valor médio da flexibilidade do grupo na avaliação inicial (t0) de 22,71 $( \pm 10,8)$ quando comparado à tabela da CSTF ${ }^{82}$ é 
considerado "ruim", entretanto quando comparado aos critérios estabelecidos para a população da Grande São Paulo, por Ribeiro ${ }^{31,32}$ é considerado "abaixo da média". $\mathrm{Na}$ avaliação final (t4) a média do grupo foi de $31,43( \pm 10,3)$ sendo classificada como "na média" pela CSTF e "acima da média" por Ribeiro.

Apesar das diferenças verificou-se a melhora significativa $(p<0,001)$ na flexibilidade, medida pela média e pelas variáveis categorizadas segundo as duas classificações, em todas as etapas de avaliação do programa; no entanto acreditamos que a classificação de Ribeiro esteja mais apropriada às mulheres deste estudo, por se tratar de uma população oriunda da mesma região geográfica (Grande São Paulo).

As médias de flexibilidade, nos diferentes tempos de pesquisa, do grupo de mulheres em estudo, se assemelham ao estudo de Katsura et al. ${ }^{67}$, realizado também com pessoas saudáveis, porém mais idosas. Os autores realizaram exercícios e caminhadas na água com e sem o uso de um equipamento de resistência acoplado às pernas e verificaram uma melhora da flexibilidade ao nível de $p<0,001$ no grupo com equipamento e ao nível de $p<0,005$ no grupo com caminhada na água sem o equipamento, mostrando que a resistência ao deslocamento em imersão afeta o resultado final da mobilidade.

Da mesma forma, o estudo de Bocalini et al. ${ }^{112}$, realizado com mulheres na faixa etária entre 62 a 75 anos comparou dois grupos experimentais (exercícios na água e caminhada no solo) com um grupo controle sem exercícios. Os autores relataram que o grupo de exercícios na água foi eficiente para aumentar a flexibilidade dos membros inferiores (MMII) e da cintura escapular e tronco, mesmo sem aplicar um programa específico para desenvolver flexibilidade articular, enquanto o grupo de caminhada no solo melhorou somente a flexibilidade dos MMII. O grupo de exercícios aquáticos apresentou uma média de $24( \pm 3) \mathrm{cm}$ na avaliação inicial do TSA e de 36 
( \pm 3$) \mathrm{cm}$ na avaliação após 12 semanas, obtendo um resultado melhor do que do nosso estudo.

Considerando ambos os critérios de classificação da flexibilidade adotados (CSTF e de Ribeiro) e os estudos supracitados ${ }^{67,112}$, verificou-se a pouca flexibilidade dos MMII no início do programa. Todavia, observou-se que o ganho de flexibilidade foi maior nos últimos 3 meses de programa com variação absoluta de $3,14 \mathrm{~cm}$, e o ganho entre os 12 meses de programa teve uma variação absoluta de $8,72 \mathrm{~cm}$ e variação percentual (t0-t4) de 54,55\%.

Estes dados foram superiores aos encontrados no estudo de Colado et al. ${ }^{12}$, com mulheres na mesma faixa etária deste estudo, mas com protocolo com a metade do tempo de treinamento (24 semanas) do nosso estudo. Desta forma entendemos que um tempo mais longo de trabalho influencia positivamente o ganho de flexibilidade. Os autores analisaram a flexibilidade de mulheres pós-menopausa, com média de idade entre 52 e 54 anos, comparando dois grupos de intervenção e um grupo controle sem exercício. Ambos os grupos de intervenção apresentaram diferença significativa $(p \leq 0,05)$ no pré-pós intervenção, com melhora de $27,94 \%$ para o grupo de exercícios aquáticos, melhora de $44,2 \%$ para o grupo que utilizou resistência elástica e sem alteração para o grupo controle.

Moreira et al. ${ }^{10,11}$ também demonstraram um efeito positivo de um programa de 6 meses de exercício aquático de alta intensidade na flexibilidade de mulheres com média de $58,8( \pm 6,4)$ anos apresentando aumento de $26,6 \%$ na flexibilidade do grupo experimental. No entanto, os autores também observaram uma melhora de $14,4 \%$ na flexibilidade do grupo controle, sem atividade física regular. Ambos os grupos receberam suplementação diária de $500 \mathrm{mg}$ de cálcio elementar e 1.000 UI de vitamina $\mathrm{D}$ (colecalciferol), combinados na mesma pílula. 
O estudo de Tsourlou et al. ${ }^{70}$, com mulheres saudáveis e idade variando entre 60 e 75 anos, indicou um percentual de melhora de $11,6 \%$ na flexibilidade do grupo que recebeu treinamento com exercícios no meio aquático enquanto o grupo controle, sem exercícios, teve uma piora de $-2,7 \%$.

Carral et al. ${ }^{113}$, em estudo com mulheres com mais de 65 anos, comparou dois grupos com intervenção, um com programa combinado de exercícios aquáticos associados de treinamento de força de alta intensidade e outro de exercícios aquáticos com treinamento calistênico aeróbico. Em ambos os grupos de intervenção foi observada melhora na flexibilidade ( $7 \%$ e $14 \%)$.

\subsection{Equilíbrio Estático}

No presente estudo, os dados resultantes da avaliação por meio do TAU mostrou melhora do equilíbrio nas medidas obtidas com olhos abertos e fechados. Como esperado e relatado na literatura, o equilíbrio tende a ser pior com olhos fechados do que quando a visão está presente ${ }^{37,91}$, visto que a visão auxilia de forma contundente o equilíbrio. Desta forma, medidas na avaliação inicial (t0) com olhos fechados, média de 7,20 ( $\pm 2,9)$, foram inferiores às obtidas com os olhos abertos $21,93( \pm 4,1)$ mantendo a diferença nos diferentes tempos de investigação.

Embora o tempo de execução da atividade teste durante o teste com olhos abertos tenha apresentado médias superiores aos do teste com olhos fechados, o percentual de melhora com olhos fechados foi superior ao resultado da prova com os olhos abertos em todas as fases de avaliação, evidenciando a relevância do programa 
no equilíbrio estático atuando em mecanismos que compensaram a ausência da visão, ou seja, percepção e controle postural.

O sistema visual fornece informações do ambiente e da direção e velocidade dos movimentos corporais em relação ao ambiente, além de diferenciar o movimento do próprio corpo, do movimento de um objeto no ambiente. Quando a informação visual não está disponível outras fontes de informação sensorial são utilizadas ${ }^{40}$. A diversidade de estímulos sensoriais e motores advindos do meio aquático justifica a melhora nos mecanismos adaptativos do controle de equilíbrio tanto com olhos abertos quanto fechados, além disto a nulidade de chance de queda também é um elemento importante neste tipo de treinamento, especialmente com os olhos fechados.

Os dados da avaliação to sugerem um perfil inicial da amostra com melhor equilíbrio estático com os olhos abertos do que o equilíbrio estático com olhos fechados, no entanto, a variação percentual entre as avaliações (t0-t4) mostrou melhora expressiva do equilíbrio estático com olhos fechados, com um índice de variação de $261,96 \%$. Desta forma, as medidas de equilíbrio estático do TAU-OF, inicialmente com tempo de realização baixo, no final do programa (t4) aproximaramse das medidas do TAU-OA. Não foram encontrados estudos que tenham medido o TAU-OF e utilizado exercícios aquáticos como intervenção terapêutica para melhorar o equilíbrio.

Apesar dos ganhos significativos $(p<0,005)$ em todas as etapas do programa pode-se considerar baixo o valor médio obtido na avaliação final (t4) de 28,66 $( \pm 1,6)$ s para o TAU-AO. Para Dominguez-Carrillo, Arellano-Aguilar e Leos-Zierold ${ }^{111} \mathrm{o}$ equilíbrio estático medido pelo TAU em idosos deve resultar em períodos de tempo superiores a 30s, valores inferiores devem ser interpretados como um indicador de quedas em idosos. 
Os resultados significativos $(p<0,001)$ indicativos de melhora de equilíbrio apresentados em todas as avaliações do teste TAU-AO com aumento de $31,51 \%$ corroboram os resultados de Moreira et al. ${ }^{10,11}$ obtidos em estudo com 108 mulheres no período pós-menopausa ( $58,8 \pm 6,4$ anos). Nestes estudos os autores mostraram aumento significativo $(14,1 \%)$ do equilíbrio corporal medido pelo teste TAU-OA entre os participantes do grupo de intervenção com exercícios aquáticos (AEG), sem diferença no grupo controle. O valor médio do TAU após a intervenção no AEG foi de 22,8 s e os grupos apresentaram desempenho estatisticamente diferentes, assim sendo, os autores indicaram que o programa de 24 semanas de exercícios aquáticos é uma maneira segura e eficiente de melhorar o equilíbrio estático e de reduzir quedas nesta população.

Em nosso estudo, o valor médio do TAU com 12 semanas (t1) foi semelhante com 23,2 s, no entanto com 12 meses de intervenção verificamos um valor médio de $28,6 s$.

\subsection{Equilíbrio Dinâmico}

Quanto ao equilíbrio dinâmico, avaliado pelo TUG, os resultados deste estudo corroboram os estudos de Moreira et al. ${ }^{10,11}$, Resende, Rassi e Viana ${ }^{115}$ e de Bergamin et al. ${ }^{46}$. A variação percentual de melhora no equilíbrio dinâmico, do início para o final do programa (t0-t4) foi de $31,78 \%$ com resultados significativos $(p<0,001)$ apresentados em todas as avaliações (t1, t2, t3 e t4) do teste TUG.

No presente estudo a variação no tempo das mulheres que melhoram o equilíbrio variou de 12 para 8 segundos. Segundo Bohannon ${ }^{84}$ este valor foi 
determinado para a execução do TUG por pessoas na faixa etária de 60 a 69 anos. Neste sentido mulheres na faixa etária de 50 a 55 anos deveriam executar a prova em menos de 8s., entretanto não foram encontrados valores indicativos para uma população abaixo de 60 anos de idade.

Nos estudos de Moreira- et al. ${ }^{10,11}$, citados anteriormente, foi encontrado efeito de interação nas comparações TUG $(p<0,001)$ e embora tenha apresentado melhora significativa nos dois grupos após o estudo (10,1\% no grupo controle e $23,7 \%$ no grupo de exercícios aquáticos) o grupo exercícios aquáticos foi significativamente melhor do que o grupo controle.

O estudo de Resende, Rassi e Viana ${ }^{115}$, com 25 idosas com idade média de $72,6( \pm 7,11)$ anos, embora não tenha sido realizado exclusivamente com caminhada em imersão, utilizou 8 exercícios de marcha, de um total de 14 exercícios contidos em seu programa, podendo, portanto, ser comparado a este estudo. Neste estudo foi observado que no teste TUG ocorreu diminuição significativa dos tempos de execução, avaliados após a $6^{\mathrm{a}}$ e $12^{\mathrm{a}}$ semanas de treinamento, indicando aumento do equilíbrio dinâmico. Da mesma forma, nossos resultados também demonstraram melhora significativa $(p<0,001)$ em todas as etapas de avaliação.

O estudo de Bergamin et al. ${ }^{46}$, com 59 idosos de ambos os sexos e idade média de $71,2( \pm 5,4)$ anos, sugere que exercícios melhoraram o equilíbrio dinâmico, medido pelo TUG, para os realizados, tanto em imersão, quanto no solo, porém a variação percentual entre a avaliação inicial e final de um programa de 6 meses de exercícios demonstrou melhores resultados para os exercícios aquáticos (19,3 \%) em relação aos exercícios executados em solo (12,6\%) e piora para o grupo controle que não realizou nenhum tipo de exercício controlado (-3,3 \%). Em nosso estudo a variação 
percentual entre a avaliação inicial e final, após 12 meses foi de 31,78 \% acima dos valores obtidos pelo grupo de exercícios aquáticos do estudo supra citado.

O estudo de Zhu et al. ${ }^{79}$, apesar de ter sido realizado com uma amostra formada por $86 \%$ de homens que sofreram AVC 6 meses antes do estudo, mostra que o teste TUG é capaz de medir as mudanças ocorridas no equilíbrio em curto período de intervenção (4 sessões) e também aponta a viabilidade de utilização do teste em quadros de doença. A média da avaliação inicial do grupo de exercícios aquáticos foi de 29,7s, mostrando que a amostra tinha um equilíbrio precário. Apesar das limitações, os autores mostraram melhora na capacidade de equilíbrio dinâmico apresentando uma média final de 21,2s.

Katsura et al. ${ }^{67}$ também observaram uma melhora significativa no equilíbrio dinâmico com intervenção realizada com caminhada na água por 8 semanas (90 minutos, 3 vezes na semana). Este estudo, realizado com 20 indivíduos (4 homens e 16 mulheres) idosos saudáveis, distribuídos em 2 grupos, um com idade média de $68,5( \pm 4,2)$ anos, que utilizou um equipamento de resistência acoplado nas pernas e outro grupo com idade média de $70( \pm 5,1)$ anos que executou o mesmo protocolo de caminhada na água sem o equipamento. Não foi verificada diferença significativa entre os grupos.

Contrapondo-se a estes estudos e aos nossos resultados, o estudo de Hale, Waters e Herbison ${ }^{63}$ não apresentou diferença significativa nos resultados do TUG pós intervenção com um programa de 12 semanas, de exercícios no meio aquático, realizado duas vezes por semana.

Outros estudos ${ }^{64,116-118}$, com metodologia de intervenção semelhantes, apontaram benefícios dos exercícios aquáticos na melhora do equilíbrio, porém utilizando instrumentos de medida diferentes, como por exemplo, plataforma de força 
com teste de organização sensorial, Escala de Equilíbrio de Berg e Performance Oriented Mobility Assessment - POMA ${ }^{64}$, teste de alcance funcional ${ }^{116}$, avaliação da autonomia funcional - GDLAM ${ }^{117}$, Índice de Marcha Dinâmica ${ }^{118}$ não sendo possível comparar seus resultados com os nossos.

Alguns estudos compararam exercícios no meio aquático aos exercícios realizados no solo, com ou sem diferença significativa entre eles ${ }^{10,11,46,116}$. Programas no solo produzem melhora no equilíbrio e devem ser incentivados, contudo, o mesmo pode-se dizer sobre programas em meio aquático. A escolha do meio vai depender principalmente das limitações de recursos, no entanto vale ressaltar que, além dos benefícios aqui registrados para o equilíbrio estático e dinâmico, exercícios aquáticos produzem outros efeitos físicos e psicossociais vantajosos com ausência de perigo de quedas durante o treinamento.

Os efeitos benéficos do programa sobre o equilíbrio estático e dinâmico de mulheres de meia idade saudáveis indicaram que esta forma de atividade permite grande variedade de exercícios terapêuticos, que impõem baixo impacto articular e eliminam a possibilidade de quedas durante o treinamento, além de ser uma atividade lúdica e estimulante, constituindo uma opção interessante a ser considerada para esta população.

\subsection{Limitações da pesquisa}

Esta pesquisa apresenta as limitações de um estudo quase-experimental, com amostra de conveniência e sem grupo controle, porém, foram tomados os cuidados 
necessários para a realização da avaliação e aplicação do programa proposto para assegurar a validade interna do mesmo.

Ressaltamos novamente que o programa teve uma duração considerada longa (12 meses) com cinco momentos de coleta de dados o que dificulta a aderência de pessoas sem nenhum tratamento. Nas raras situações em que o grupo controle apresenta uma pequena melhora, na maioria das vezes é atribuída ao aprendizado da realização do teste ou ao estímulo desencadeado pelo teste para busca de melhora no desempenho especificamente avaliado. No presente estudo, manter um grupo controle sem atividade física durante 12 meses não seria aceitável, além de eticamente incorreto. 
6. CONCLUSÃO 


\subsection{Considerações finais:}

Os resultados relacionados com a percepção subjetiva das usuárias do programa sobre o estado de saúde, a mobilidade e o estado de humor mostraram variação percentual $(\Delta \%)$ com melhora de $16,13 \%$ na percepção do estado de saúde $(p<0,001)$; de $22,15 \%$ na mobilidade $(p<0,001)$ e de $9,69 \%$ no humor $(p<0,005)$. As mulheres participantes do estudo relataram ter melhorado a disposição e a qualidade do sono, sentir o corpo menos dolorido, com menos inchaço e com mais confiança e maior resistência para andar. Ficou clara a viabilidade das atividades em grupo, favorecendo a diminuição da relação custo versus benefícios, além de permitir o foco lúdico das atividades e a socialização das participantes.

A força dos músculos flexores e extensores do quadril, dos flexores plantares e dorsiflexores do tornozelo foi analisada pela contração isométrica com um dinamômetro portátil. A força dos flexores do quadril melhorou em todas as fases $(p<0,001)$ com $48,81 \%$ de ganho de força. A força dos extensores do quadril com $27,67 \%$ de ganho, dos flexores plantares com $32,59 \%$ e dos dorsiflexores com $40,75 \%$ de incremento na força, melhorou significativamente $(p<0,001)$ nas fases t1-t2; t2-t3 e t3-t4, bem como entre a avaliação inicial e final (t0-t4).

Quanto aos efeitos da caminhada em imersão na flexibilidade de mulheres de meia idade, foram observadas melhoras significativas $(p<0,001)$ da flexibilidade, em todas as cinco etapas do programa. Por meio do teste "sentar e alcançar", foi possível encontrar variação percentual com melhora de 54,55\% na flexibilidade. Quanto aos efeitos da caminhada em imersão no equilíbrio, foram constatadas melhoras significativas $(p<0,001)$ nas cinco etapas do programa, tanto no equilíbrio estático como no dinâmico. O estudo mostrou a melhora no equilíbrio estático pelo aumento 
na média do tempo de execução com variação percentual de 35,51\% no teste de apoio unipodal com olhos abertos (TAU-AO) e de $261,96 \%$ no teste de apoio unipodal com olhos fechados (TAU-OF). O equilíbrio dinâmico, analisado pelo teste timed up and go (TUG), apresentou melhora na diminuição da média do tempo de execução de $31,78 \%$.

Os efeitos benéficos do programa sobre o equilíbrio estático e dinâmico de mulheres quinquagenárias saudáveis, porém sedentárias, indicaram que, esta forma de atividade permite o uso de grande variedade de exercícios de forma recreacional e estimulante, além disto, impõe baixo impacto articular e elimina a possibilidade de quedas durante o treinamento, sendo uma opção com custo versus benefícios interessante de ser considerada para esta população, visto seus efeitos no equilíbrio, cuja perda é uma das consequências mais grave da senescência a serem prevenidas.

De forma pré-estabelecida, o programa foi elaborado para ser de fácil aplicação e para atender grupos de participantes, de forma a amenizar o custo em relação aos benefícios. Com isto, ressaltamos a relevância de políticas públicas que favoreçam e incentivem a prática dos exercícios físicos prazerosos visando um envelhecimento natural e com autonomia funcional.

\subsection{Publicação}

Em relação à publicação desta pesquisa, os resultados foram divididos em 3 partes com conteúdos específicos e afins, a saber:

- Percepção de saúde, mobilidade e humor de mulheres participantes de caminhada em imersão (Submetido - Anexo D) 
— Impacto de um programa de caminhada em imersão na flexibilidade e força de mulheres quinquagenárias saudáveis

- Efeitos de caminhadas em imersão sobre o equilíbrio de mulheres quinquagenárias saudáveis

Esta divisão permite uma discussão mais ampla e pertinente, que seria inviável em um único artigo. 
7. REFERÊNCIAS 


\section{REFERÊNCIAS}

1. IBGE. Instituto Brasileiro de Geografia e Estatística. Expectativa de vida ao nascer em 2016. [Citado em 27 mai 2018]. Disponível em: https://agenciadenoticias.ibge.gov.br

2. Vagetti GC, Boneti MN, Barbosa Filho VC, De Oliveira V, Ferreira Cancian C, Mazzardo O, De Campos W. Domínios da qualidade de vida associados à percepção de saúde: um estudo com idosas de um programa de atividade física em bairros de baixa renda de Curitiba, Paraná, Brasil. Ciência \& Saúde Coletiva. 2013;18:3483-3493. Disponível em: https://www.scielosp.org/article/csc/2013.v18n12/3483-3493/

3. De Vitta A, Neri AL, Padovani CR. Saúde percebida em homens e mulheres sedentários e ativos, adultos jovens e idosos. Salusvita. 2006; 25(1):23-34. Disponível em:

https://secure.usc.br/static/biblioteca/salusvita/salusvita_v25_n1_2006

4. Salgado CDS. Mulher idosa: a feminização da velhice. Estudos interdisciplinares sobre o envelhecimento. 2002 [Citado 05 mai 2017];4. ISSN: e 2316-2171 (eletrônico). Disponível em: http://www.seer.ufrgs.br/index.php/RevEnvelhecer/article/view/4716/264

5. Freitas GL, Vasconcelos CTM, Moura ERF, Pinheiro AKB. Discutindo a política de atenção à saúde da mulher no contexto da promoção da saúde. Rev. Eletr. Enf. [Internet]. 2009 [Citado 27 mai 2018];11(2):424-8. Disponível em: http://www.fen.ufg.br/revista/v11/n2/v11n2a26.htm 
6. Brasil. Ministério da Saúde. Secretaria de Atenção à Saúde. Departamento de Atenção Básica. Envelhecimento e saúde da pessoa idosa. Brasília; 2006. (Cadernos de Atenção Básica, n. 19).

7. Ciosak SI, Braz EFBAC, Nakano NGR, Rodrigues J, Alencar RA, Rocha ACAL. Senescência e senilidade: novo paradigma na atenção básica de saúde. Revista da Escola de Enfermagem da USP. 2011;45(spe2): 17631768. Disponível em: http://www.redalyc.org/html/3610/361033314022/

8. Agra KOA, Borges AEA, Araújo KMB, Carvalho SMCR, Barreto JM, Oliveira EA. A Terapia Aquática como Coadjuvante na Variação do Humor em Mulheres Pós-Menopáusicas. Revista Brasileira de Ciências da Saúde. 2014;17(4): 327-334. DOI:10.4034/RBCS.2013.17.04.02.

9. Tairova OS, DeLorenzi DRS. Influência do exercício físico na qualidade de vida de mulheres na pós-menopausa: um estudo caso-controle. Rev bras geriatra gerontol. 2011;14(1):135-145. Disponível em: http://www.scielo.br/pdf/rbgg/v14n1/a14v14n1

10. Moreira LDF, Oliveira ML de, Lirani-Galvão AP, et al. Physical exercise and osteoporosis: effects of different types of exercises on bone and physical function of postmenopausal women. Arq Bras Endocrinol Metabol 2014; 58: 514-522. On-line version ISSN 1677-9487 http://dx.doi.org/10.1590/0004-2730000003374

11. Moreira LDF, Fronza FCAO, Dos Santos RN, et al. The benefits of a highintensity aquatic exercise program (HydrOS) for bone metabolism and bone mass of postmenopausal women. J Bone Miner Metab 2014; 32 : 411-419. https://doi.org/10.1007/s00774-013-0509-y 
12. Colado JC, Triplett NT, Tella V, Saucedo P, Abellán J. Effects of aquatic resistance training on health and fitness in postmenopausal women. Eur $\mathrm{J}$ Appl Physiol (2009) 106:113-122. DOI 10.1007/s00421-009-0996-7

13. Colado JC, Garcia-Masso X, Rogers ME, Tella V, Benavent J, Dantas EH. Effects of Aquatic and Dry Land Resistance Training Devices on Body Composition and Physical Capacity in Postmenopausal Women. Journal of Human Kinetics. 2012; 32:185-195 Section - Aquatic Activities. DOI:10.2478/v10078-012-0035-3

14. Motta ABD. Mulheres Entre o Cuidado de Velhos/as e a Reprodução de Jovens em Famílias no Brasil. Ex aequo. 2012 [Citado 22 fev 2018]; 26:87-101. Disponível em: http://www.scielo.mec.pt/scielo.php?script=sci_arttext\&pid=S0874$55602012000200008 \& \operatorname{lng}=$ pt\&nrm=iso

15. Mazza SR. Para além das osteoporose: experiências e modos de levar a vida de mulheres entre 50 e 59 anos. [Tese]. São Paulo (Brasil): Programa de Pós-Graduação em Saúde Pública. Universidade de São Paulo; 2012;188 p. Disponível em:

http://www.teses.usp.br/teses/disponiveis/6/6136/ tde-23032012163128/en.php

16. Assis LTM, Fernandes BF. Saúde da mulher: a enfermagem nos programas e políticas públicas nacionais no período de 1984 a 2009. Revista Mineira de Enfermagem. 2011;15(3):356-364. DOI: http://www.dx.doi.org/S1415-27622011000300007

17. Wong LLR, Carvalho JA. O rápido processo de envelhecimento populacional do Brasil: sérios desafios para as políticas públicas. Rev 
Bras Estud Popul. 2006 [Citado 22 fev 2018];23(1): 5-26. Disponível em: http://www.scielo.br/pdf/rbepop/v23n1/v23n1a02

18. Queiroz Júnior CA, Castellano SM, De Paulo TRS, Moreira WW, Simões R. Motivos de adesão das mulheres idosas participantes dos programas públicos de exercícios físicos em Uberaba-MG. Colec Pesq Educ Fis. 2012;11(4):135-42. Disponível em: http://www.fontouraeditora.com.br/periodico/upload/967_1503345505.pdf

19. De Freitas ERFS, Guedes Rogério FRP, Yamacita CM, Vareschi ML, Da Silva RA. Prática habitual de atividade física afeta o equilíbrio de idosas? Fisioterapia em Movimento. 2013;26(4):813-21. Disponível em: http://www.scielo.br/pdf/fm/v26n4/a10v26n4

20. Kahn EB, Ramsey LT, Brownson RC, Heath GW, Howze EH, Powell KE, Stone EJ, Rajab W, Corso P and the Task Force on Community Preventive Services. The Effectiveness of Interventions to Increase Physical Activity: A Systematic Review. American Journal of Preventive Medicine. 2002;22(4S). DOI: https://doi.org/10.1016/S07493797(02)00434-8.

21. Haskell WL, Lee IM, Pate RR, Powell KE, Blair SN, Franklin BA, et al. Physical activity and public health: updated recommendation for adults from the American College of Sports Medicine and the American Heart Association. Circulation. 2007;116(9):1081-93. https://doi.org/10.1161/CIRCULATIONAHA.107.185649.

22. Ferreira MS, Najar AL. Programas e campanhas de promoção da atividade física. Ciênc. saúde coletiva [online]. 2005 [Citado 27 mai 2018]; 
10(suppl): 207-219. ISSN 1413-8123, Disponível em:

https://www.scielosp.org/pdf/csc/2005.v10suppl0/207-219/pt

23. Fechine BRA, Trompieri N. O processo de envelhecimento: as principais alterações que acontecem com o idoso com o passar dos anos. InterSciencePlace. 2015;1(20). ISSN: 1679-9844. DOI: 10.6020. Disponível em: http://ftp.interscienceplace.org/isp/index.php/isp/article/view/196

24. Rizzi PRS, Leal RM, Vendrusculo AP. Efeito da hidrocinesioterapia na força muscular e na flexibilidade em idosas sedentárias. Fisioterapia em Movimento. 2010;23(4):535-543. ISSN 1980-5918. Disponível em: http://dx.doi.org/10.1590/S0103-51502010000400004.

25. Hughes VA, Frontera WR, Roubenoff R, Evans WJ, Singh MAF. Longitudinal changes in body composition in older men and women: role of body weight change and physical activity. The American journal of clinical nutrition. 2002;76(2):473-481.

26. Da Silva Pícoli T, de Figueiredo LL, Patrizzi LJ. Sarcopenia e envelhecimento. Fisioterapia em Movimento. 2011;24(3):455-462. http://dx.doi.org/10.1590/S0103-51502011000300010

27. Silva TA, Frisoli Júnior A, Pinheiro MDM, Szejnfeld VL. Sarcopenia associada ao envelhecimento: aspectos etiológicos e opções terapêuticas. Rev Bras Reumatol. 2006;46(6):391-397. http://dx.doi.org/10.1590/S0482-50042006000600006

28. Liu SP, Li J, Sheng Z, Wu X, Liao E. Relationship between body composition and age, menopause and its effects on bone mineral density at segmental regions in Central Southern Chinese postmenopausal elderly 
women with and without osteoporosis. Archives of gerontology and geriatrics. 2011;53(2):e-192-e197.

https://doi.org/10.1016/j.archger.2010.09.002

29. Douchi T, Yamamoto S, Yoshimitsu N, Andoh T, Matsuo T, Nagata Y. Relative contribution of aging and menopause to changes in lean and fat mass in segmental regions. Maturitas. 2002;42(4):301-306.

https://doi.org/10.1016/S0378-5122(02)00161-5

30. Montenegro CM, Carvalho GA. Avaliação da flexibilidade em escolares do ensino fundamental na cidade de Manaus-AM. Revista Brasileira de Ciência e Movimento. 2013;22(2):5-12. http://dx. doi. org/10.18511/01031716/rbcm. Português, Inglês.

31. Ribeiro CCA. Nível de flexibilidade obtido pelo teste de sentar e alcançar a partir de estudo realizado na Grande São Paulo. [Dissertação]. São Paulo: Universidade de São Paulo, Programa de Pós-Graduação em Cardiologia da Escola Paulista de Medicina; 2010.

32. Ribeiro CCA, Abad CCC, Barros RV, Leite de Barros Neto, T. Nível de flexibilidade obtida pelo teste de sentar e alcançar a partir de estudo realizado na Grande São Paulo. Revista Brasileira de Cineantropometria e Desempenho Humano 2010;12(6):415-421 DOI: 10.5007/19800037.2010v12n6p415

33. Fidelis LT, Patrizzi LJ, de Walsh IAP. Influência da prática de exercícios físicos sobre a flexibilidade, força muscular manual e mobilidade funcional em idosos. Revista Brasileira de Geriatria e Gerontologia. 2013;16(1):109116. Disponível em: http://www.scielo.br/pdf/rbgg/v16n1/a11v16n1. Português, Inglês. 
34. Nelson ME, Rejeski WJ, Blair SN, Duncan PW, Judge JO, King AC, Macera CA, Castaneda-Sceppa, C. Physical activity and public health in older adults: recommendation from the American College of Sports Medicine and the American Heart Association. Circulation. 2007;116(9):1094-1105. DOI:10.1161/CIRCULATIONAHA.107.185650.

35. Kaneda $\mathrm{K}$, Sato $\mathrm{D}$, Wakabayashi $\mathrm{H}$, et al. A comparison of the effects of different water exercise programs on balance ability in elderly people. $J$ Aging Phys Act 2008 Oct;16:381-392. https://doi.org/10.1123/japa.16.4.381

36. Arnold CM, Busch AJ, Schachter CL, Harrison EL, Olszynski WP. A randomized clinical trial of aquatic versus land exercise improve balance, function, and quality of life in older women with osteoporosis. Physiother Canada 2008; 60: 296-306. https://doi.org/10.3138/physio.60.4.296

37. Bankoff ADP, Campelo TS, Ciol P, Zamai CA. Postura e equilíbrio corporal : um estudo das relações existentes. Mov Percepção 2006; 6: 55-70. Disponível em: http://ferramentas.unipinhal.edu.br/movimentoepercepcao/include/getdoc. php id $=332 \&$ article $=103 \&$ mode $=$ pdf .

38. Kleiner AFR, De Camargo Schlittler DX, Del Rosário Sánchez-Arias M. O papel dos sistemas visual, vestibular, somatosensorial e auditivo para o controle postural. Revista neurociencias, 2011;19(2):349-357. Disponível em: http://hdl.handle.net/11449/72584. Português, Inglês.

39. Soares AV. A Contribuição visual para o controle Postural. Rev Neurociência 2010; 18: 370-379. Disponível em: 
http://www.revistaneurociencias.com.br/edicoes/2010/RN1803/415\%20rev isao.pdf

40. Júnior PF, Barela JA. Alterações no funcionamento do sistema de controle postural de idosos: Uso da informação visual TT. Rev Port Ciências do Desporto 2006; 6: 94-105. versão impressa ISSN 1645-0523 http://www.scielo.mec.pt/scielo.php?script=sci_arttext\&pid=S164505232006000100011

41. Graef FI, Kruel LFM. Freqüência cardíaca e percepção subjetiva do esforço no meio aquático: diferenças em relação ao meio terrestre e aplicações na prescrição do exercício-uma revisão. Revista brasileira de medicina do esporte. 2006 Jul-Ago;12(4):221-228. https://doi.org/10.1590/S1517-86922006000400011. Português, Inglês.

42. Biasoli MC, Machado CMC. Hidroterapia: aplicabilidades clínicas. Rev Bras Med. 2006 Mai;63(5):225-37. LLXP: S0034-72642006001600008. Disponível em: http://www.moreirajr.com.br/revistas.asp?fase=r003\&id_materia=3288

43. Geytenbeek J. Evidence for effective hydrotherapy. Physiotherapy. $2002 ; 88(9): 514-529$. https://doi.org/10.1016/S0031-9406(05)60134-4.

44. Delevatti, RS. Efeitos do treinamento aquático em posição vertical: diferentes aplicações e suas respostas fisiológicas. RBNE-Revista Brasileira de Nutrição Esportiva 2013 [Citado 28 mai 2018]; 5(30). ISSN 1981-9927 versão eletrônica. Disponível em: https://www.researchgate.net/publication/309548922 
45. Pinto LLT, Morbeck DI, Moreira RM. Análise Reflexiva Sobre os Benefícios da Hidroginástica para a Saúde de Pessoas Idosas. Saúde e Pesquisa, 2014;7(2). Disponível em:

http://periodicos.unicesumar.edu.br/index.php/saudpesq/article/view/3084/ 2385

46. Bergamin M, Ermolao A, Tolomio S, Berton L, Sergi G ZM, Zaccaria M. Water- versus land-based exercise in elderly subjects: Effects on physical performance and body composition. Clinical Interventions in Aging 2013; 8:1109-1017. http://doi.org/10.2147/CIA.S44198

47. Ferreira RJ, Kleinubing MC. Natação: relações do corpo com a água... Em busca do prazer. Arq. ciências saúde UNIPAR. 2003;7(2):159-165. https://doi.org/10.25110/arqsaude.v7i2.2003.1073

48. Ide MR, Belini MAV, Caromano FA. Effects of an aquatic versus nonaquatic respiratory exercise program on the respiratory muscle strength in healthy aged persons. Clinics. 2005;60(2):151-158. http://dx.doi.org/10.1590/S1807-59322005000200012

49. Eversden L, Maggs F, Nightingale $P$, Jobanputra P. A pragmatic randomised controlled trial of hydrotherapy and land exercises on overall well being and quality of life in rheumatoid arthritis. BMC Musculoskeletal Disorders. 2007;8(1):23. doi:10.1186/1471-2474-8-23

50. Sabioni RR, Galante AC, Pelá NTR. The meaning of hydrotherapy: a study with adult women. In: Proceedings of the 8. Brazilian Nursing Communication Symposium [Proceedings online]; 2002 [Citado $22 \mathrm{fev}$ 2018]; São Paulo, SP, Brazil. Disponível em: 
http://www.proceedings.scielo.br/scielo.php?script=sci_arttext\&pid=MSC0 $000000052002000100003 \&$ Ing=en\&nrm=van.

51. Santana CA, Montenegro SMRS, Costa CSP, Lopes Júnior JEG. Análise da hidroterapia em mulheres com dor lombar e relação com as atividades da vida diária. Fisioterapia Brasil. 2014; 15(4):263-268. ISSN: 2526-9747 Disponível em: https://slidex.tips/download/artigo-original-fisioterapiabrasil-volume-15-numero-4-julho-agosto-de-2014-5.

52. Scliar M. História do conceito de saúde. Physis. 2007;17(1):29-41. Disponível em: https://www.scielosp.org/article/physis/2007.v17n1/29$41 / \mathrm{pt} /$

53. Batistella C. Saúde, Doença e Cuidado: complexidade teórica e necessidade histórica In: Fonseca, AF, Corbo AMD’A (orgs). O território e o processo saúde-doença. Rio de Janeiro: EPSJV/Fiocruz. 2007. Série: Educação Profissional e Docência em Saúde: a formação e o trabalho do agente comunitário de saúde. Disponível em:

http://www.epsjv.fiocruz.br/publicacao/livro/o-territorio-e-o-processo-saudedoenca.

54. Canguilhem G. O Normal e o Patológico. 2009. 6.ed. revisada, $2^{\mathrm{a}}$ reimp. Rio de Janeiro: Forense Universitária. 154p.

55. Fonseca AF. O território e o processo saúde-doença. In: Fonseca, AF, Corbo AMD`A (orgs). O território e o processo saúde-doença. Rio de Janeiro: EPSJV/Fiocruz. 2007. Série: Educação Profissional e Docência em Saúde: a formação e o trabalho do agente comunitário de saúde. Disponível em: http://www.epsjv.fiocruz.br/publicacao/livro/o-territorio-e-oprocesso-saude-doenca. 
56. Segre M, Ferraz FC. O conceito de saúde. Rev. Saúde Pública. 1997.;31 538 (5): 538-42. https://www.scielosp.org/article/rsp/1997.v31n5/538-542/

57. World Confederation for Physical Therapy - WCPT. Aquatic physical therapy. 2010.Updated: 28/10/2010. [Citado 19 sep 2016] Disponível em: http://www.wcpt.org/apti/terminology.

58. Candeloro J, Caromano F. Efeito de um programa de hidroterapia na flexibilidade e na força muscular de idosas. Revista Brasileira de Fisioterapia, 2007;11:303-309. Disponível em: http://www.redalyc.org/articulo.oa?id=235016480010

59. Haupenthal A, Ruschel C, Hubert M, de Brito Fontana H, Roesler, H. Força de reação do solo como subsídio para prescrição de exercícios aquáticos: estudo de caso. Fisioterapia em Movimento. 2017 Apr-Jun;23(2).

On-line version ISSN 1980-5918. http://dx.doi.org/10.1590/S0103-51502010000200013

60. Nascimento NAP, Moreira PFP, Marin RV, Moreira LDF, Lazaretti Castro M, Santos CAF et al. Relation among $25(\mathrm{OH}) \mathrm{D}$, aquatic exercises, and multifunctional fitness on functional performance of elderly women from the community. The journal of nutrition, health \& aging. 2016;20(4):376382. https://doi.org/10.1007/s12603-015-0569-x

61. Molina Gomes MCS, Garcia RR. Comparação entre o tratamento no solo e na hidroterapia para pacientes com osteoporose: revisão da literatura. Revista de Atenção à Saúde (antiga Rev. Bras. Ciên. Saúde), 2006 Jan-Mar;4(7):45-56. Disponível em: http://seer.uscs.edu.br/index.php/revista_ciencias_saude/article/viewFile/4 $47 / 300$ 
62. Balsamo S, Mota LMHD, Santana FSD, Nascimento DDC, Bezerra LMA, Balsamo DOC, Bottaro M. Resistance training versus weight-bearing aquatic exercise: a cross-sectional analysis of bone mineral density in postmenopausal women. Revista brasileira de reumatologia. 2013;53(2):193-198. Disponível em: http://www.scielo.br/scielo.php?pid=S0482-50042013000200006

63. Hale LA, Waters D, Herbison P. A Randomized Controlled Trial to Investigate the Effects of Water-Based Exercise to Improve Falls Risk and Physical Function in Older Adults With Lower-Extremity Osteoarthritis. Arch Phys Med Rehabil 2012 Jan;93: 27-34. https://doi.org/10.1016/j.apmr.2011.08.004

64. Meereis ECW, Favretto C, De Souza J, et al. Influência da hidrocinesioterapia no equilíbrio postural de idosas institucionalizadas. Motriz Rev Educ Fis 2013; 19: 269-277. https://doi.org/10.1590/S1980-65742013000200004. Português, Inglês.

65. Dos Santos AA. Flexibilidade em praticantes de hidroginástica. Revista Brasileira de Prescrição e Fisiologia do Exercício (RBPFEX). 2010;4(21):11.Disponível em: http://www.rbpfex.com.br/index.php/rbpfex/article/viewFile/253/254

66. Bento PCB, Pereira G, Ugrinowitsch C, Rodack ALF. The effects of a water-based exercise program on strength and functionality of older adults. J Aging Phys Act. 2012 Oct;20:469-483. Epub 2012 Jun 18. PMID: 22714953. 
67. Katsura Y, Yoshikawa T, Ueda S-Y, Usui T, Sotobayashi D, Nakao H, Sacamoto H, Okumoto T, Fujimoto S. Effects of aquatic exercise training using water-resistance equipment in elderly. Eur J Appl Physiol. 2010 Dec;108(5):957-964. https://doi.org/10.1007/s00421-009-1306-0

68. Chevutschi A, Dengremont B, Lensel G, Pardessus V, Thevenon A. La balnéothérapie au sein de la littérature: Applications thérapeutiques. Kinesitherapie, la revue. 2007;7(71):14-23. https://doi.org/10.1016/S1779-0123(07)70501-6

69. Pöyhönen T, Spila S, Keskinen KL, Hautala A, Savolainen J, Mälkiä E. Effects of aquatic resistance training on neuromuscular performance in healthy women. Official Journal of the American College of Sports / Medicine Medicine \& Science in Sports \& Exercise 2002 [Citado 27 mai 2018]:2103-2109. DOI: 10.1249/01.MSS.0000039291.46836.86. Disponível em: http://www.institutosarkis.com.br/v1/artigos/novos/

70. Tsourlou, T., Benik, A., Dipla, K., Zafeiridis, A., and Kellis, S. The effects of a twenty-four-week aquatic training program on muscular strength performance in healthy elderly women. Journal of Strength and Conditioning Researc. 2006 Nov;20(4):811-818. Disponível em: https://search.proquest.com/openview/99cc8992229d651891ca9e9863ef3 36c/1 ?pq-origsite=gscholar $\& \mathrm{cbl}=30912$

71. Ide MR, Belini MAV, Caromano FA. Effects of an aquatic versus nonaquatic respiratory exercise program on the respiratory muscle strength in healthy aged persons. Clinics, 2005 Apr;60(2):151-158. http://dx.doi.org/10.1590/S1807-59322005000200012

72. Tomas-Carus P, Gusi N, Häkkinen A, Häkkinen K, Raimundo A, Ortega- 
Alonso A. Improvements of muscle strength predicted benefits in HRQOL and postural balance in women with fibromyalgia: an 8-month randomized controlled trial. Rheumatology. 2009 Jul-Sep;48(9):1147-1151.

https://doi.org/10.1093/rheumatology/kep208

73. Munguía-Izquierdo D, Legaz-Arrese A. Assessment of the effects of aquatic therapy on global symptomatology in patients with fibromyalgia syndrome: a randomized controlled trial. Archives of physical medicine and rehabilitation 2008 Dec 89(12):2250-2257.

https://doi.org/10.1016/j.apmr.2008.03.026

74. Baena-Beato PÁ, Artero EG, Arroyo-Morales M, Robles-Fuentes A, GattoCardia MC, Delgado-Fernández M. Aquatic therapy improves pain, disability, quality of life, body composition and fitness in sedentary adults with chronic low back pain. A controlled clinical trial. Clinical rehabilitation 2014 Apr; 28(4):350-360. https://doi.org/10.1177/0269215513504943

75. Han G, Cho M, Nam G, Moon T, Kim J, Kim S, Hong S, Cho B. The effects on muscle strength and visual analog scale pain of aquatic therapy for individuals with low back pain. Journal of Physical Therapy Science. 2011;23(1):57-60. Online ISSN: 2187-5626 https://doi.org/10.1589/jpts.23.57

76. Bartels EM, Juhl CB, Christensen R, Hagen KB, Danneskiold-Samsøe B, Dagfinrud $\mathrm{H}$, Lund $\mathrm{H}$, Aquatic exercise for the treatment of knee and hip osteoarthritis. Cochrane Database of Systematic Reviews 2016, Issue 3. DOI: 10.1002/14651858.CD005523.pub3 
77. Aldenucci BG. Fisioterapia aquatica: utilização do métado Bad Ragaz e do Water Pilates e em espondilite anquilosante: um estudo de caso. Cinergis 2011;11(1). http://dx.doi.org/10.17058/cinergis.v11i1.1120

78. Matos LM, Morais RA de, Souza RM de, et al. Avaliação dos efeitos da dança em meio aquático na habilidade funcional de indivíduos de 50 a 75 anos. Geriatr Gerontol Aging 2015 [Citado 28 mai 2018];9(2):60-65. ISSN (Online) 2447-2123. Disponível em: http://www.ggaging.com/details/62/ptBR/evaluation-of-the-effects-of-dance-in-aquatic-environment-of-thefunctional-ability-of-individuals-with-50-to-75-years-old. Português, Inglês.

79. Zhu Z, Cui L, Yin M, et al. Hydrotherapy vs. conventional land-based exercise for improving walking and balance after stroke: A randomized controlled trial. Clin Rehabil 2015 Jun;30:587-593.

https://doi.org/10.1177/0269215515593392

80. Meneghetti CHZ, Basqueira C, Fioramonte C, Júnior LCF. Influência da fisioterapia aquática no controle de tronco na síndrome de pusher: estudo de caso. Fisioterapia e Pesquisa 2009;16(3):269-273. http://dx.doi.org/10.1590/S1809-29502009000300014

81. Arrieiro AN. Efeitos do treinamento aeróbio por meio de caminhada na água ou no solo no desempenho físico-funcional e na qualidade de vida de mulheres idosas com osteoartrite de joelho. [Dissertação] Programa Multicêntrico de Pós-Graduação em Ciências Fisiológicas. Universidade Federal dos Vales dos Jequitinhonha e Mucuri, 2011;115p. Disponível http://acervo.ufvjm.edu.br/jspui/bitstream/1/452/1/arthur_nascimento_arriei ro.pdf

82. American College of Sports Medicine. Diretrizes de ACSM para os testes 
de esforço e sua prescrição. Rio de Janeiro: Guanabara Koogan, 2007.

83. Kendall FP, McCreary EK, Provance PG, Kendall M. Músculos, provas e funções; com Postura e dor. $5^{\mathrm{a}}$ ed. Barueri/São Paulo: Editora Manole, 2007.

84. Bohannon RW. Reference values for the timed up and go test: a descriptive meta-analysis. J Geriatr Phys Ther 2006 Aug;29: 64-8. Disponível em: https://journals.Iww.com/jgpt/Abstract/2006/08000/

85. Nonaka L, Caromano FA, Mendes FAS. Avaliação de dois testes de flexibilidade em idosos do sexo feminino: método fotográfico. Rev. ter. ocup 1999;10(2/3):75-80. Disponível em: https://www.researchgate.net/profile/Fatima_Caromano/publication/27345 5259

86. Caromano FA, Durigon OFS, Ide MR, Pardo MS, Candeloro JM, Yamagata RA, Silva RL. Make-test e break-test na mensuração da força isométrica dos músculos extensores do joelho em mulheres idosas. Salusvita 2004;23(3):417-427. Disponível em: https://secure.usc.br/static/biblioteca/salusvita/salusvita_v23_n3_2004.htm \&lang $=$ \&\&nextAction $=$ Ink\&exprSearch $=424399 \&$ indexSearch $=I D$

87. Schaubert KL, Bohannon RW. Reliability and validity of three strength measures obtained from community-dwelling elderly persons. The Journal of Strength \& Conditioning Research 2005;19(3):717-720. Disponível em: https://search.proquest.com/openview/7bcfff96e0c6aa0b44cd54d0253aa8 25/1 ?pq-origsite $=$ gscholar $\& \mathrm{cbl}=30912$ 
88. Wells K, Dillon, E. The Sit and Reach, a test of back and leg flexibility. Reserch Quaterly. 1952;23:115-118. https://doi.org/10.1080/10671188.1952.10761965

89. Chillón P, Castro-Piñero J, Ruiz J, Soto V, Carbonell-Baeza A, Dafos J et al. Hip flexibility is the main determinant of the back-saber sit and reach test in adolescents. Journal of Sports Sciences. 2010;28(6):641-8. https://doi.org/10.1080/02640411003606234

90. Signori LU, Voloski FRS, Kerkhoff AC, Brignoni L, Plentz RDM. Efeito de agentes térmicos aplicados previamente a um Programa de alongamentos na flexibilidade dos músculos isquiotibiais encurtados. Rev Bras Med Esporte. 2008;14(4):328-331. Disponível em: http://www.scielo.br/pdf/rbme/v14n4/v14n4a01

91. Alfieri FM, Riberto M, Gatz LS, et al. Uso de testes clínicos para verificação do controle postural em idosos saudáveis submetidos a programas de exercícios físicos. Acta Fisiátrica. 2010;17:153-158. Disponível em: https://www.revistas.usp.br/actafisiatrica/article/view/103382

92. Podsiadlo D, Richardson S. The Timed 'Up \&amp; Go': A Test of Basic Functional Mobility for Frail Elderly Persons. J Am Geriatr Soc. 1991 Feb;39: 142-148. https://doi.org/10.1111/j.1532-5415.1991.tb01616.x

93. Collado-Mateo D, Domínguez-Muñoz FJ, Adsuar JC, et al. Reliability of the Timed Up and Go Test in Fibromyalgia. Rehabil Nurs 2016 Oct;1-5. https://doi.org/10.1002/rnj.307

94. Drootin M. Panel on Prevention of Falls in Older Persons, American Geriatrics Society and British Geriatrics Society: Summary of the Updated 
American Geriatrics Society/British Geriatrics Society clinical practice guideline for prevention of falls in older persons. J Am Geriatr Soc. 2011 Jan;59(1):148-157. https://doi.org/10.1111/j.1532-5415.2010.03234.x

95. Shumway-Cook A, Brauer S, Woollacott M. Predicting the probability for falls in community-dwelling older adults using the Timed Up \& Go Test. Physical therapy 2000 Sep;80(9), 896-903. https://doi.org/10.1093/ptj/80.9.896

96. Campos CJG. Método de Análise de Conteúdo: ferramenta para a análise de dados qualitativos no campo da saúde. Rev Bras Enferm. 2004 Oct;7(5):611-4. http://dx.doi.org/10.1590/S0034-71672004000500019

97. Caregnato RCA, Mutti R. Pesquisa qualitativa: análise de discurso versus análise de conteúdo. Texto contexto enferm 2006 Oct-Dec;15(4), 679-84. Disponível em: http://www.scielo.br/pdf/tce/v15n4/v15n4a17

98. Coutinho MPL. Análise de conteúdo: breve histórico, conceitos e aplicabilidade. In: Coutinho, MPL, Saraiva, ERA. Métodos de pesquisa em psicologia social. Perspectivas qualitativas e quantitativas. João Pessoa: Ed. Universitária da UFPB, 2011, 465p.

99. Bardin L. Análise de conteúdo, $3^{a}$ reimpressão. São Paulo: Edições 70, 2016, 279p.

100. Associação Brasileira para o Estudo da Obesidade e da Síndrome Metabólica - ABESO. Diretrizes brasileiras de obesidade. 2016 [Citado 28 mai 2018] 4.ed. - São Paulo, SP. Disponível em: www.abeso.org.br/uploads/downloads/92/57fccc403e5da.pdf

101. Nascimento CDM, Ribeiro AQ, Sant'Ana LFDR, Oliveira RMS, Franceschini SDCC, Priore SE. Estado nutricional e condições de saúde 
da população idosa brasileira: revisão da literatura. Rev Med Minas Gerais. 2011 Mar;21(2):174-180. ISSN (on-line): 2238-3182.

Disponível em: http://rmmg.org/artigo/detalhes/195

102. Belza B, Topolski T, Kinne S, Patrick DL, Ramsey SD. Does adherence make a difference? Results from a community-based aquatic exercise program. Nursing research. 2002;51(5):285-291. doi: 10.1097/00006199200209000-00003 .

103. Gomes KV, Zazá DC. Motivos de adesão a prática de atividade física em idosas. Revista Brasileira de Atividade Física \& Saúde. 2012;14(2):132138. http://dx.doi.org/10.12820/

104. Leitão MB, Lazzoli JK, De Oliveira MPB, De Nóbrega ACL, Da Silveira GG, De carvalho T et al. Posicionamento oficial da Sociedade Brasileira de Medicina do Esporte: atividade física e saúde na mulher. Revista brasileira de medicina do esporte. 2000;6():215-220. http://dx.doi.org/10.1590/S1517-86922000000600001

105. Viana MF, Almeida P, Santos RC. Adaptação portuguesa da versão reduzida do Perfil de Estados de Humor-POMS. Análise Psicológica. 2012;19(1):77-92. http://dx.doi.org/10.14417/ap.345

106. Werneck FZ e Navarro CA. Efeito agudo do tipo e da intensidade do exercício sobre os estados de humor. Revista Brasileira de Atividade Física \& Saúde. 2012;15(4):211-217. http://dx.doi.org/10.12820/RBAFS.V.15N4P211-217

107. Vieira JLL, Da Rocha PGM, Porcu M. Influência do exercício físico no humor e na depressão clínica em mulheres. Motriz rev. educ. fís. 2008;14(2):179-186. Disponível em: 
http://www.periodicos.rc.biblioteca.unesp.br/index.php/motriz/article/view/1 $444 / 1721$

108. Wang CY, Olson SL, Protas EJ. Test-retest strength reliability: hand-held dynamometry in community-dwelling elderly fallers. Archives of physical medicine and rehabilitation 2002 Jun;83(6), 811-815. https://doi.org/10.1053/apmr.2002.32743

109. Bohannon RW. Reference values for extremity muscle strength obtained by hand-held dynamometry from adults aged 20 to 79 years. Archives of physical medicine and rehabilitation 1997 Jan; 78(1):26-32. https://doi.org/10.1016/S0003-9993(97)90005-8

110. Cichanowski HR, Schmitt JS, Johnson RJ, Niemuth PE. Hip strength in collegiate female athletes with patellofemoral pain. Medicine \& Science in Sports \& Exercise 2007. 39(8), 1227-1232.

DOI:10.1249/mss.0b013e3180601109

111. Thorborg K, Petersen J, Magnusson SP, Hölmich P. Clinical assessment of hip strength using a hand-held dynamometer is reliable. Scandinavian journal of medicine \& science in sports 2010 May;20(3):493-501. https://doi.org/10.1111/j.1600-0838.2009.00958.x

112. Bocalini DS, Serra AJ, Murad N, Levy RF. Water-based versus land-based exercise effects on physical fitness in older women. Geriatr Gerontol Int 2008 Nov;8:265-271. https://doi.org/10.1111/j.1447-0594.2008.00485.x

113. Carral JC, Pérez CA. Effects of high-intensity combined training on women over 65. Gerontology 2007;53(6):102-108.

https://doi.org/10.1159/000104098 
114. Domínguez-Carrillo LG, Arellano-Aguilar G, Leos-Zierold H. Unipedal stance time and fall risk in the elderly. Cirugia y cirujanos. 2006 MarApr;75(2):107-12 PMID: 17511906. Disponível em: https://www.ncbi.nlm.nih.gov/pubmed/17511906

115. Resende S, Rassi C, Viana F. Efeitos da hidroterapia na recuperação do equilíbrio e prevenção de quedas em idosas. Revista Brasileira de Fisioterapia [Internet]. 2008;12(1):57-63. Disponível em: http://www.redalyc.org/articulo.oa?id=235016536010

116. Simmons V, Hansen PD. Effectiveness of water exercise on postural mobility in the well elderly: an experimental study on balance enhancement. J Gerontol Med Sci 1996 Sep;51:233-238. https://doi.org/10.1093/gerona/51A.5.M233

117. Pernambuco CS, Borba-Pinheiro CJ, Vale RGS, Mazi FD, Monteiro PKP, Dantas EHM. Functional autonomy, bone mineral density (BMD) and serum osteocalcin levels in older female participants of an aquatic exercise program (AAG). Arch Gerontol Geriatr 2013;56:466-471. https://doi.org/10.1016/j.archger.2012.12.012

118. Oliveira LS, Medeiros ES, Machado HTA, Moraes AAC, Oliveira EM, Rocha RSB. Hidroterapia no equilíbrio dinâmico e nas atividades de vida diária de pacientes com neurotoxoplasmose associada à Síndrome da Imunodeficiência Adquirida. Abcs Heal Sci Cs 2013; 38: 133-141. Disponível em: https://nepas.emnuvens.com.br/abcshs/article/view/845 
8. ANEXOS 


\section{Anexo A.}

Aprovação da Comissão de Ética da Faculdade de Medicina da USP

\section{USP - FACULDADE DE MEDICINA DA UNIVERSIDADE \\ DE SÃO PAULO - FMUSP}

\section{PARECER CONSUBSTANCIADO DO CEP}

\section{DADOS DO PROJETO DE PESQUISA}

Titulo da Pesqulsa: Eteltos da caminhada em imersto em mulheres jovens Idosas saudavels

Pesqulsador: Fatima Aparedida Caromano

Área Tematica:

Versao: 1

CAAE: 66719817.1 .0000 .0065

Institulçă Proponente:Faculdade de Medlcina da Unlversldade de Săo Paulo

Patrocinador Princlpal: Financlamento Proprio

DADOS DO PARECER

Numero do Parecer: 2.056 .538

Apresentaçao do Projeto:

Apresentaçă boa - entretanto, multos erros gramaticals necessitando de uma boa revisdo (concondancia, plura , tempo verbal ,etc)

Objettvo da Pesqulsa:

Avallar o efelto programa preventivo de caminhada em imersfo em mulheres jovens ldosas saudavels.

Aval laç:so dos Riscos $\theta$ Beneficlos:

Nato existem ralcos e 05 beneficios sto evidentes

Comentarlos e Consideraçoes sobre a Pesqulsa:

Pesquisa bem elaborada com boa metodologla

Consideraç0es sobre 08 Termos de apresentaçà obrigatorla:

Necesslita somente d ecorreços da lingua portuguesa

Recomendaç08:

Correços gramaticals

Conclus0es ou Pendenclas $\theta$ Llata de Inadequaçoes:

nร5o ha

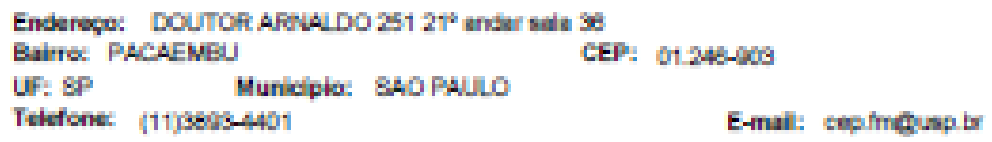




\section{USP - FACULDADE DE MEDICINA DA UNIVERSIDADE DE SÃO PAULO - FMUSP}

Cont-ucte da Fanar 2 ancu

Consideragoes Finals a crtterlo do CEP:

Este parecer fol edaborado beseado nos documentos abalxo relaclonados:

\begin{tabular}{|c|c|c|c|c|}
\hline Tpo Documento & Arqulwo & Postagem & Aufor & Sthesto \\
\hline $\begin{array}{l}\text { Infomactes Baslcas } \\
\text { do Proleto }\end{array}$ & 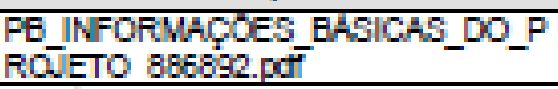 & $\begin{array}{c}05 / 04 / 2017 \\
225403 \\
\end{array}$ & & Acelto \\
\hline $\begin{array}{l}\text { Projeto Detalhado / } \\
\text { Erochura } \\
\text { Investiogor }\end{array}$ & projeto docx & $\begin{array}{c}05 / 04 / 2017 \\
2255: 16\end{array}$ & $\begin{array}{l}\text { Fatima Aparedda } \\
\text { Caromano }\end{array}$ & Acelto \\
\hline Eroctura Pesqulsa & brochura.docx & $\begin{array}{c}05 / 04 / 2017 \\
2251: 02\end{array}$ & $\begin{array}{l}\text { Fatima Apareclda } \\
\text { Caromano }\end{array}$ & Acelto \\
\hline Ouros & A2.,pdr' & $\begin{array}{c}0.5042017 \\
2250: 11\end{array}$ & $\begin{array}{l}\text { Fatma Aparedda } \\
\text { Caromano }\end{array}$ & Acelto \\
\hline Folha de Rosib & Folhar.pdt & $\begin{array}{c}05 / 04 / 2017 \\
22,49: 29\end{array}$ & $\begin{array}{l}\text { Fatima Apareslda } \\
\text { Caromano }\end{array}$ & Acelto \\
\hline
\end{tabular}

sttuapa do Parecer.

Aprovado

Necaselta Apreclaço da CONEP.

No

SAO PAULO, 10 de Malo de 2017

Assinado por:

Marla Aparecida Azevedo Kolke Folguelra

(Coordenador)

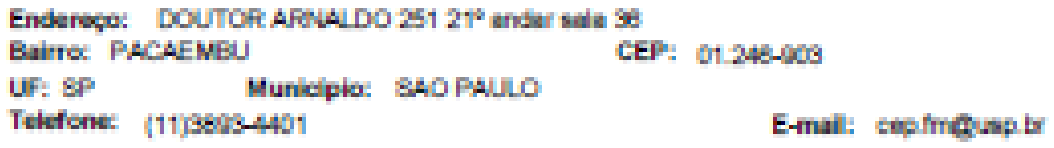




\section{Anexo B.}

Estatística: Testes não paramétricos de Friedman e Wilcoxon

\begin{tabular}{|l|c|}
\hline \multicolumn{2}{|c|}{ Classificações } \\
\hline & Postos de média \\
\hline Peso_t0 & 2,85 \\
Peso_t1 & 3,18 \\
Peso_t2 & 3,35 \\
Peso_t3 & 3,31 \\
Peso_t4 & 2,31 \\
\hline
\end{tabular}

\begin{tabular}{|c|c|}
\hline \multicolumn{2}{|c|}{ Estatísticas de teste } \\
\hline N & 59 \\
Qui-quadrado & 17,798 \\
df & 4 \\
Significância Sig. &, 001 \\
\hline
\end{tabular}

a. Teste Friedman

PESO - Estatísticas de teste ${ }^{a}$

\begin{tabular}{|c|c|c|c|c|c|c|c|c|c|c|}
\hline & $\mathrm{t} 1-\mathrm{t} 0$ & t2 - t0 & t3 - to & t4 - to & $\mathrm{t} 2-\mathrm{t} 1$ & $\mathrm{t} 3-\mathrm{t} 1$ & $\mathrm{t} 4-\mathrm{t} 1$ & $\mathrm{t} 3-\mathrm{t} 2$ & $\mathrm{t} 4-\mathrm{t} 2$ & $\mathrm{t} 4-\mathrm{t} 3$ \\
\hline $\begin{array}{l}\text { Z } \\
\text { Significância }\end{array}$ & $-1,383^{b}$ &,$- 103^{b}$ &,$- 103^{c}$ & $-1,924^{c}$ &,$- 286^{c}$ &,$- 589^{c}$ & $-2,835^{c}$ &,$- 841^{c}$ & $-3,935^{c}$ & $-3,983^{c}$ \\
\hline $\begin{array}{l}\text { Sig. ( } 2 \\
\text { extremidades) }\end{array}$ & ,167 & ,918 & ,918 & ,046 & ,775 & ,556 & ,005 & ,400 &, 000 & ,000 \\
\hline
\end{tabular}

a. Teste de Classificações Assinadas por Wilcoxon

b. Com base em postos negativos.

c. Com base em postos positivos.

\begin{tabular}{|c|c|c|c|}
\hline \multicolumn{2}{|c|}{ Classificações } & \multicolumn{2}{|c|}{ Estatísticas de teste $\mathrm{a}^{\mathrm{a}}$} \\
\hline & Postos de média & & \\
\hline \multirow{6}{*}{$\begin{array}{l}\text { IMC_t0 } \\
\text { IMC_t1 } \\
\text { IMC_t2 } \\
\text { IMC_t3 } \\
\text { IMC t4 }\end{array}$} & 2,85 & & \\
\hline & 3,18 & & 17, \\
\hline & 3,35 & & \\
\hline & 331 & Jig. &, 001 \\
\hline & & a. Teste Friedma & \\
\hline & 2,31 & & \\
\hline
\end{tabular}


IMC - Estatísticas de teste ${ }^{a}$

\begin{tabular}{|c|c|c|c|c|c|c|c|c|c|c|}
\hline & $\mathrm{t} 1 \mathrm{-}-\mathrm{t} 0$ & $\mathrm{t} 2-\mathrm{t} 0$ & t3 - t0 & t4 - t0 & $\mathrm{t} 2-\mathrm{t} 1$ & $t 3-t 1$ & $\mathrm{t} 4-\mathrm{t} 1$ & $\mathrm{t} 3-\mathrm{t} 2$ & $\mathrm{t} 4-\mathrm{t} 2$ & $\mathrm{t} 4-\mathrm{t} 3$ \\
\hline Zignificância & $-1,382^{b}$ &,$- 195^{b}$ &,$- 060^{c}$ & $-1,920^{c}$ &,$- 222^{c}$ &,$- 511^{c}$ & $-2,783^{c}$ &,$- 747^{c}$ & $-3,897^{c}$ & $-3,960^{c}$ \\
\hline $\begin{array}{l}\text { Sig. (2 } \\
\text { extremidades) }\end{array}$ & , 167 & ,846 & ,952 &, 049 & ,824 & ,609 &, 005 & ,455 &, 000 &, 000 \\
\hline
\end{tabular}

a. Teste de Classificações Assinadas por Wilcoxon

b. Com base em postos negativos.

c. Com base em postos positivos.

\begin{tabular}{|l|c|}
\multicolumn{2}{c}{ Classificações } \\
\hline & Postos de média \\
\hline Saúde_t0 & 2,21 \\
Saúde_t1 & 2,61 \\
Saúde_t2 & 3,09 \\
Saúde_t3 & 3,25 \\
Saúde_t4 & 3,83 \\
\hline
\end{tabular}



a. Teste Friedman

\section{SAÚDE - Estatísticas de teste ${ }^{\mathrm{a}}$}

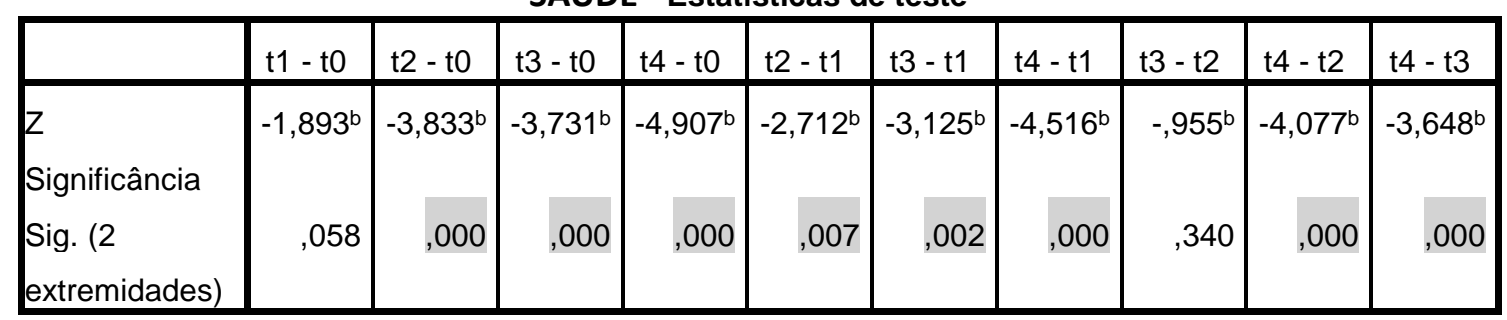

a. Teste de Classificações Assinadas por Wilcoxon

b. Com base em postos negativos.

\section{Classificações}

\begin{tabular}{|l|c|}
\hline & $\begin{array}{c}\text { Postos de } \\
\text { média }\end{array}$ \\
\hline Mobilidade_t0 & 1,66 \\
Mobilidade_t1 & 2,61 \\
Mobilidade_t2 & 3,05 \\
Mobilidade_t3 & 3,60 \\
Mobilidade_t4 & 4,08 \\
\hline
\end{tabular}

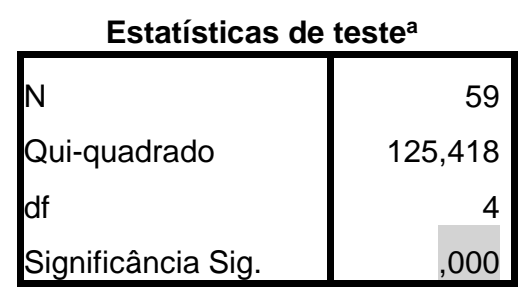

a. Teste Friedman 
MOBILIDADE - Estatísticas de teste ${ }^{\mathrm{a}}$

\begin{tabular}{|c|c|c|c|c|c|c|c|c|c|c|}
\hline & $\mathrm{t} 1-\mathrm{t} 0$ & $\mathrm{t} 2-\mathrm{t} 0$ & t3 $-\mathrm{t} 0$ & $\mathrm{t} 4-\mathrm{t} 0$ & $\mathrm{t} 2-\mathrm{t} 1$ & $\mathrm{t} 3-\mathrm{t} 1$ & $\mathrm{t} 4-\mathrm{t} 1$ & $\mathrm{t} 3-\mathrm{t} 2$ & $\mathrm{t} 4-\mathrm{t} 2$ & $\mathrm{t} 4-\mathrm{t} 3$ \\
\hline $\begin{array}{l}\text { Z } \\
\text { Significância }\end{array}$ & $-5,020^{b}$ & $-5,388^{b}$ & $-5,836^{b}$ & $-6,220^{b}$ & $-2,884^{b}$ & $-4,703^{b}$ & $-5,574^{b}$ & $-3,578^{b}$ & $-5,048^{b}$ & $-3,153^{b}$ \\
\hline $\begin{array}{l}\text { Sig. (2 } \\
\text { extremidades) }\end{array}$ &, 000 &, 000 &, 000 &, 000 & ,004 & ,000 &, 000 &, 000 & ,000 & ,002 \\
\hline
\end{tabular}

a. Teste de Classificações Assinadas por Wilcoxon

b. Com base em postos negativos.

\begin{tabular}{|l|c|}
\hline \multicolumn{2}{c|}{ Classificações } \\
\hline & Postos de média \\
\hline Humor_t0 & 2,47 \\
Humor_t1 & 2,79 \\
Humor_t2 & 3,15 \\
Humor_t3 & 3,24 \\
Humor_t4 & 3,36 \\
\hline
\end{tabular}

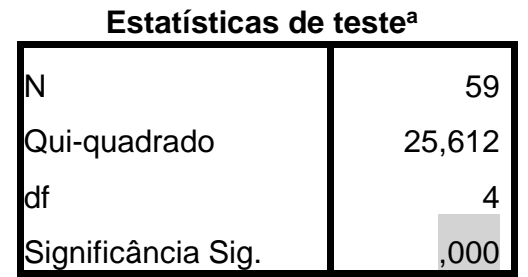

a. Teste Friedman

HUMOR - Estatísticas de teste ${ }^{a}$

\begin{tabular}{|c|c|c|c|c|c|c|c|c|c|c|}
\hline & $t 1-t 0$ & t2 - to & t3 - t0 & t4 - t0 & $\mathrm{t} 2-\mathrm{t} 1$ & $t 3-t 1$ & $\mathrm{t} 4-\mathrm{t} 1$ & t3 - t2 & $\mathrm{t} 4-\mathrm{t} 2$ & t4 - t3 \\
\hline Zignificância & $-1,956^{b}$ & $-2,611^{b}$ & $-2,765^{b}$ & $-3,171^{b}$ & $-2,500^{b}$ & $-2,854^{b}$ & $-3,052^{b}$ & $-1,000^{b}$ & $-1,641^{b}$ & $-1,265^{b}$ \\
\hline $\begin{array}{l}\text { Sig. ( } 2 \\
\text { extremidades) }\end{array}$ & ,051 & ,009 & ,006 & ,002 &, 012 & ,004 & ,002 & ,317 & ,101 & ,206 \\
\hline
\end{tabular}

a. Teste de Classificações Assinadas por Wilcoxon

b. Com base em postos negativos.

\begin{tabular}{|l|c|}
\hline \multicolumn{2}{|c|}{ Classificações } \\
\hline & Postos de média \\
\hline FM_extquadril_t0 & 1,68 \\
FM_extquadril_t1 & 1,68 \\
FM_extquadril_t2 & 2,84 \\
FM_extquadril_t3 & 3,86 \\
FM_extquadril_t4 & 4,95 \\
\hline
\end{tabular}

Força Muscular dos extensores

\begin{tabular}{|l|r|}
\multicolumn{2}{l}{ do quadril Estatísticas de teste } \\
\hline N & 59 \\
Qui-quadrado & 209,401 \\
df & 4 \\
Significância Sig. &, 000 \\
\hline
\end{tabular}

a. Teste Friedman 
FORÇA MUSCULAR dos músculos extensores do quadril - Estatísticas de teste ${ }^{a}$

\begin{tabular}{|c|c|c|c|c|c|c|c|c|c|c|}
\hline & $\mathrm{t} 1-\mathrm{t} 0$ & t2 - t0 & t3 - t0 & t4 - t0 & $\mathrm{t} 2-\mathrm{t} 1$ & $\mathrm{t} 3-\mathrm{t} 1$ & $\mathrm{t} 4-\mathrm{t} 1$ & $\mathrm{t} 3-\mathrm{t} 2$ & $\mathrm{t} 4-\mathrm{t} 2$ & $\mathrm{t} 4-\mathrm{t} 3$ \\
\hline $\begin{array}{l}\text { Z } \\
\text { Significância }\end{array}$ & $-1,632^{b}$ & $-5,565^{b}$ & $-6,579^{b}$ & $-6,719^{b}$ & $-5,875^{b}$ & $-6,762^{b}$ & $-6,732^{b}$ & $-5,922^{b}$ & $-6,695^{b}$ & $-6,522^{b}$ \\
\hline $\begin{array}{l}\text { Sig. (2 } \\
\text { extremidades) }\end{array}$ & 103 &, 000 &, 000 &, 000 &, 000 &, 000 &, 000 &, 000 &, 000 &, 000 \\
\hline
\end{tabular}

a. Teste de Classificações Assinadas por Wilcoxon

b. Com base em postos negativos.

\begin{tabular}{|l|c|}
\hline \multicolumn{2}{|c|}{ Classificações } \\
\hline & Postos de média \\
\hline FM_flexquadril_t0 & 1,49 \\
FM_flexquadril_t1 & 1,64 \\
FM_flexquadril_t2 & 2,89 \\
FM_flexquadril_t3 & 4,13 \\
FM_flexquadril_t4 & 4,85 \\
\hline
\end{tabular}

Força muscular dos flexores do

quadril

Estatísticas de teste ${ }^{a}$

\begin{tabular}{|l|r|}
\hline N & 59 \\
Qui-quadrado & 219,635 \\
df & 4 \\
Significância Sig. &, 000 \\
\hline
\end{tabular}

a. Teste Friedman

FORÇA MUSCULAR dos flexores do quadril

Estatísticas de teste

\begin{tabular}{|c|c|c|c|c|c|c|c|c|c|c|}
\hline & $\mathrm{t} 1-\mathrm{t} 0$ & $\mathrm{t} 2-\mathrm{t} 0$ & t3 - t0 & $\mathrm{t} 4-\mathrm{t} 0$ & $\mathrm{t} 2-\mathrm{t} 1$ & $\mathrm{t} 3-\mathrm{t} 1$ & $\mathrm{t} 4-\mathrm{t} 1$ & $\mathrm{t} 3-\mathrm{t} 2$ & $\mathrm{t} 4-\mathrm{t} 2$ & $\mathrm{t} 4-\mathrm{t} 3$ \\
\hline Z & $-1,980^{b}$ & $-6,306^{b}$ & $-6,711^{b}$ & $-6,701^{b}$ & $-6,260^{b}$ & $-6,706^{b}$ & $-6,700^{b}$ & $-6,551^{b}$ & $-6,715^{b}$ & $-5,370^{b}$ \\
\hline $\begin{array}{l}\text { Sig. (2 } \\
\text { extremidades) }\end{array}$ & ,048 & ,000 &, 000 & ,000 & ,000 &, 000 & ,000 & ,000 &, 000 &, 000 \\
\hline
\end{tabular}

a. Teste de Classificações Assinadas por Wilcoxon

b. Com base em postos negativos.

\begin{tabular}{|c|c|}
\hline \multicolumn{2}{|c|}{ Classificações } \\
\hline & Postos de média \\
\hline FM_flexplantar_t0 & 1,68 \\
\hline FM_flexplantar_t1 & 1,42 \\
\hline FM_flexplantar_t2 & 3,15 \\
\hline FM_flexplantar_t3 & 3,81 \\
\hline FM_flexplantar_t4 & 4,93 \\
\hline
\end{tabular}

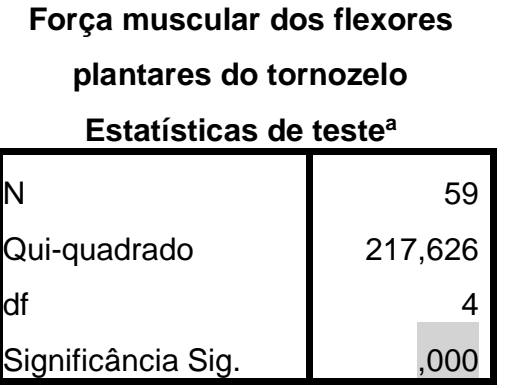

a. Teste Friedman 
Força muscular dos flexores plantares do tornozelo

Estatísticas de teste ${ }^{a}$

\begin{tabular}{|l|r|r|r|r|r|r|r|r|r|r|}
\hline & $\mathrm{t} 1-\mathrm{t} 0$ & $\mathrm{t} 2-\mathrm{t} 0$ & $\mathrm{t} 3-\mathrm{t} 0$ & $\mathrm{t} 4-\mathrm{t} 0$ & $\mathrm{t} 2-\mathrm{t} 1$ & $\mathrm{t} 3-\mathrm{t} 1$ & $\mathrm{t} 4-\mathrm{t} 1$ & $\mathrm{t} 3-\mathrm{t} 2$ & $\mathrm{t} 4-\mathrm{t} 2$ & $\mathrm{t} 4-\mathrm{t} 3$ \\
\hline $\mathrm{Z}$ & $-1,768^{\mathrm{b}}$ & $-6,402^{\mathrm{c}}$ & $-6,581^{\mathrm{c}}$ & $-6,740^{\mathrm{c}}$ & $-6,690^{\mathrm{c}}$ & $-6,761^{\mathrm{c}}$ & $-6,789^{\mathrm{c}}$ & $-5,026^{\mathrm{c}}$ & $-6,719^{\mathrm{c}}$ & $-6,440^{\mathrm{c}}$ \\
$\begin{array}{l}\text { Significância } \\
\text { Sig. }(2\end{array}$ &, 077 &, 000 &, 000 &, 000 &, 000 &, 000 &, 000 &, 000 &, 000 &, 000 \\
\hline
\end{tabular}

a. Teste de Classificações Assinadas por Wilcoxon

b. Com base em postos positivos.

c. Com base em postos negativos.

\begin{tabular}{|l|c|}
\hline \multicolumn{2}{|c|}{ Classificações } \\
\hline & Postos de média \\
\hline FM_dorsiflex_t0 & 1,58 \\
FM_dorsiflex_t1 & 1,53 \\
FM_dorsiflex_t2 & 3,10 \\
FM_dorsiflex_t3 & 3,89 \\
FM_dorsiflex_t4 & 4,91 \\
\hline
\end{tabular}

Força muscular dos dorsiflexores do tornozelo

\begin{tabular}{|l|r|}
\hline \multicolumn{2}{|c|}{ Estatísticas de teste } \\
\hline a \\
Qui-quadrado \\
df \\
216,551 \\
Significância Sig. & 4 \\
\hline
\end{tabular}

a. Teste Friedman

\section{Força muscular dos dorsiflexores do tornozelo}

Estatísticas de teste ${ }^{a}$

\begin{tabular}{|c|c|c|c|c|c|c|c|c|c|c|}
\hline & $\mathrm{t} 1-\mathrm{t} 0$ & t2 - to & t3 - t0 & $\mathrm{t} 4-\mathrm{t} 0$ & $\mathrm{t} 2-\mathrm{t} 1$ & $\mathrm{t} 3-\mathrm{t} 1$ & $\mathrm{t} 4-\mathrm{t} 1$ & $\mathrm{t} 3-\mathrm{t} 2$ & $\mathrm{t} 4-\mathrm{t} 2$ & $\mathrm{t} 4-\mathrm{t} 3$ \\
\hline Z &,$- 408^{b}$ & $-6,640^{c}$ & $-6,670^{c}$ & $-6,730^{c}$ & $-6,656^{c}$ & $-6,666^{c}$ & $-6,735^{c}$ & $-5,956^{c}$ & $-6,627^{c}$ & $-6,312^{c}$ \\
\hline Sig. (2 & ,683 &, 000 & ,000 & ,000 & ,000 & ,000 & ,000 &, 000 & ,000 & ,000 \\
\hline extremidades) & & & & & & & & & & \\
\hline
\end{tabular}

a. Teste de Classificações Assinadas por Wilcoxon

b. Com base em postos positivos.

c. Com base em postos negativos.

\begin{tabular}{|l|c|}
\hline \multicolumn{2}{|c|}{ Classificações } \\
\hline & Postos de média \\
\hline Flex_tronco_t0 & 1,10 \\
Flex_tronco_t1 & 2,16 \\
Flex_tronco_t2 & 3,14 \\
Flex_tronco_t3 & 3,81 \\
Flex_tronco_t4 & 4,78 \\
\hline
\end{tabular}

Força muscular dos dorsiflexores do tornozelo

Estatísticas de teste ${ }^{a}$

\begin{tabular}{|l|r|}
\hline N & 59 \\
Qui-quadrado & 192,675 \\
df & 4 \\
Significância Sig. &, 000 \\
\hline
\end{tabular}

a. Teste Friedman 
Força muscular dos dorsiflexores do tornozelo - Estatísticas de teste ${ }^{a}$

\begin{tabular}{|c|c|c|c|c|c|c|c|c|c|c|}
\hline & $\mathrm{t} 1-\mathrm{t} 0$ & t2 - t0 & t3 - t0 & t4 - t0 & $\mathrm{t} 2-\mathrm{t} 1$ & $t 3-t 1$ & $\mathrm{t} 4-\mathrm{t} 1$ & $t 3-t 2$ & $\mathrm{t} 4-\mathrm{t} 2$ & $\mathrm{t} 4-\mathrm{t} 3$ \\
\hline Z & $-6,683^{b}$ & $-6,681^{b}$ & $-6,349^{b}$ & $-6,616^{b}$ & $-6,627^{b}$ & $-5,492^{b}$ & $-6,549^{b}$ & $-4,945^{b}$ & $-6,383^{b}$ & $-6,237^{b}$ \\
\hline $\begin{array}{l}\text { Sig. (2 } \\
\text { extremidades) }\end{array}$ &, 000 &, 000 &, 000 &, 000 &, 000 &, 000 &, 000 & ,000 &, 000 &, 000 \\
\hline
\end{tabular}

a. Teste de Classificações Assinadas por Wilcoxon

b. Com base em postos negativos.

\begin{tabular}{|c|c|}
\hline \multicolumn{2}{c}{ Classificações } \\
\hline & Postos de média \\
\hline TAU_OA_t0 & 1,47 \\
TAU_OA_t1 & 1,84 \\
TAU_OA_t2 & 3,02 \\
TAU_OA_t3 & 3,76 \\
TAU_OA_t4 & 4,92 \\
\hline
\end{tabular}



a. Teste Friedman

TAU_OA - Teste de Equilíbrio estático com Apoio Unipodal e olhos abertos

Estatísticas de teste ${ }^{a}$

\begin{tabular}{|c|c|c|c|c|c|c|c|c|c|c|}
\hline & $t 1-t 0$ & t2 - t0 & t3 - t0 & t4 - t0 & $\mathrm{t} 2-\mathrm{t} 1$ & $\mathrm{t} 3-\mathrm{t} 1$ & $\mathrm{t} 4-\mathrm{t} 1$ & $t 3-t 2$ & $\mathrm{t} 4-\mathrm{t} 2$ & $\mathrm{t} 4-\mathrm{t} 3$ \\
\hline Z & $-3,709^{b}$ & $-5,985^{b}$ & $-6,434^{b}$ & $-6,692^{b}$ & $-5,885^{b}$ & $-6,499^{b}$ & $-6,639^{b}$ & $-5,242^{b}$ & $-6,592^{b}$ & $-6,410^{b}$ \\
\hline $\begin{array}{l}\text { Sig. (2 } \\
\text { extremidades) }\end{array}$ &, 000 &, 000 & ,000 &, 000 &, 000 &, 000 & ,000 &, 000 & ,000 &, 000 \\
\hline
\end{tabular}

a. Teste de Classificações Assinadas por Wilcoxon

b. Com base em postos negativos.

\begin{tabular}{|c|c|}
\hline \multicolumn{2}{c}{ Classificações } \\
\hline & Postos de média \\
\hline TAU_OF_t0 & 1,03 \\
TAU_OF_t1 & 2,00 \\
TAU_OF_t2 & 3,02 \\
TAU_OF_t3 & 3,98 \\
TAU_OF_t4 & 4,97 \\
\hline
\end{tabular}

Teste de Equilíbrio com Apoio

Unipodal e olhos fechados

Estatísticas de teste ${ }^{a}$

\begin{tabular}{|l|r|}
\hline $\mathrm{N}$ & 59 \\
Qui-quadrado & 232,414 \\
$\mathrm{df}$ & 4 \\
Significância Sig. &, 000 \\
\hline
\end{tabular}

a. Teste Friedman 
TAU_OF - Teste de Equilíbrio estático com Apoio Unipodal e olhos fechados

Estatísticas de teste ${ }^{a}$

\begin{tabular}{|l|r|r|r|r|r|r|r|r|r|r|}
\hline & \multicolumn{1}{c}{$\mathrm{t} 1-\mathrm{t} 0$} & $\mathrm{t} 2-\mathrm{t} 0$ & $\mathrm{t} 3-\mathrm{t} 0$ & $\mathrm{t} 4-\mathrm{t} 0$ & $\mathrm{t} 2-\mathrm{t} 1$ & $\mathrm{t} 3-\mathrm{t} 1$ & $\mathrm{t} 4-\mathrm{t} 1$ & $\mathrm{t} 3-\mathrm{t} 2$ & $\mathrm{t} 4-\mathrm{t} 2$ & $\mathrm{t} 4-\mathrm{t} 3$ \\
\hline $\mathrm{Z}$ & $-6,522^{\mathrm{b}}$ & $-6,686^{\mathrm{b}}$ & $-6,686^{\mathrm{b}}$ & $-6,686^{\mathrm{b}}$ & $-6,612^{\mathrm{b}}$ & $-6,688^{\mathrm{b}}$ & $-6,690^{\mathrm{b}}$ & $-6,493^{\mathrm{b}}$ & $-6,691^{\mathrm{b}}$ & $-6,544^{\mathrm{b}}$ \\
Significância \\
$\begin{array}{l}\text { Sig. (2 } \\
\text { extremidades) }\end{array}$
\end{tabular}

a. Teste de Classificações Assinadas por Wilcoxon

b. Com base em postos negativos.

\begin{tabular}{|c|c|}
\hline \multicolumn{2}{c}{ Classificações } \\
\hline & Postos de média \\
\hline TUG_t0 & 4,74 \\
TUG_t1 & 4,12 \\
TUG_t2 & 2,94 \\
TUG_t3 & 2,03 \\
TUG_t4 & 1,18 \\
\hline
\end{tabular}

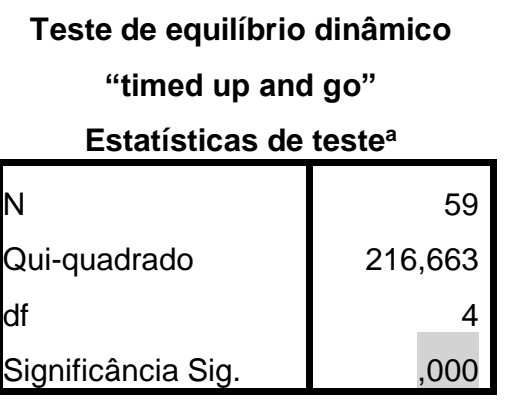

a. Teste Friedman

TUG - Teste de equilíbrio dinâmico "timed up and go"

Estatísticas de teste ${ }^{a}$

\begin{tabular}{|c|c|c|c|c|c|c|c|c|c|c|}
\hline & $\mathrm{t} 1-\mathrm{t} 0$ & $\mathrm{t} 2-\mathrm{t} 0$ & t3 - t0 & t4 - to & $\mathrm{t} 2-\mathrm{t} 1$ & $t 3-t 1$ & $\mathrm{t} 4-\mathrm{t} 1$ & $\mathrm{t} 3-\mathrm{t} 2$ & $\mathrm{t} 4-\mathrm{t} 2$ & t4 - t3 \\
\hline $\begin{array}{l}\text { Z } \\
\text { Significância }\end{array}$ & $-5,105^{b}$ & $-6,513^{b}$ & $-6,659^{b}$ & $-6,699^{b}$ & $-6,282^{b}$ & $-6,635^{b}$ & $-6,719^{b}$ & $-5,747^{b}$ & $-6,586^{b}$ & $-5,788^{b}$ \\
\hline $\begin{array}{l}\text { Sig. ( } 2 \\
\text { extremidades) }\end{array}$ &, 000 &, 000 & ,000 & ,000 &, 000 & ,000 &, 000 &, 000 & ,000 &, 000 \\
\hline
\end{tabular}

a. Teste de Classificações Assinadas por Wilcoxon

b. Com base em postos positivos. 
Anexo C.

Poder estatístico: Cálculo amostral (post hoc)
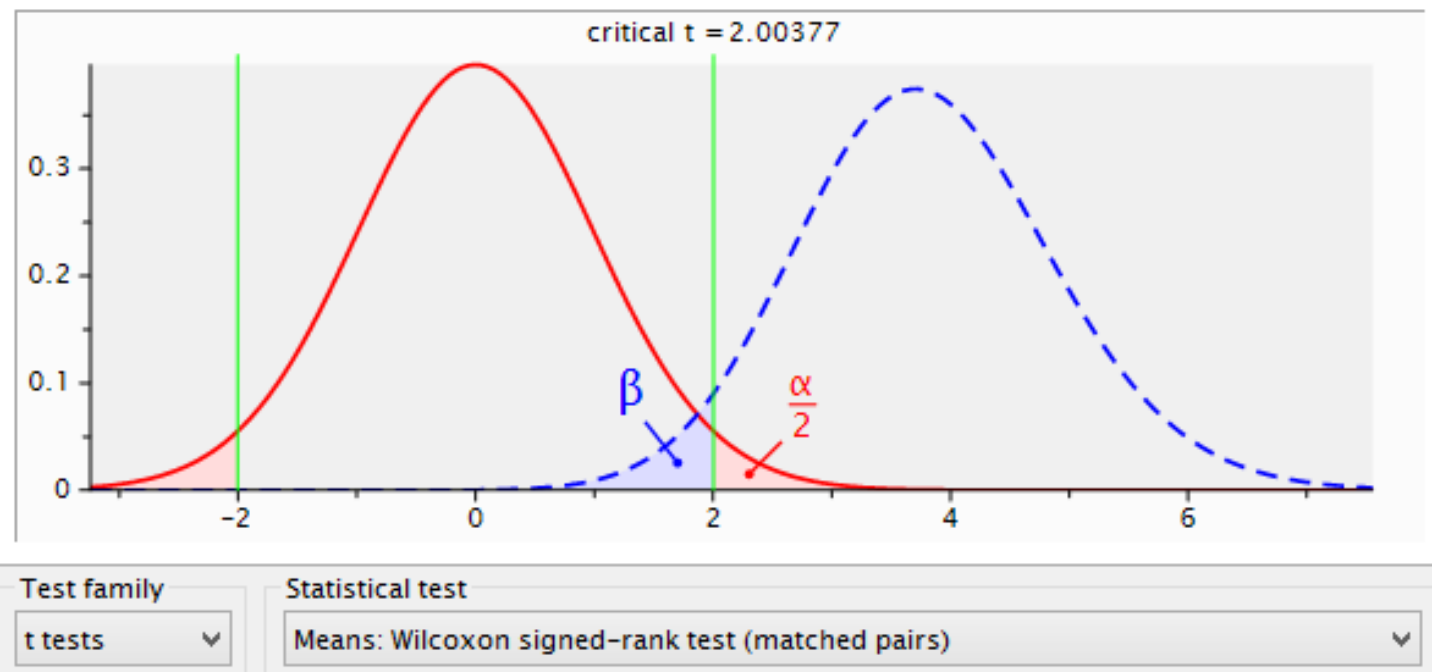

Type of power analysis

Post hoc: Compute achieved power - given $\alpha$, sample size, and effect size

Input Parameters

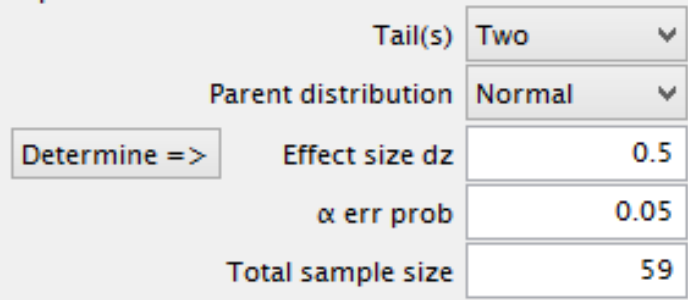

\section{Output Parameters}

Noncentrality parameter $\delta$

Critical t 3.7530271 2.0037674

Df 55.3408499 Power (1- $\beta$ err prob) 0.9579316 
Anexo D.

Artigo submetido



Thank you for your submission

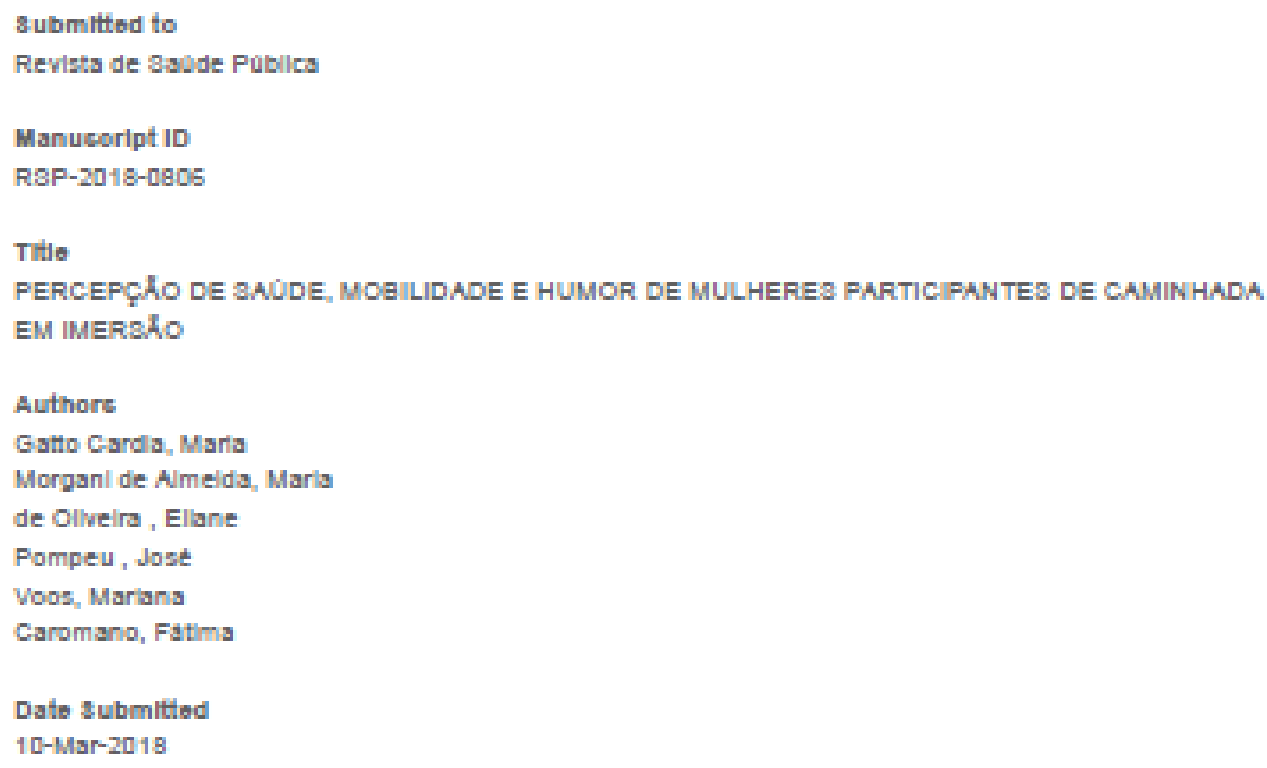

